\title{
Relating urban forests and urban tourism: Exploring people's perceptions, preferences and movement in Washington DC
}

\author{
Rogelio T. Andrada II
}

Follow this and additional works at: https://researchrepository.wvu.edu/etd

\section{Recommended Citation}

Andrada II, Rogelio T., "Relating urban forests and urban tourism: Exploring people's perceptions, preferences and movement in Washington DC" (2015). Graduate Theses, Dissertations, and Problem Reports. 5106.

https://researchrepository.wvu.edu/etd/5106

This Dissertation is protected by copyright and/or related rights. It has been brought to you by the The Research Repository @ WVU with permission from the rights-holder(s). You are free to use this Dissertation in any way that is permitted by the copyright and related rights legislation that applies to your use. For other uses you must obtain permission from the rights-holder(s) directly, unless additional rights are indicated by a Creative Commons license in the record and/ or on the work itself. This Dissertation has been accepted for inclusion in WVU Graduate Theses, Dissertations, and Problem Reports collection by an authorized administrator of The Research Repository @ WVU.

For more information, please contact researchrepository@mail.wvu.edu. 
Relating urban forests and urban tourism: Exploring people's perceptions, preferences and movement in Washington DC

\title{
Rogelio T. Andrada II
}

\author{
Dissertation submitted \\ to the Davis College of Agriculture, Natural Resources and Design \\ at West Virginia University \\ in partial fulfillment of the requirements for the degree of \\ Doctor of Philosophy in \\ Forest Resource Science
}

\author{
Jinyang Deng, Ph.D., Chair \\ Chad Pierskalla, Ph. D. \\ Kathryn Gazal, Ph.D. \\ John Brooks, Ph.D. \\ Jamison Conley, Ph.D. \\ School of Natural Resources
}
Morgantown, West Virginia
2015

Keywords: Urban forest, tourism, GIS, conjoint analysis, SEM, spatial movement Copyright 2015 Rogelio T. Andrada II 


\section{ABSTRACT \\ Relating urban forests and urban tourism: Exploring people's preferences, perceptions, and movement in Washington DC}

\section{Rogelio T. Andrada II}

Exploring the connection between urban forests and urban tourism has not been given much attention in recent investigative efforts. This study is designed to describe, explore and explain the specific elements where these two fields converge. There is no better vehicle to do this than by eliciting data from people, who are collectively, the beneficiaries and clientele of these entities. Therefore, a face-to-face survey, spanning one year, collected data on people's perception, preferences, movement, demographics and trip background in a popular and busy city destination: Washington DC. The survey was conducted at three sites: the U.S. National Arboretum, U.S. Botanic Garden, and the National Mall where two surveyors were assigned to ask respondents to complete a self-administered questionnaire. Data collection was conducted twice a month on weekends from Friday to Sunday, 10AM to 5PM. Each respondent was versed with the objectives of the study and their concerns and questions were addressed while they completed the questionnaire.

Data collection yielded 1,146 completed questionnaires out of 3,210 respondents who participated which sets the response rate at $35.7 \%$. Non-response was mainly due to respondents not having time to answer the questionnaire or not having the capability to properly answer the questionnaire because English was not their first language. There are slightly more female respondents than males, almost all of them have college degrees and two-thirds are visitors while the rest are residents. Among the visitors, half are there for leisure and majority are repeat visitors and would stay at least overnight.

Results are subdivided into sections and in terms of preferences the findings revealed that the respondents regard urban forests are at par with the other major attractions of the city with regards to its relative importance. The respondents regarded that season is the most important factor that influences their timing of visit to Washington DC. Sub-groups of the respondents who are more familiar with the city such as repeat visitors and residents have more variety in terms of the attractions that they tend to enjoy. Despite being aware of urban forest attractions, only residents and the visitors who accompany them are the ones that are exposed and are able to visit these attractions proving that urban forests continue to be an underutilized resource in the tourism status of the city.

With regards to the preferences of the respondents on specific urban forest attributes, they expressed their tendency to prefer urban forests that are composed of at least trees and grass; those that are planted throughout the city having a verdant quality with many other colors, and are trimmed. Furthermore, they expressed that plant variety, planting pattern, color variety and growth form are important attributes that influence their preferences. Insights such are these indicate that people, in general, are aware of the natural landscape of the city and not just the 
built landscape. Consequently, maintenance activities should be guided by these findings in response to the people's feedback.

Another aspect of this study is looking at the perception of the respondents on urban forests. Observations based on the data revealed that respondents' knowledge on the uses of urban forests (i.e. parks, gardens and street trees) positively influence their leisure experience and has a fairly acceptable influence on their satisfaction and loyalty to the city. This confirms the level of awareness that the respondents harbor concerning the importance of urban forests in their experiences in the city. It can be deduced that people who know more about the uses and the role that urban forests play in the urban ecosystem tend to have a more positive leisure experience while in the city, and therefore tend to be more satisfied and loyal to it.

Lastly, the behavior of the respondents was explored by looking into their mobility, concentration and spatial movement. After these variables were described and defined, study results showed that most respondents congregate at the National Mall and its vicinity because the most popular attractions are clustered there. Relative to the Washington monument, which is located at the center of the National Mall, the various Smithsonian museums are clustered to the east together with the different art galleries while to the west, the major memorials and monuments are located - the Lincoln Memorial, World War II Memorial, Vietnam and Korean War Memorials, and the newly built Martin Luther King Jr. Memorial. These attractions have high visit concentrations and are considered hot spots, which in turn, are regarded as high traffic areas of people, and thus requiring intensive management. Moreover, as the respondents were subdivided, various sub-groups exhibited differences in their movement patterns which also differed based on the season when they visited. In relation to urban forests, a potential to disperse the concentration of people visiting the city is feasible by promoting visitation to urban forests that are currently regarded as less popular attractions. Some examples of such attractions are the National Zoo, Rock Creek Park, the National arboretum and the Kenilworth aquatic gardens.

Overall, the findings of this study highlighted that the link between urban forests and urban tourism is undeniably strong and presents unique opportunities in terms of its management. Urban forests and tourism have the potential to be utilized as complementary resources to be managed. Specifically, the insights gained from the respondents have corresponding implications on the management of both resources in the aspects of planning, development, maintenance, and marketing. 


\section{DEDICATION}

This dissertation is dedicated to all the people who in one way or another have influenced and helped me through this process. I am most grateful to my family (Rogelio, Catherine, Reinhard, and Rogerine) who nurtured and shaped me into who I am today. I also dedicate this work to all my mentors and colleagues at the College of Forestry and Natural Resources of the University of the Philippines Los Baños who continued sharpening my academic skills not only as a student but also as a teacher and academic.

I also dedicate this work to all my friends at West Virginia University, students and staff alike, for being a part of my academic life in this institution. Special thanks to Prof. Robin Jones, Ms. Rhonda Black, and Dr. Bernadette Jungblut of the University College for the opportunity to make a difference in the students of WVU. This work is also dedicated to my

friends here in Morgantown, West Virginia especially to the Filipino community who are always there to help. 


\section{ACKNOWLEDGEMENT}

Funding for this study is from a grant awarded to my major advisor, Dr. Jinyang Deng by the USDA Forest Service. We would like thank Ms. Mary Willeford Bair of the National Park Service, Ms. Christine Flanagan of the US Botanic Gardens, Dr. Monica Lear of the Urban Forestry Administration, DDOT, Ms. Nancy Luria of the US National Arboretum, Mr. David M. Dyre, Dr. Ishwar Dhami, Dr. Sudiksha Dhami, and Ms. Rosheila Rodriguez for their help and cooperation in the data collection phase of the study.

Also, I would like to thank my major advisor, Dr. Deng for his unwavering support, patience, and encouragement throughout the course of my study. Similarly, I am thanking the members of my committee: Dr. Pierskalla, Dr. Brooks, Dr. Gazal, and Dr. Conley for their expertise, time, and patience.

My gratitude also extends to the Division of Forestry faculty and staff for their assistance during the conduct of my study. Special thanks also go to the Recreation, Parks and Tourism Resources department faculty for mentoring me through the course of my program.

Lastly, I am thankful to the Regional Research Institute and the University College for funding me during the course of my program. 


\section{TABLE OF CONTENTS}

Page

DEDICATION iv

ACKNOWLEDGEMENTS $\quad$ v

TABLE OF CONTENTS Ni vi

LIST OF TABLES - xi

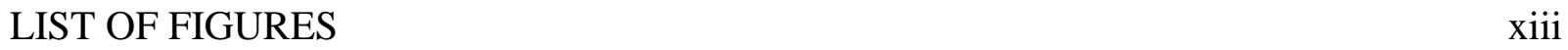

$\begin{array}{ll}\text { CHAPTER } 1 & 1\end{array}$

1.1 Introduction 1

1.2 Structure and organization of the study 3

$\begin{array}{ll}1.3 \text { References } & 7\end{array}$

$\begin{array}{lr}\text { CHAPTER } 2 & 8\end{array}$

A conjoint approach in estimating the importance of urban forest versus other

major tourism attractions in urban tourism destinations: Insights from Washington

DC

$\begin{array}{ll}\text { Abstract } & 8\end{array}$

2.1 Introduction 9

$\begin{array}{ll}2.2 \text { Literature review } & 10\end{array}$

2.2.1 Urban forest and tourism 10 
$\begin{array}{ll}2.3 \text { Methods } & 14\end{array}$

$\begin{array}{ll}\text { 2.3.1 Study area } & 14\end{array}$

$\begin{array}{ll}\text { 2.3.2 Data collection } & 15\end{array}$

$\begin{array}{ll}\text { 2.3.3 Questionnaire and conjoint design } & 16\end{array}$

$\begin{array}{ll}\text { 2.3.4 Data analysis } & 17\end{array}$

$\begin{array}{lr}2.4 \text { Results and discussion } & 18\end{array}$

$\begin{array}{ll}\text { 2.4.1 The sample } & 18\end{array}$

$\begin{array}{ll}\text { 2.4.2 Relative importance and part-worth values } & 20\end{array}$

2.4.3 Comparison among respondent sub-groups 23

$\begin{array}{ll}2.5 \text { Conclusion } & 25\end{array}$

2.6 Suggestions for future studies 28

$\begin{array}{lr}2.7 \text { References } & 29\end{array}$

$\begin{array}{lr}\text { CHAPTER } 3 & 34\end{array}$

Estimating people's preferences on specific attributes of urban forests in Washington DC: A conjoint approach

$\begin{array}{ll}\text { Abstract } & 34\end{array}$

$\begin{array}{ll}3.1 \text { Introduction } & 35\end{array}$

3.2 Literature review 36

$\begin{array}{ll}\text { 3.3 Methods } & 38\end{array}$

3.3.1 Survey site and data collection $\quad 38$

$\begin{array}{ll}\text { 3.3.2 Questionnaire design } & 38\end{array}$ 
3.3.3 Data analysis $\quad 39$

$\begin{array}{ll}3.4 \text { Results } & 40\end{array}$

$\begin{array}{ll}3.4 .1 \text { The sample } & 40\end{array}$

3.4.2 Overall conjoint analysis results $\quad 42$

3.4.3 Results by sub-group $\quad 44$

3.5 Discussion and conclusion $\quad 52$

3.6 Limitations and suggestions for future studies 53

$\begin{array}{ll}3.7 \text { References } & 55\end{array}$

$\begin{array}{ll}\text { CHAPTER } 4 & 57\end{array}$

People's attitudes towards urban forests in Washington DC as related to satisfaction and loyalty

$\begin{array}{ll}\text { Abstract } & 57\end{array}$

$\begin{array}{ll}4.1 \text { Introduction } & 58\end{array}$

4.2 Literature review $\quad 58$

4.2.1 Urban forest and people $\quad 58$

4.2.2 Relationship of attitude, satisfaction and loyalty 61

$\begin{array}{ll}4.3 \text { Methods } & 63\end{array}$

$\begin{array}{ll}\text { 4.3.1 Study area } & 63\end{array}$

$\begin{array}{ll}\text { 4.3.2 Data collection } & 64\end{array}$

4.3.3 Questionnaire design and data analysis 64

4.4 Results and discussion $\quad 66$

4.4.1 Sample descriptives $\quad 66$ 
$\begin{array}{ll}\text { 4.4.2 Exploratory factor analysis (EFA) } & 68\end{array}$

4.4.3 Comparison of factors among sample sub-groups 70

$\begin{array}{ll}\text { 4.4.4 Structural equation model (SEM) } & 73\end{array}$

$\begin{array}{ll}4.5 \text { Conclusions } & 78\end{array}$

4.6 Limitations and suggestions for future research $\quad 80$

$\begin{array}{ll}4.7 \text { References } & 82\end{array}$

$\begin{array}{ll}\text { CHAPTER } 5 & 86\end{array}$

Characterizing visitors' and residents' movement and its implications on urban forest and tourism management in Washington DC

$\begin{array}{ll}\text { Abstract } & 86\end{array}$

$\begin{array}{ll}5.1 \text { Introduction } & 87\end{array}$

$\begin{array}{ll}5.2 \text { Methods } & 89\end{array}$

5.2.1 Study area and data collection $\quad 89$

5.2.2 Questionnaire design and analysis $\quad 90$

$\begin{array}{ll}5.3 \text { Results } & 92\end{array}$

$\begin{array}{ll}\text { 5.3.1 The sample } & 92\end{array}$

$\begin{array}{ll}\text { 5.3.2 Getting around the city } & 94\end{array}$

5.3.3 Distribution of visits by respondent sub-groups 96

5.3.4 Movement patterns of people within Washington DC 104

5.4 Discussion and conclusions 106

$\begin{array}{ll}5.5 \text { Suggestions for future studies } & 109\end{array}$

$\begin{array}{ll}5.6 \text { References } & 110\end{array}$ 
Linking urban forests and urban tourism through peoples's preferences, perception, and spatial movement

6.1 Introduction

6.2 On urban forest and urban tourism planning and development

6.3 On maintenance of urban forests and tourism facilities

6.4 On marketing of urban forests as tourism attractions

6.6 References 


\section{LIST OF TABLES}

Table no

Title

Page

2.1 Attributes and levels used in conjoint analysis

2.2 Socio-demographics of the sample

2.3 Relative importance and part-worth values

$2.4 t$ tests of group means 23

3.1 Urban forest attributes and levels used in the analysis 39

3.2 Demographics of the sample $\quad 41$

3.3 Overall relative importance and utility values of the sample 43

3.4 Relative importance and utility values for visitors, residents, male and 44

female sub-groups

3.5 Relative importance and utility values for age sub-groups 46

3.6 Relative importance and utility values for educational attainment sub- $\quad 47$ groups

3.7 Relative importance and utility values for timing of visit sub-groups $\quad 48$

3.8 Relative importance and utility values by visitors frequency of visit and $\quad 50$ length of stay

3.9 Relative importance and utility values by visitors' reason for visit $\quad 51$

4.1 Summary of perception statements used for the study 65

$\begin{array}{lll}\text { 4.2 Demographics and trip characteristics of the sample } & 67\end{array}$

$\begin{array}{lll}4.3 & \text { Summary results of factor analysis } & 68\end{array}$

4.4 Comparison between first time and repeat visitors, residents and visitors $\quad 71$ 
4.5 Summary of mean attitude scores by age sub-group $\quad 72$

4.6 One-way analysis of variance of mean attitude scores by age sub-group 73

4.7 Summary of standardized path coefficients and model fit statistics $\quad 75$

5.1 Demographics and trip characteristics of the sample 93

5.2 Means of getting around Washington DC 95

5.3 Parameter estimates on movement patterns analyzed 105 


\section{LIST OF FIGURES}

Figure no.

Title

Page

$\begin{array}{lll}1.1 & \text { Study framework } & 4\end{array}$

4.2 Structural model showing the relationship of the variables used in the 74 study

5.1 Map illustrating grouping of attractions by ward 91

5.2 Density map of respondents' visit throughout Washington DC 97

5.3 Density maps comparing visitors and residents 98

$\begin{array}{lll}5.4 & \text { Density maps of different seasons } & 99\end{array}$

5.5 Density maps of residents' visits by season $\quad 100$

5.6 Density maps of residents' visits by season 101

$\begin{array}{lll}5.7 & \text { Density maps by reason of visit } & 103\end{array}$

$\begin{array}{lll}5.8 & \text { Spatial movement patterns } & 105\end{array}$ 


\section{CHAPTER 1}

\subsection{Introduction}

Tourism is one of the largest and most extensive industries worldwide. Over the years, it has continued to grow, as people all over the world travel in search of new experiences, activities and destinations that satisfy their curiosity and need to escape. The growth of the tourism industry is fueled by the development and changes in technology, people's preferences and capacity to travel. Existing and new destinations that offer a variety of itineraries and tour packages try to compete for visitor groups (Goeldner \& Ritchie, 2006).

According to the definition given by the United Nations' World Tourism Organization (UNWTO), "Tourism comprises the activities of persons traveling to and staying in places outside their usual environment for not more than one consecutive year for leisure, business and other purposes." (Goeldner \& Ritchie, 2006). One focal element of this definition is the set of activities that the travelers do and participate in. From an industrial point of view, attractions, events and entertainment are primary sectors that supply activities to visitors. In this study, tourism is examined using a combination of the product and managerial approaches where focus and emphasis are given to different tourism products, specifically, tourism attractions in a city destination.

In 2014 , the tourism industry in the United States generated over 800,000 jobs making it one of the top ten industries in 50 states in terms of employment (U. S. Travel Association, 2015). With these figures, the tourism industry in the country is seen as a major factor contributing to both the national and local economy. Prior to the September 11, 2001 terrorist attacks, tourism in major U. S. cities was on a steady rise over the past decades. Immediately after the attacks, the travel and tourism sector was adversely affected. On one end, visitation in 
New York, Washington DC and Pennsylvania declined mainly because of security concerns on the part of the government, as well as on the part of the travelers. On the other end, the events were instrumental in shifting attention to other tourism destinations as well as other forms of travel.

A decade after the incident, tourism in Washington DC has rebounded. Domestic and international visits have steadily increased and the industry has since slowly recovered. Presently, the nation's capital is ranked $8^{\text {th }}$ among the top destination cities in the country. Between 2009 and 2013 it gets an averaged 17.7 million visitors annually. Consequently, it has generated an average of US\$ 5.9 billion annually from visitor spending (Destination DC, 2013). According to Destination DC, the lead marketing organization that promotes Washington DC as a major international destination for culture, history and arts, the city's major attractions are its museums, memorials, historic sites, shops, parks, nightlife activities, festivals, city tours, sports events, and shows. Annual visitor surveys conducted by this organization have confirmed the important status of these attractions. It is important to note that parks are included among the popular attractions in Washington DC and such areas are major components of the urban forest.

Parks can be major attractions for tourism, as in the case of Washington DC. On a wider scope, parks are also considered a portion of a city's urban forests. Urban forests are portions of urban areas both privately and publicly owned predominantly covered by trees and other related green resources, which are managed for the benefit of society. It includes parks, gardens, trees along streets, and woodlands located within and surrounding cities. Aside from being a tourism resource, urban forests play environmental, social and aesthetic functions (Konijnendijk, 2008). These green areas provide shade that cools the air, reduce noise, beautify the cityscape and 
provide venues for recreation and social interaction (Nadel, Oberlander, \& Bohm, 1977; Nowak \& Dwyer, 2007).

The aforementioned roles of urban forests in cities provide the basis for studying how urban forests relate to urban tourism. Specific studies have shown that urban forests contribute to social well-being (Ellis, Lee \& Kweon, 2006), health (Maas, Verheij \& Groenewegen, 2006), and the local economy (Wolf, 2005). Thus, it is interesting to explore the relationship between urban forests and the tourism industry in a primary tourist destination such as Washington DC. This study is specifically looking into the influence of urban forests on the perceptions, preferences, attitudes and movement of visitors and residents of the city. The link between urban forests and urban tourism is further explored by discussing the implications of the findings of the study to management.

\subsection{Structure and organization of the study}

Figure 1.1 illustrates the components and elements of the study including the relationship among them. In summary, the figure shows that data gathered from the respondents (i.e. visitors and residents of Washington DC) include: 1) their expression on their preferences for urban forests as a tourism attraction, thus obtaining its relative importance; 2) their preferences on specific urban forest attributes; 3 ) their perception on the aspects of urban forests that affect their satisfaction and loyalty; and 4) their visit distribution and movement around the city. The data solicited from the respondents were analyzed and discussed in terms of their influence and implications on the management of urban forests as related to urban tourism in the context of planning, maintenance, marketing and development. A description on the concentration of each chapter of this dissertation is given in the succeeding paragraphs. 


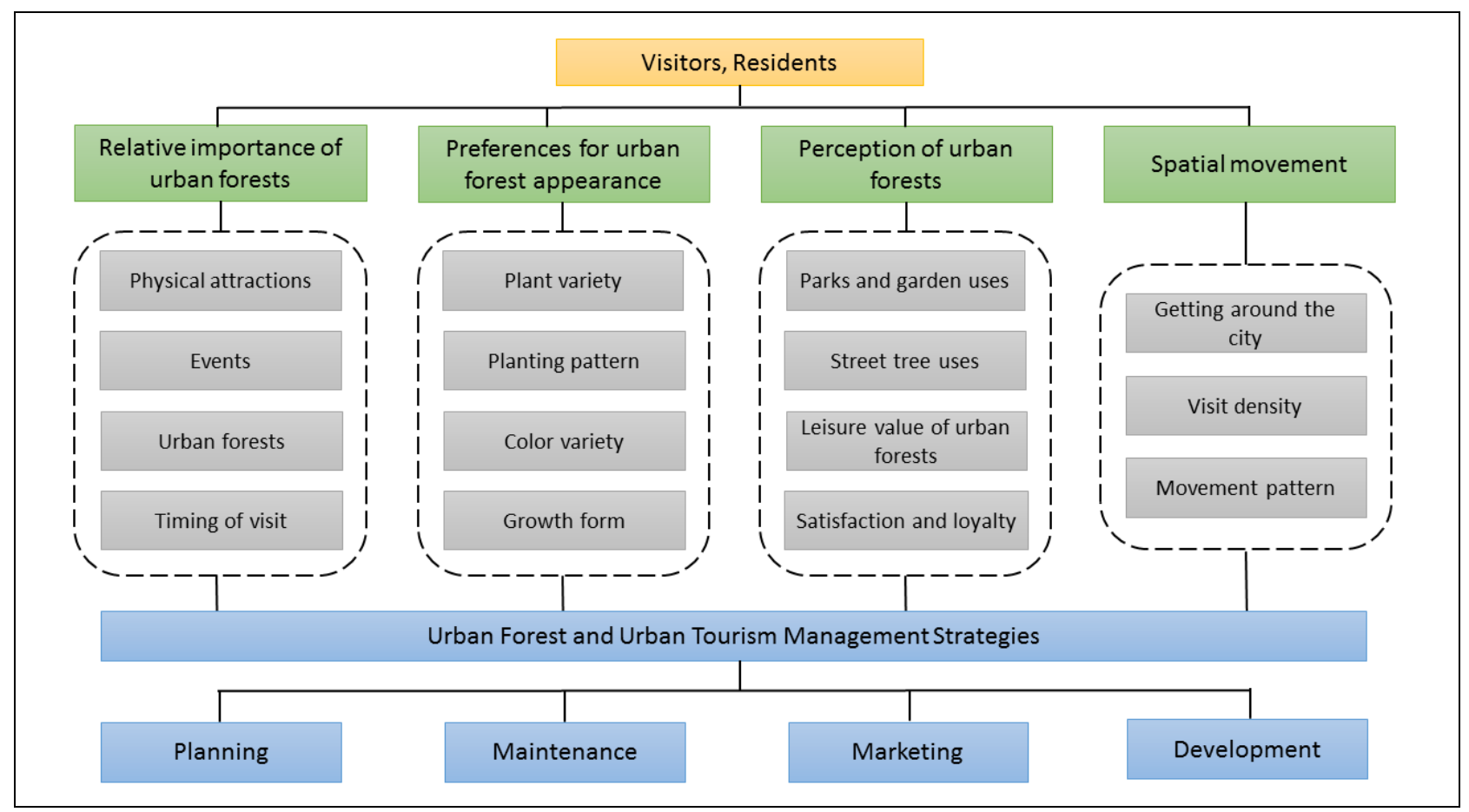

Figure 1.1 Study framework

Each chapter in the manuscript focuses on each of the component in the data collected from respondents. Each component is unique on their own and therefore analyzed using an appropriate statistical technique. Consequently, the results are explained in the context of urban forest and tourism management.

Chapter 2 examines the relative importance attributed by various groups of people on the different tourism attractions in Washington DC, particularly highlighting the role that urban forests play as a tourist attraction. This chapter draws insights from respondents on their preferences for the major attractions that the city has and looks at how urban forests figure in this mix. Among the attributes studied are: timing of visit, physical attractions, events, and urban forests. It is the aim of this segment to investigate the status of urban forests as a tourist attraction in relation to other tourism resources. Conjoint analysis is used to quantify the relative importance values for urban forests as an attraction. Findings discussed in this chapter are 
valuable in understanding the status of urban forests in Washington DC's character and image as a destination from the perspective of different demographics of people.

Chapter 3 describes and discusses a segment of the study where the preferences of respondents were explored to identify specific urban forest attributes and characteristics that are important to them as well as those that they tend to prefer. The specific attributes studied were plant variety, planting pattern, color variety and growth form. These are the common attributes that urban forest managers generally manipulate in developing and managing urban forests aimed to appeal to people. Similarly, conjoint analysis was the tool employed in analyzing the data. Findings from this study are discussed in the context of its practical application in influencing the management of urban forests in the city.

Furthermore, chapter 4 delves into the influence of urban forests on people's knowledge, experiences, satisfaction, and loyalty to Washington DC in general and to urban forests in particular. Respondents were asked about their perception on the different aspects of their experiences while in the city, as influenced by urban forests. It is the aim of this part of the study to look into the level of awareness that respondents possess on the presence, appearance and impact of urban forests in the appeal of Washington DC and how much influence urban forests have in shaping the experiences of groups of people in the city. Structural equation modelling was the analysis tool used in investigating the relationship among the elements of people's perception. Findings from this part of the study can help direct the management of urban forests to be more socially guided and responsive.

Chapter 5 explores the traffic of people in the city. Data on the respondents' mobility, the attractions that they tend to visit, and the flow of their spatial movement within the city were collected and analyzed. Descriptive statistics, combined with density analysis and general log- 
linear models are used in the analysis of the data. The maps generated and the findings are discussed in the context of its impacts on urban forest and tourism management for Washington DC.

Lastly, chapter 6 focuses on the discussion of the implications that the results of the study presents as applied to specific aspects of management: planning, maintenance, marketing and development. This section is aimed at giving credence to the importance of linking urban forests and urban tourism together and support the notion that both are complementary resources that can be tapped and utilized for the benefit of its clientele. 


\subsection{References}

Destination DC. (2013). Visitor statistics [PDF Document]. Retrieved from http://washington.org/press/DC-information/washington-dc-visitor-research.

Ellis, C. D., Lee, S. W. \& Kweon, B. S. (2006). Retail land use, neighbourhood satisfaction and the urban forest: an investigation into the moderating and mediating effects of trees and shrubs. Landscape and Urban Planning, 74, 70-78.

Goeldner, C. R., \& Ritchie, J. B. (2006). Tourism: Principles, practices, philosophies. New Jersey, USA: John Wiley \& Sons.

Konijnendijk, C. C. (2008). The forest and the city: The cultural landscape of urban woodland. Amsterdam, The Netherlands: Springer Science \& Business Media.

Maas, J., Verheij, R. A., Groenewegen, P. P., de Vries, S. \& Spreeuwenberg, P. (2006). Green space, urbanity and health: How strong is the relation?. Journal of Epidemiology and Community Health, 60, 587-592.

Nowak, D. J., \& Dwyer, J. F. (2007). Understanding the benefits and costs of urban forest ecosystems. In Kuser, J. E. (Ed.) Urban and community forestry in the northeast (pp. 2546). The Netherlands: Springer.

Nadel, I. B., Oberlander, C. H., \& Bohm, L. R. (1977). Trees in the City. New York, USA: Pergamon Press.

Wolf, K. L. (2005). Business district streetscapes, trees, and consumer response. Journal of Forestry, 103, 396-400. 


\title{
CHAPTER 2
}

A conjoint approach in estimating the importance of urban forests versus other major tourism attractions in urban tourism destinations: Insights from Washington DC

\author{
Abstract \\ The study used a conjoint approach to assess the relative importance of urban forests compared \\ to the major attractions of Washington DC, a top city destination in the United States. Survey \\ data collected through self-administered questionnaires, were analyzed using conjoint analysis. \\ Results showed that the attributes of the city that people regarded as important to tourism \\ include: timing of visit, physical attractions, events and urban forests. Respondents expressed \\ that timing of their visit is the most important attribute with an assigned relative importance \\ value of $39.55 \%$, this is followed by events, physical attractions, and urban forests respectively. \\ Despite the fact that Washington DC is currently being marketed as a business and cultural \\ destination, respondents still considers urban forests as integral to its tourism appeal. Gardens \\ were observed to be the most preferred form of urban forests. The study also highlighted the \\ need to expand marketing of Washington DC's tourism products to emphasize other attractions. \\ These resources can be tapped to enlarge the city's tourism market and improve its tourism \\ products. Furthermore, the study supports that Washington DC's urban forests add to its appeal \\ and that tourism managers should consider new strategies to incorporate this resource into the \\ mainstream attractions.
}

Keywords: urban tourism; visitor preferences; conjoint analysis 


\subsection{Introduction}

Studies examining the relationship among visitor attractions in cities have been limited. In general, most studies on visitor attractions were geared towards a specific set of similar attractions, many focused on cultural/heritage attractions (Boyd, 2003; Frost, 2003; Kantaven \& Tikkanen, 2006; Kim, Cheng, \& O’Leary, 2007; Tian, Crompton, \& Witt, 1996), others focused on nature-based attractions (Ballentyne, Packer, \& Hughes, 2008; Connell, 2005; Deng, Araño, Pierskalla, \& McNeel, 2010), events (Gibson, Willming, \& Holdnak, 2003; McHone \& Rungeling, 2000; Prentice \& Andersen, 2003; Quinn, 2005), while others were very specific on religious sites (Nolan \& Nolan, 1992), and disaster and death (Cohen, 2011; Lennon \& Foley, 1999; Strange \& Kempa, 2003). Studies that have combined groups of attractions for comparison and assessment were primarily aimed at developing a tourism product or identifying a tourism market niche for the city (Bramwell, 1998).

Furthermore, a number of studies have been conducted that look into the status and performance of urban tourist destinations in the United States. Two major cities: New York and Los Angeles were compared in terms of the spatial arrangement of their attractions (Gladstone \& Fainstein, 2001) while the competitiveness of New Orleans' attractions was compared with other major cities that are considered more popular tourist destinations (Woodside, Pierce, \& Wallo, 1989). On a larger scope, there is also no shortage of studies assessing competitiveness of global cities for urban tourism. The cities of Sheffield and London in the United Kingdom were observed to have increasing visitation trends in the 1990s and thus, require assessment of the contribution of various attractions towards sustaining the level of visitation (Bull \& Church, 2001; Bramwell, 1998). Another study looked into the redevelopment of a London suburb from a "red light" district to give it a more cultural hue by changing the attractions in the area (Maitland 
$\&$ Newman, 2004). Other global cities and local towns such as Athens, Greece; Genoa, Italy, and Toronto, Canada are currently re-examining their tourist attraction systems in order to develop new strategies for marketing and improve competitiveness (Asprogerakas, 2007; Galdini, 2007; Joppe, Martin, \& Waalen, 2001). In Asia, a similar trend of visitor attraction assessment is happening. A clustering of attractions based on tourists' tendency to converge was developed in Jerusalem, Israel for marketing purposes (Shoval \& Raveh, 2004). In Seoul, South Korea the perceptions of six different groups of international visitors were examined to develop tourism attraction profiles that certain groups of visitors typically enjoy (Suh \& Gartner, 2004). These studies attest to the importance of attractions to the sustainability of tourism in urban areas. The capability of these attractions to motivate visitors is the foundation of a thriving tourism industry.

It is undeniable that when the character of a city as a tourist destination is thoroughly studied, the natural landscape resources of an urban area plays a key role in cementing the city's image as well as providing social and environmental benefits. Subsequently, a majority of these natural resources in the urban setting are those green spaces where vegetation such as trees, shrubs and turf are established and maintained, which incidentally are developed to primarily balance the built environment in cities (Paquot, 2005).

\subsection{Literature Review}

\subsubsection{Urban forest and tourism}

Parks and gardens can be major attractions for tourism. On a wider scope, parks are considered a large portion of a city's urban forests, which can be described as portions of urban areas mostly covered by trees and other forms of vegetation, and managed for the people's benefits. These areas can be both private and public lands, and can include parks, gardens, trees 
along streets, and woodlands located within and surrounding cities (Konijnendijk, 2008). Aside from being a tourism resource, urban forests also play environmental, social and aesthetic functions (Paquot, 2005). These green areas provide shade and cool the air, reduce noise, enhance the cityscape and provide venues for recreation and social interaction (Konijnendijk, 2008; Kuser, 2007; Nadel et al., 1977). People, in general, regard areas with more abundant urban vegetation as having relatively higher scenic quality (Buhyoff, Gauthier, \& Wellman, 1984).

City destinations are often depicted in promotional materials as having natural landscapes that are neat and groomed for tourists. A collection of tourism promotional materials from 21 tourism destinations were analyzed based on the photographs that they contain and it was observed that the second and third most frequent representations are that of natural and cultivated landscapes, highlighting the role of greenery as an important part of destination image that is used in marketing (Hunter, 2008).

In Hong Kong, urban forests known locally as the city countryside are being used to redistribute visitor concentration away from congested shopping centers as well as to promote ecotourism. The potential for incorporating the green areas just outside the urban centers in Hong Kong is projected to address congestion of tourists in sites where the popular attractions are located. Currently, the countryside green areas are used as venues for recreation with the development of picnic areas, nature trails and campsites, and are widely used by the local population. The study also suggests that the tourism industry can harness the potential of these facilities for tourists and promote them as part of the destination marketing for Hong Kong, provided that the local population is amenable to such development (Jim, 2000). 
The aforementioned roles and functions of urban forests as depicted in these previous studies provide the basis for further investigating how urban forests relate to urban tourism. On a social context, specific studies have also shown that urban forests contribute to social well-being (Cackowski \& Nasar, 2003; Chen, Bao, \& Zhu, 2006) and health (Maas et al., 2006), and most importantly the local economy (Ellis et al., 2006; Wolf, 2005).

It is important to note that in the studies mentioned above, very few explored the interplay between tourism in terms of visitor experiences and urban forests. With the significance of the contribution of urban forests towards the cityscape's aesthetics, it is interesting and beneficial to both city planners and tourism managers alike to explore the relationship between urban forests and the tourism industry in a primary and increasingly global tourist destination the city, specifically, looking into the influence of urban forests on the perceptions and preferences of its users.

\subsubsection{Conjoint analysis and urban tourism}

Conjoint analysis is essentially a marketing research tool for consumer products that possess different specifications or attributes (Louviere, 1988). Using this tool, manufacturers attempt to identify the correct combination of attributes that would appeal to their target market. The field of tourism has a number of studies that used a conjoint approach in examining the tourism product. In one particular approach, visitor attractions are categorized into groups and are often examined in various combinations, as exemplified by itineraries, tour and vacation packages, and tourism portfolios (Goeldner \& Ritchie, 2003).

For example, conjoint analysis was used to identify specific mixes of activities that can be done in a city in one weekend. The study conducted by Dellaert, Borgers, and Timmermans, 
(1995) tested the viability of the conjoint approach in determining the importance of various activities in which a tourist may participate on a weekend in Paris, France. It highlighted the practical use of this method in establishing the popularity and preference of specific sets and combinations of tourism activities such as shopping, sightseeing, bus tour, visiting museums, and watching a show. It distinguished between preferred daytime and nighttime activities as well as defined the most popular combination of activities to visitors.

The use of conjoint analysis in tourism research also varies in scope. It can be used at the level of a destination such as a city, country or region. One study examined the preferences of people grouped by travel-style (novelty seekers, average tourists, and familiarity seekers) on specific attributes that affect tourist experience: type of accommodation, travel companions and the language predominantly used at the destination. The study succeeded in noting differences on the preferences of respondents grouped based on travel-style to visit a hypothetical country destination as well as the change in preferences of these groups in varying the levels of the tourism attributes (Basala \& Klenosky, 2001). At the city level, another study (van Limburg, 1998) explored the image of a city destination based on the main tourism attractions that encompass it. The relative importance of the attributes: events, history, shops and pubs were estimated and specific levels of the attributes were compared, and the attributes that are most attractive to visitors were identified.

On the other hand, conjoint analysis has been applied to studies at a smaller-scale like at the level of a specific attraction or tourism activity. One study (McKenzie, 1992) focused on the factors affecting people's choice to visit a specific hunting area, and another (Turpie \& Joubert, 2004) explored the effect of the various attributes of a destination on the visitors' experience. 
However, the sites of both studies described are pristine and rural destinations, which underscores the need to also focus on urban tourist destinations.

All these studies have demonstrated the practical use of the conjoint approach as an analysis tool for the tourism industry. Such studies focused on site-specific attributes with the results aimed at improving marketing for the destination through developing the tourism product or establishing market segments in the general tourism population.

This part of the study aims to contribute towards cementing the relationship between urban forests and tourism by exploring the relative importance of urban forests in comparison with the major tourism attractions in a popular city destination - Washington DC. Furthermore, it also observes similarities and differences in preferences among user sub-groups based on selected demographic and other related variables; and examine how the changing appearance of the urban forests over the seasons impact visitors' experience.

\subsection{Methods}

\subsubsection{Study area}

The city of Washington DC is the site for the study. The city was chosen for several reasons, one of which is its unique status as the capital of the United States. Another reason is that its character and landscape have a significant portion of its land devoted for urban forests in the form of parks, gardens and tree-lined streets. Also, despite the fact that the city is one of the top tourist destinations in the United States for both domestic and foreign visitors, there are few studies that explored or elicited feedback from people on the city's tourism. Annual visitor surveys conducted by Destination DC, the leading tourism marketer of the city, have confirmed the important status of attractions such as museums, memorials, historic places, parks, nightlife 
activities and events. It is important to note that parks are included among these and that such areas are major components of the city's urban forests.

The study area is limited to the city of Washington DC where the survey sites were identified and located. Specifically, the sites where the face-to-face surveys were conducted are: the U. S. Botanic Garden; the U. S. National Arboretum; and the National Mall. The following specific locations within the National Mall were selected: area in front of the Lincoln memorial, the tidal basin and the area in front of the Smithsonian museums. These sites were chosen specifically because of high concentrations of prospective participants for the study.

\subsubsection{Data collection}

Data were collected through a face-to-face survey of both visitors and residents encountered at the locations listed previously. The survey was conducted for a full year, starting on October 2009 until September 2010. The timing of data collection was dictated by the approval of the permits secured from concerned agencies with jurisdiction over the survey sites. Surveys were conducted twice per month and scheduled every Friday to Sunday to maximize the number of respondents sampled. Two surveyors rotated among the study sites and spent an average of seven hours per day administering the survey. Furthermore, a number of surveys were scheduled to coincide with major events such as holidays and festivals to maximize participation.

Purposive sampling, a convenience sampling approach, was used to select prospective respondents. Visitors and residents were approached and asked to participate in the study. Nonresponse bias was addressed by giving the prospective respondent a clear and concise background on the objectives and importance of the study, thus they have an informed decision 
to participate to the study or not. The surveyors were trained to supervise and guide the respondents while they go through the self-administered questionnaire.

\subsubsection{Questionnaire and conjoint design}

A total of four attributes with varying levels were identified for the study in consultation with the city's Urban Forest Administration and based on the results of the 2009 visitor survey conducted for the city. Table 2.1 lists the attributes and their corresponding levels used in the study.

Table 2.1

Attributes and levels used in conjoint analysis

\begin{tabular}{|c|c|}
\hline Attributes & Levels \\
\hline \multirow[t]{3}{*}{ Physical attractions } & Monuments and memorials \\
\hline & Museums \\
\hline & Historical places \\
\hline \multirow[t]{3}{*}{ Events } & Festivals \\
\hline & Celebrations and parades \\
\hline & Sports events \\
\hline \multirow[t]{3}{*}{ Urban forests } & Parks \\
\hline & Gardens \\
\hline & Street trees \\
\hline \multirow[t]{3}{*}{ Timing of visit } & Spring \\
\hline & Summer \\
\hline & Fall \\
\hline
\end{tabular}


The primary reason for selecting these attributes and levels was to quantitatively compare the relative importance of the most popular visitor attractions in the city. Urban forests were included as an attribute because parks and gardens are ranked among popular attractions. Moreover, it is the study's focus to assess how the urban forest components influence the enjoyment of people in conjunction with the city's other main attractions. Lastly, the timing of visit was included as an attribute because the city's aesthetics change and different events happen throughout the year offering a unique set of attraction at various times of the year.

Out of the total 108 potential combinations of attractions, an orthogonal design was obtained using the Statistical Package for the Social Sciences (SPSS). The design consisted of 16 sets of visitor attraction combinations that the respondents rated. Respondents were asked to rate each combination of attractions in terms of their perceived preferences of the set. A rating scale of 1 to 10 was employed where 1 means least preferable and 10 means most preferable. The surveyors played a key role in explaining and describing each set of attractions that the respondents rated.

\subsubsection{Data analysis}

Sample demographics is reported using descriptive statistics while data from the conjoint experiment were analyzed using regression analysis. The model used in the study is given by Equation 2.1.

$Y=b_{1}($ Physical attraction $)+b_{2}$ (Events $)+b_{3}($ Urban forests $)+b_{4}($ Timing of visit $)+e$ 
Where $Y$ denotes the respondent's preferences for a given combination of attractions, $b_{1}$ through $b_{4}$ are the utility values for the levels in each attribute, and $e$ is an error term.

The relative importance values for each attribute was calculated by dividing the partworth of a given attribute by the total part-worth value of all attributes where the part-worth values are the unstandardized regression coefficients from the regression (Won, Hwang, \& Kleiber, 2009).

Conjoint analyses of sample sub-groups based on socio-demographic variables were also conducted to compare their preferences. Comparisons among sub-groups were made using $t$-tests and analysis of variance (ANOVA) following assumptions of normality and equal variances.

\subsection{Results and discussion}

\subsubsection{The sample}

There were 1,146 completed questionnaires analyzed out of a total 3,210 people who were asked to participate in the study, yielding a response rate of $35.7 \%$. Table 2.2 summarizes the demographics for the sample.

Table 2.2

Socio-demographics of the sample $(N=1146)$

\section{Variable}

Place of residence

Residents

Visitors

Gender

Male

Female
Percent (\%)

65.8

52.0 
Age

18 to 25

17.6

26 to 39

35.6

40 to 49

18.4

50 to 59

17.0

60 and above

11.4

Educational Attainment

High school

College

41.5

Graduate

52.2

Income level

Low (below \$40,000)

Middle $(\$ 40,000$ to 79,999$)$

High (\$80,000 and above)

Frequency of visits

First timers

Repeaters

81.1

Timing of visit

Fall 36.8

Winter

Spring

Summer

Purpose of visit

Leisure/vacation 47.9

Business

13.0 
Visiting family, friends and relatives

Education-related
16.1

23.0

As seen from Table 2.2, 65.8\% were visitors and 34.2\% were residents. With respect to sex, the sample has slightly more females $(52 \%)$ than males $(48 \%)$. The sample is relatively middle aged where more than half of the respondents are below 40 years old and well educated, with more than $90 \%$ having at least a college degree. This translates to the respondents having a higher income level with about $80 \%$ having relatively middle and high income, therefore validating their capacity to engage in tourism-related travel. Majority were repeat visitors $(81.1 \%)$ with only $18.9 \%$ being first timers. In terms of the timing of visit, most respondents were sampled during the fall season while the winter season had the smallest proportion of respondents because surveys were limited due to unfavorable weather conditions. Lastly, about half $(47.9 \%)$ of the respondents (both residents and visitors) visited the city for leisure, with only $13.0 \%$ visited for business purposes.

\subsubsection{Relative importance and part-worth values}

Table 2.3 summarizes the results obtained after conjoint analysis. The table lists the average overall relative importance and part-worth values or utilities given by the respondents as well as several sub-groups of the sample: visitors, residents, first timers and repeat visitors. Table 2.3

Relative importance and part-worth values.

\section{Relative importance/Part-worth values}

\begin{tabular}{llllll}
\cline { 2 - 4 } Attributes/Levels & Overall & Visitors & Residents & First timers & Repeaters
\end{tabular}




\begin{tabular}{|c|c|c|c|c|c|}
\hline Timing of visit & 39.55 & 44.17 & 41.31 & 45.63 & 44.01 \\
\hline Spring & 0.6686 & 0.9109 & 0.7034 & 0.6356 & 0.6631 \\
\hline Fall & 0.3415 & 0.4379 & 0.4684 & 0.1778 & 0.3090 \\
\hline Summer & -0.1910 & 0.0178 & 0.0284 & 0.1266 & -0.0557 \\
\hline Winter & -0.9910 & -1.3667 & -1.2002 & -0.9400 & -0.9164 \\
\hline Events & 24.47 & 22.09 & 24.60 & 19.36 & 22.62 \\
\hline Festivals & 0.1906 & 0.3770 & 0.5655 & -0.0980 & 0.0712 \\
\hline Sports events & -0.2932 & -0.3814 & -0.4907 & 0.0692 & -0.1909 \\
\hline Celebrations/ & 0.0486 & 0.0044 & -0.0748 & 0.0288 & 0.1197 \\
\hline \multicolumn{6}{|l|}{ Parades } \\
\hline Physical attractions & 18.22 & 17.57 & 17.91 & 17.17 & 17.66 \\
\hline Museums & -0.0610 & -0.0236 & 0.0063 & -0.0514 & -0.0890 \\
\hline Historical places & -0.0376 & -0.0551 & -0.1443 & 0.0727 & -0.0066 \\
\hline Monuments/ & 0.9870 & 0.0787 & 0.1380 & -0.0213 & 0.0956 \\
\hline \multicolumn{6}{|l|}{ Memorials } \\
\hline Urban forests & 17.77 & 16.17 & 16.18 & 17.84 & 15.71 \\
\hline Gardens & 0.1058 & 0.2225 & 0.2169 & 0.2767 & 0.0278 \\
\hline Parks & 0.0259 & -0.0539 & -0.0106 & -0.0255 & 0.0460 \\
\hline Street trees & -0.1317 & -0.1686 & -0.2063 & -0.2512 & -0.0738 \\
\hline
\end{tabular}

It can be seen from Table 2.3 that all the attributes identified for the study are important in terms of preference. The timing of visit is regarded as the most important among the attributes with a relative importance of $39.55 \%$, followed by events with an importance of $24.47 \%$, physical attractions and urban forests with relative importance values of $18.22 \%$ and $17.77 \%$ respectively. Under each attribute, levels with positive part-worth values indicate that these add to the preference of the respondents. Overall, spring and fall seasons were regarded as the 
seasons when respondents prefer to visit the city. In terms of events, respondents viewed festivals to have a positive influence on preference. For physical attractions, the monuments and memorials were the most preferred. Lastly, gardens were the urban forest components observed to be most preferred.

Overall, the attributes earned relative importance values of higher than $15 \%$, signifying that the timing of visit, events, physical attractions and urban forests are all important factors that play a role when people decide to visit Washington DC (Chiam, Soutar, \& Yeo, 2009).

Furthermore, the results of the study showed that the combination of a spring time visit, attending a festival and going around monuments, memorials and gardens is the most preferred by the respondents. Museums, even though a popular and important attraction for locals, are not at the forefront in attracting visitors. They play a supporting role behind the monuments and memorials that are visibly marketed in the city's tourism promotional materials. However, when visitors learn more about the city during their visit or if they are oriented by a local on the main attractions of the city, the museums become part of the itinerary because it offers new options and most of them for no additional cost. Furthermore, in 2009 the success and popularity of the movie featuring the Smithsonian museums in the box office, boosted the popularity of the museums among visitors who have seen the movie.

\subsubsection{Comparison among respondent sub-groups}

Conjoint analyses were also conducted on the following segments of the sample: visitors, residents, first timers, and repeat visitors. As shown in Table 2.4, visitors in general, residents and repeat visitors all regarded the relative importance of the attributes the same way as the overall results. Specifically, visitors in general, residents and repeat visitors followed the overall trend in terms of the relative importance of the city attributes of Washington DC. First timers, on 
the other hand, expressed that the timing of visit is the most important attribute that influences their preference in visiting the city, followed by events. Physical attractions and urban forests were regarded as almost equally important. In terms of the specific levels under each attribute, visitors and residents agreed that spring and fall seasons, festivals, and gardens are more preferred. On the other hand, first time visitors consider summer in addition to fall and spring as another preferred time to visit the city. For repeat visitors, celebrations and parades are more preferred than festivals.

Table 2.4

$t$ tests of group means.

\begin{tabular}{lccc|ccc}
\hline \multicolumn{1}{c}{ Attribute } & Visitor & Resident & $\boldsymbol{t}$ value & First & Repeaters & $\boldsymbol{t}$ value \\
& & & & & \\
& & & & & \\
\hline Timing of visit & 44.17 & 41.31 & $2.019^{*}$ & 45.63 & 44.01 & 0.688 \\
Events & 22.09 & 24.60 & $-2.514^{*}$ & 19.36 & 22.62 & $-2.046^{*}$ \\
Physical & 17.57 & 17.91 & -0.459 & 17.17 & 17.66 & -0.394 \\
attractions & & & & & & \\
Urban forests & 16.17 & 16.18 & -0.016 & 17.84 & 15.71 & 1.835 \\
\hline
\end{tabular}

*Significant at $p<.05$

To examine the differences in the relative importance values given to the attributes by visitors and residents, a statistical comparison was conducted through a $t$ test of group mean relative importance on the four attributes. As seen in Table 2.4, the results showed that residents gave more preference to events as a preferable attraction to the city while visitors gave more importance to the timing of visit. Furthermore, repeat visitors gave more importance to events as more preferable attraction compared to first timers. 
It can be noted that visitors and residents have very similar levels of preferences on the main attributes analyzed in the study. Both groups agreed that timing of visit is the most important factor influencing their preference, followed by events, physical attractions and urban forests. Moreover, the two groups scored spring as the most preferred time to visit the city followed by fall and summer. However, differences in preference are expressed in the other attributes where visitors preferred festivals, celebrations and parades while residents do not. As expressed by some of the resident respondents, this can be attributed to their general tendency to stay away from concentrated crowds and things that cause slow traffic in the city. Also, visitors only preferred monuments and memorials while residents included the museums as a preferred tourism attraction because they are aware that some museum exhibits are dynamic which can be ascribed to residents' familiarity and knowledge of the city's attractions.

For visitors in general, the most preferred combination of attribute levels is a spring time visit attending a festival and going around monuments and memorials. The sub-groups (first timers and repeat visitors), however, differ slightly in terms of the most preferred combination. Both sub-groups agree that a spring time visit is most preferred but first timers regard the combination of sports events, historical places and gardens to be preferable while repeat visitors regard the combination of celebrations, parades, monuments and parks to be more preferable.

Zeroing in on the most preferable Washington DC attractions as expressed by its clientele give tourism planners and marketers a strong basis to steer future marketing and promotion strategies geared towards a more balanced emphasis on the city's major attractions as well as improving the appeal and character of Washington DC as a tourist destination. Based on the study results, spring, summer and fall are all preferred seasons to visit with spring being the most preferred. The best example of a tourist draw that confirms the results of this study is the annual 
National Cherry Blossom festival, which has grown in popularity every year. The organizers provide a variety of activities for all groups of visitors by highlighting the historical, cultural and aesthetic significance of the cherry trees in the city.

This study further reinforced the difference among user groups in terms of their preferences on the attributes of a city as a tourism destination; in this case, Washington DC and this can be attributed to some groups having more familiarity with the city compared to others.

\subsection{Conclusion}

The study highlighted that in a premier city destination popular as a socio-economic and political center such as Washington DC, urban forests still proved to be a tourism resource that both residents and visitors recognize. In terms of tourism marketing, urban forest attractions in Washington DC are still currently secondary to its cultural, historic and heritage attractions, but scoring a relative importance higher than $15 \%$ implies that the urban forest attractions are considered important by its market (Chiam et al., 2009). At present, the city is being promoted as a global center for business, convention and culture. However, as the results of the study revealed, there are more people in the city who visit for leisure and that Washington DC's urban forests still remains underutilized. City and tourism planners can tap the urban forest resources to expand the appeal of the city and to offer variety for prospective visitors. At present, local and nearby residents are the main users that enjoy the city's extensive urban forests. Visitors who are accompanied by residents during their visit are the people who get to enjoy these attractions. Visitors, for the most part, are limited to enjoying areas where the memorials are concentrated the National Mall area, which is maintained by the National Park Service. Programs that showcase urban forests for tourists are currently not a popular choice for visitors. Given the 
demographics of Washington DC's tourist market, the status quo can change. In general, more educated visitors tend to plan their trips more and research on the attractions that cities offer and thus get a higher chance of reading about the city's urban forests. Residents, on the other hand, utilize these urban forest areas mainly for recreation although some residents bring visitors to these places to add a different dimension to their visit. The grassy areas of the National Mall also serve as venues for exercise and fitness enthusiasts who get together and play sports every afternoon as observed by the surveyors. Furthermore, a significant portion of residents, mainly families and couples, also use these areas for picnic and other similar socializing activities.

For tourism planners and promoters, the findings of this study are useful to direct marketing initiatives towards urban forests that can serve more than a secondary role to Washington DC's main attractions. Stine (2006) stated that the development of the extensive gardens and parks in Washington DC went hand in hand with its history. A program that showcases the historical, environmental and aesthetic elements of the city's urban forests make interesting and educational alternatives in appreciating the nation's capital.

Another reason behind the urban forests being underappreciated is that visitors currently do not have easy access to most of the parks and even if they do, they are not aware of the means to get there and the amenities that the parks offer unless a local orients them. Intensifying efforts to disseminate information about how to best navigate the city can prove useful to make visitors more mobile. By doing so, not only will the relatively less popular park and garden attractions be showcased, but also high visitor use areas in the city can be relieved from visitor traffic during the peak tourist season. Potentially, this can change the way people enjoy the city.

The results of the study also showed that familiarity plays a key role in the manner of enjoying city destinations. Repeat visitors as well as residents seem to have a better sense of the 
specific attractions and city attributes that are worth enjoying. Tourism managers can capitalize on this segment of the market for promotional purposes. Giving them trip incentives can encourage word of mouth advertising as well as help ensure their satisfaction. Also, marketing of tour packages should equally promote the city's museums and parks with its monuments and memorials.

The conjoint approach was successful in assimilating and establishing the status of urban forests as part of the mainstream attractions of Washington DC. Through the survey, the respondents were more aware of not only the cultural and historical tourism resources but also the nature-based tourism resources as well. The results of the study revealed that Washington DC is currently underutilizing it nature-based tourism resources with the exception of the notable annual National Cherry Blossom Festival. Therefore, it is a strategic move for tourism planners and managers in Washington DC to expand the focus of their marketing scheme to include the parks throughout the city. By doing so, they will be able to improve visitor experience by dispersing people on high use areas and utilizing other unique and equally appealing tourism resources in the city. Furthermore, the management of urban forest can earn income through tourism that can be devoted for the implementation of research and development programs.

\subsection{Suggestions for further studies}

This study is not without limitations. One of which is the non-response of foreign visitors who are not well versed in English. As the surveyors observed, this segment of the population tends to refuse to participate in the study. Future studies can design a multi-lingual form of data collection instrument so a wider group of respondents can participate. Secondly, the limitation on the variety of survey sites used may have limited the study in capturing a more representative 
sample of Washington DC's tourism market. Other survey sites can include hotels, transportation hubs, and restaurants. Furthermore, the conjoint design used for the study is relatively simple and straightforward, and this can be expanded to include more city attributes as well as more levels under each attribute. Subsequently, attributes that were not used in this study can be the main focus of subsequent studies. These issues can be important considerations to improve future research to be conducted on this area. 


\subsection{References}

Asprogerakas, E. (2007). City competition and urban marketing: The case of tourism industry in Athens. Tourismos: An International Multidisciplinary Journal of Tourism, 2, 89-114.

Ballentyne, R., Packer, J., \& Hughes, K. (2008). Environmental awareness, interests and motives of botanic garden visitors: Implications for interpretive practice. Tourism Management, $29,439-444$.

Basala, S. L., \& Klenosky, D .B. (2001). Travel-style preferences for visiting a novel destination: a conjoint investigation across the novelty-familiarity continuum. Journal of Travel Research, 40, 172-182.

Boyd, S. (2002). Cultural and heritage tourism in Canada: Opportunities, principles, and challenges. Tourism and Hospitality Research, 3, 211-233.

Bramwell, B. (1998). User satisfaction and product development in urban tourism. Tourism Management, 19, 35-47.

Buhyoff, G. J., Gauthier, L. J., \& Wellman, J. D. (1984). Predicting scenic quality of urban forests using vegetation measurements. Forest Science, 30, 71-82.

Bull, P., \& Church, A. (2001). Understanding urban tourism: London in the early 1990s. International Journal of Tourism Research, 3, 141-150.

Cackowski, J. M., \& Nasar, J. L. (2003). The restorative effects of roadside vegetation: Implications for automobile driver anger and frustration. Environment and Behavior, 36, 736-751.

Chen, B., Bao, Z., \& Zhu, Z. (2006). Assessing the willingness of the public to pay to conserve urban green space: The Hangzhou city, China case. Journal of Environmental Health, 69, 26-30. 
Chiam, M., Soutar, G. \& Yeo, A. (2009). Online and off-line travel packages preferences: A conjoint analysis. International Journal of Tourism Research, 11, 31-40.

Cohen, E. H. (2011). Educational dark tourism at an in populo site: The Holocaust museum in Jerusalem. Annals of Tourism Research, 38, 193-209.

Connell, J. (2005). Managing gardens for visitors in Great Britain: A story of continuity and change. Tourism Management, 26, 185-201.

Dellaert, B., Borgers, A., \& Timmermans, H. (1995). Using conjoint choice experiments to model urban tourists' choice of activity packages. Tourism Management, 16, 347-353.

Deng, J., Araño, K. G., Pierskalla, C., \& McNeel, J. (2010). Linking urban forests and urban tourism: A case of Savannah, Georgia. Tourism Analysis, 15, 167-181.

Destination DC. (2013). Visitor statistics [PDF Document]. Retrieved from http://washington.org/press/DC-information/washington-dc-visitor-research.

Ellis, C. D., Lee, S. W., \& Kweon, B. S. (2006). Retail land use, neighbourhood satisfaction and the urban forest: an investigation into the moderating and mediating effects of trees and shrubs. Landscape and Urban Planning, 74, 70-78.

Frost, W. (2003). The financial viability of heritage tourism attractions: Three cases from rural Australia. Tourism Review International, 7, 13-22.

Galdini, R. (2007). Tourism and the city: Opportunity for regeneration. Tourismos: An International Multidisciplinary Journal of Tourism, 2, 95-111.

Gladstone, D. L., \& Fainstein, S. S. (2001). Tourism in Global Cities: A comparison of New York and Los Angeles. Journal of Urban Affairs, 23, 23-40.

Gibson, H. J., Willming, C., \& Holdnak, A. (2003). Small-scale event sport tourism: fans as touritsts. Tourism Management 24, 181-190. 
Goeldner, C. R., \& Ritchie, J. R. B. (2003). Tourism: Principles, practices, philosophies (9th Ed). New Jersey: Wiley.

Hunter, W. C. (2008). A typology of photographic representations for tourism: Depiction of groomed spaces. Tourism Management, 29, 354-365.

Jim, C. Y. (2000). Environmental changes associated with mass urban tourism and nature tourism development in Hong Kong. The Environmentalist, 20, 233-247.

Joppe, M., Martin, D. W., \& Waalen, J. (2001). Toronto’s image as a destination: A comparative importance-satisfaction analysis by origin of visitor. Journal of Travel Research, 39, 252260.

Kantaven, T., \& Tikkanen, I. (2006). Advertising in low and high involvement cultural tourism attractions: Four cases. Tourism and Hospitality Research, 6, 99-110.

Kim, H., Cheng, C. K., \& O’Leary, J. T. (2007). Understanding participation patterns and trends in tourism cultural attractions. Tourism Management, 28, 452-460.

Konijnendijk, C.C. (2008). The forest and the city: The cultural landscape of urban woodland. New York: Springer.

Kuser, J. E. (2007). Urban and community forestry in the northeast (2nd Ed). The Netherlands: Springer.

Lennon, J. J., \& Foley, M. (1999). Interpretation of the unimaginable: The U.S. holocaust memorial museum, Washington D. C. and dark tourism. Journal of Travel Research, 38, 46-50.

Louviere, J. J. (1988). Analyzing decision making: Metric conjoint analysis. CA: Sage Publications. 
Maitland, R., Newman, P. (2004). Developing metropolitan tourism on the fringe of central London. International Journal of Tourism Research, 6, 339-348.

Maas, J., Verheij, R. A., Groenewegen, P. P., de Vries, S., \& Spreeuwenberg, P. (2006). Green space, urbanity and health: How strong is the relation?. Journal of Epidemiology and Community Health, 60, 587-592.

McHone, W. W., \& Rungeling, B. (2000). Practical issues in measuring the impact of a cultural tourist event in a major tourist destination. Journal of Travel Research, 38, 300-303.

McKenzie, J. (1992). Evaluating recreation trip attributes and travel time via conjoint analysis. Journal of Leisure Research, 24, 171-184.

Nadel, I. B., Oberlander, C. H., \& Bohm, L. R. (1977). Trees in the city. New York: Pergamon Press.

Nolan, M. L., \& Nolan, S. (1992). Religious sites as tourism attractions in Europe. Annals of Tourism Research, 19, 68-78.

Paquot, T. (2005). City and nature, a missed opportunity?. Diogenes, 52, 65-74.

Prentice, R., \& Andersen, V. (2003). Festival as creative destination. Annals of Tourism Research, 30, 7-30.

Quinn, B. (2005). Arts festivals and the city. Urban Studies, 42, 927-943.

Shoval, N., \& Raveh, A. (2004). Categorization of tourist attractions and the modelling of tourist cities: Based on the co-plot method of multivariate analysis. Tourism Management, 25, $741-750$.

Stine, J. K. (2006). Nature and the City: Explorations of Washington's Natural and Built Environment. OAH Newsletter, 34,(1), A13. 
Strange, C., Kempa, M. (2003). Shades of dark tourism: Alcatraz and Robben Island. Annals of Tourism Research, 30, 386-405.

Suh, Y. K., \& Gartner, W. C. (2004). Perceptions in international urban tourism: An analysis of travellers to Seoul, Korea. Journal of Travel Research, 43, 39-45.

Tian, S., Crompton, J. L., \& Witt, P. A. (1996). Integrating constraints and benefits to identify responsive target markets for museum attractions. Journal of Travel Research, 35, 34-45.

Turpie, J., \& Joubert, A. (2004). The value of flower tourism on the Bokkeveld plateau - a botanical hotspot. Development South Africa, 21, 645-662.

Van Limburg, B. (1998). City marketing: a multi-attribute approach. Tourism Management, 19, 475-477.

Wolf, K. L. (2005). Business district streetscapes, trees, and consumer response. Journal of Forestry, 103, 396-400.

Won, D., Hwang, S., \& Kleiber, D. (2009). How do golfers choose a course? A conjoint analysis of influencing factors. Journal of Park and Recreation Administration, 27, 1-16.

Woodside, A. G., Pearce, B., \& Wallo, M. (1989). Urban tourism: An analysis of visitors to New Orleans and competing cities. Journal of Travel Research, 27, 22-30. 


\title{
CHAPTER 3
}

Exploring people's preferences on specific attributes of urban forests in Washington DC: A conjoint approach

\author{
Abstract \\ The study uses conjoint analysis to determine the preferences of different groups of people on \\ specific urban forest attributes such as plant variety, planting pattern, color variety and growth \\ form. A year-long face-to-face survey was employed to collect data and conjoint analysis was \\ conducted to estimate the relative importance of the attributes as well as the part-worth values of \\ the specific levels under each attribute. Furthermore, the respondents were segmented into \\ various groups based on demographics and the corresponding preferences were estimated for \\ each group. The study revealed that, all the aforementioned attributes were important with plant \\ variety being the most important and growth form being the least important. Specifically, the \\ respondents preferred urban forests to be predominantly trees and grass, planted in patches that \\ are scattered throughout the city, mainly green with many other colors, and trimmed. Various \\ sub-groups of respondents showed slight variations in preferences which entail specific \\ adjustments on management strategies and maintenance techniques.
}

Keywords: conjoint analysis, urban forest management 


\subsection{Introduction}

Urban forests as defined by Konijnendijk (2008) are areas inside cities and urban centers that are planted to vegetation that varies from any combination of trees, shrubs and grasses. These areas serve a variety of functions among which include: improving the aesthetics of the built landscape, providing shade and protection for wildlife, serve as a venue for recreation and socialization, and helps regulate ambient urban temperature conditions. In the United States, major cities have set aside specific areas where urban forests are established and maintained. The major forms of urban forests are embodied in parks, gardens, urban trails and greenways. A number of studies have proven the key role that urban forests play in establishing the character of the city; in improving real estate value; in contributing to the health and well-being of residents; and in contributing to the local economy. It is in this light that management and maintenance of urban forests need to continue to be responsive to the needs of the population it serves (O'Brien, 2006).

It is evident that one of the primary beneficiaries of urban forest services are the local people; therefore, in the effective management of urban forests it is important to solicit feedback from them particularly the actual users of these areas. In the aspect of aesthetics, preferences of users are varied and may at times be contradictory. Thus, studies that aim to understand the nature of these differences can aid managers in developing a management scheme that can address this. This study investigates the preferences of the users of Washington DC's urban forests in terms of specific characteristics that can be influenced by management as well as observing similarities and differences in the preferences of specific demographics of people. Lastly, findings on people's preferences are also discussed in terms of its management implications. 


\subsection{Literature review}

Most studies that use conjoint analysis are involved in the field of marketing where producers or manufacturers of products try to determine specific attributes and characteristics of the product that are preferred by consumers (Louviere, 1988). However, through the years there has been a recommendation that the use of conjoint analysis be expanded to other fields for the improvement of its application (Green \& Srinivasan, 1990). A study used conjoint analysis in exploring the economics, impacts and implications of green product development (Chen, 2001). Unconventionally, another study used conjoint analysis in valuing a phenomenon called ecosystem change, and compared its applicability against the more popular contingent valuation method (Farber \& Griver, 2000). The study succeeds in noting the methods' similarities and differences. Moreover, conjoint analysis was also used in investigating services and not just actual tangible products (Gustafsson, Ekdahl, \& Bergman, 1999).

Studies outside of marketing that involve the use of conjoint analysis are often geared towards investigating people's preferences. One study attempted to develop an urban housing design based on preferences of people elicited using the conjoint approach. Among the attributes studied were proximity to work, commercial areas, air quality, presence of green spaces and recreational areas (Katoshevski \& Timmermans, 2001). In line with studies conducted in urban areas, conjoint analysis was also used in determining city attributes most preferred by tourists in the interest of developing city tourism (van Limburg, 1998). Moreover, at the city or town level, there are a number of studies that explore people's preferences of various urban resources. One such study involved investigating the preferences of visitors to specific flower attributes and its impacts on flower tourism in the city (Turpie \& Joubert, 2004). 
In the United States, a study related people's preferences with their tendencies to support local businesses. Wolf (2005) investigated the preferences of residents and visitors on business districts with tree-lined streets and related it to their patronage behavior. The study revealed that respondents were more keen on shopping and spending more time at business districts that have a more lush and relaxing atmosphere. They viewed areas with well-maintained tree-lined streets to have shops with better product quality, value and selection. Lastly, the respondents expressed their willingness to travel and spend a considerable amount of time enjoying such areas.

Urban forests also have its share of studies that uses conjoint analysis. A study looked at the differences of urban forest preferences based on race and revealed that one race prefers areas with a more natural setting where trees are abundant and not groomed while another prefer a more developed urban forest with more open spaces, established trails and facilities (Elmendorf, Willits, \& Sisidharan, 2005). Moreover, another study looked into the preferences of forest management planners on the composition and structure of urban forests. In this study, it was observed that a group of respondents preferred pure stands of urban forest with little understory vegetation and devoid of dead trees, while others prefer a more natural looking stand of mixed tree species (Tyrväinen, Silvennoinen, \& Kolehmainen, 2003).

The studies described previously prove that conjoint analysis is more than a marketing tool used to develop products and segment markets. It is evident that this tool can be used to obtain important information that can used in designing and managing places such as residential areas, tourist destinations and urban parks, to name a few. This study is geared towards contributing to this body of literature where the preferences of different groups of people are observed and related to the management of urban forests in a city as important as Washington DC. 


\subsection{Methods}

\subsubsection{Survey site and data collection}

The capital of the United States, Washington DC, was the study site and it was chosen because of its extensive urban forests that are scattered throughout its area. This fact is corroborated by Nowak, Hoehn, Crane, Stevens, \& Walton, (2006) citing the moniker, "a city within a park". These two elements make Washington DC an appropriate venue to explore public preferences on its expansive greenery for the benefit of its management. The survey to collect data was specifically done at the following sites: United States Botanic Garden, United States National Arboretum, and the National Mall (area in front of the Lincoln Memorial, tidal basin, and the area in front of the Smithsonian Institute museums).

Self-administered questionnaires were distributed to the respondents during the survey, which was done twice a month from October 2009 to September 2010. Survey activities were limited during weekends, i.e. Friday to Sunday from 10 am to 5 pm. These particular days and times were chosen because this is the peak time when people arrive and spend time in the city. Both residents and visitors were approached to participate in the study and purposive sampling was employed to identify prospective respondents. Prior to letting respondents answer the questionnaire, they were briefed on the objectives of the study and given a short background on the definition of urban forests. The surveyors were also tasked to guide the respondents in the proper way of answering the questionnaire.

\subsubsection{Questionnaire design}

This study uses the conjoint approach in eliciting the preferences of respondents to attributes of urban forests that are outlined in Table 3.1. The attributes have corresponding levels 
that detail specific conditions under each attribute. These attributes were identified and chosen based on the recommendation of professionals from the Urban Forest Administration of the city. Table 3.1

Urban forest attributes and levels used in the analysis

\begin{tabular}{ll}
\hline \multicolumn{1}{c}{ Attribute } & Levels \\
\hline Plant variety & Trees only \\
& Trees and grass \\
& Trees, grass and shrubs \\
Planting pattern & Concentrated \\
& In patches \\
& Scattered \\
Color variety & Mainly green with few other colors \\
Growth form & Mainly green with many other colors \\
& Natural \\
& Trimmed \\
\hline
\end{tabular}

From a total of $36(3 \times 3 \times 2 \times 2)$ possible mix of attributes and levels the Statistical Package for the Social Sciences (SPSS) software was used to generate plan cards orthogonally and a total of nine cards were used. The first part of the questionnaire lists all plan cards and each respondent was asked to score each plan card using a scale of 1 to 10 where 1 means least preferred and 10 means most preferred. The second part of the questionnaire asked the respondent's background information and trip characteristics for the purpose of sub-grouping and comparison.

\subsubsection{Data analysis}


The sample was characterized using the background information and visit characteristics obtained and the scores given by the respondents on each plan card of the conjoint experiment was analyzed using regression analysis. Equation 3.1 gives the regression model used for this purpose.

$Y=b_{1}($ Plant variety $)+b_{2}($ Planting pattern $)+b_{3}($ Color variety $)+b_{4}($ Growth form $)+e$

Where $Y$ denotes the respondent's preferences for a given combination of urban forest attributes, $b_{1}$ through $b_{4}$ are the utility values for the levels in each attribute, and $e$ is an error term. For each attribute, the relative importance value was calculated by dividing the part-worth of a specific attribute by the total part-worth value of all attributes. The part-worth values are the unstandardized regression coefficients from the regression model (Won et al., 2009). The sample was then divided into sub-groups based on their social and trip background and comparison among sub-groups were conducted using $t$ tests and ANOVA observing the assumptions of normality and equal variances.

\subsection{Results}

\subsubsection{The sample}

There were a total of 3,210 people asked to participate in the year-long survey and data collection produced 1,146 completed questionnaires posting a response rate of $35.7 \%$. The main reason why people were deciding not to participate is their absence of time to spend answering the questionnaire. For foreign visitors, many cited their low English reading proficiency as their hindrance from participating to the study. Data processing and organization was conducted to 
eliminate incomplete questionnaires which dropped the total responses used for the analysis to 1,065 , adjusting the response rate to $33.2 \%$.

Table 3.2 characterizes the respondents for the study based on certain demographics and trip characteristics. It shows that there are slightly more female respondents than their male counterparts, 49.0 and $51.0 \%$ respectively). The largest portion $(36.7 \%)$ of respondents is aged 26 to 39 years old and more than half $(55.8 \%)$ are under the age of 40 years. About $36 \%$ of the respondents were in the city during the fall season; and about two-thirds (66.4\%) were visitors while the rest are residents. Lastly, the respondents were considerably well-educated with $94.4 \%$ of them having at least a college degree.

Table 3.2

Demographics of the sample

\begin{tabular}{|c|c|c|}
\hline \multirow[t]{2}{*}{ Variable } & \multicolumn{2}{|c|}{ Proportion of the sample } \\
\hline & Frequency $(n)$ & Percentage $(\%)^{*}$ \\
\hline \multicolumn{3}{|l|}{ Age } \\
\hline 18 to 25 & 184 & 19.1 \\
\hline 26 to 39 & 354 & 36.7 \\
\hline 40 to 49 & 171 & 17.7 \\
\hline 50 to 59 & 157 & 16.3 \\
\hline 60 and above & 98 & 10.2 \\
\hline \multicolumn{3}{|l|}{ Educational attainment } \\
\hline High School & 54 & 5.6 \\
\hline College & 418 & 43.0 \\
\hline Graduate & 499 & 51.4 \\
\hline Gender & & \\
\hline
\end{tabular}




\begin{tabular}{|c|c|c|}
\hline Male & 476 & 49.0 \\
\hline Female & 496 & 51.0 \\
\hline \multicolumn{3}{|l|}{ Timing of visit } \\
\hline Fall & 359 & 36.0 \\
\hline Winter & 186 & 18.7 \\
\hline Spring & 203 & 20.4 \\
\hline Summer & 248 & 24.9 \\
\hline \multicolumn{3}{|l|}{ Type of respondent } \\
\hline Residents & 335 & 33.6 \\
\hline Visitors & 661 & 66.4 \\
\hline -First time visitors & 121 & 18.9 \\
\hline -Repeat visitors & 519 & 81.1 \\
\hline -Day users & 201 & 31.4 \\
\hline -Overnight visitors & 439 & 68.6 \\
\hline -Visiting on business & 104 & 15.1 \\
\hline -Visiting for leisure & 452 & 65.4 \\
\hline -Visiting family and relatives & 135 & 19.5 \\
\hline$(V F R)$ & & \\
\hline
\end{tabular}

* The valid percent values were used to exclude cases where there are missing data.

Visitors totaled 661 respondents and of this, a majority $(81.1 \%)$ were repeat visitors with only $18.9 \%$ of the visitors subgroup were in Washington DC for the first time. Furthermore, $68.6 \%$ were staying overnight and $65.4 \%$ were in the city for leisure (Table 3.2 ).

\subsubsection{Overall conjoint analysis results}

For the overall sample, Table 3.3 summarizes the relative importance values of the attributes as well as the part-worth utility values of each level under the attributes. It can be 
observed from the table that all attributes earned a relative importance value greater than $15 \%$ which means that all attributes are important considerations in understanding the preference of the respondents (Chiam et al., 2009). Plant variety and planting pattern are the most important with values over 30\% each, followed by color variety and growth form with 20.2 and 19.6\%, respectively.

Table 3.3

Overall relative importance and utility values of the sample

\begin{tabular}{|c|c|c|}
\hline Attribute & Levels & Relative Importance/Utilities \\
\hline \multirow[t]{4}{*}{ Plant variety } & & 30.214 \\
\hline & Trees only & -0.062 \\
\hline & Trees and grass & 0.310 \\
\hline & Trees, grass and shrubs & -0.248 \\
\hline \multirow[t]{4}{*}{ Planting pattern } & & 30.026 \\
\hline & Concentrated & -0.440 \\
\hline & In patches & 0.153 \\
\hline & Scattered & 0.287 \\
\hline \multirow[t]{3}{*}{ Color variety } & & 20.177 \\
\hline & With few other colors & -0.320 \\
\hline & With many other colors & 0.320 \\
\hline \multirow[t]{3}{*}{ Growth form } & & 19.583 \\
\hline & Natural & -0.359 \\
\hline & Trimmed & 0.359 \\
\hline
\end{tabular}

Part-worth utility values indicate the specific level of each attribute the respondents prefer and the highest positive values indicate the preferred level. Therefore, in Table 3.3, it can 
be noted that for the plant variety attribute, respondents prefer having urban forests with trees and grass that are scattered throughout the area. The respondents also preferred urban forests that are mainly green with many other colors and urban forests that are trimmed or groomed.

\subsubsection{Results by sub-group}

Respondents were divided into sub-groups based on their demographics and visitors' trip characteristics and this section presents the preferences for each sub-group. Two sub-groups were compared using $t$ test while more than two subgroups were compared using ANOVA.

Table 3.4

Relative importance and utility values for visitors, residents, male and female sub-groups

\begin{tabular}{lcc|cc}
\hline \multicolumn{1}{c}{ Attribute/Levels } & Visitors & Residents & Male & Female \\
& $(n=661)$ & $(n=335)$ & $(n=476)$ & $(n=496)$ \\
\hline Plant variety & 30.627 & 30.871 & 30.966 & 30.389 \\
Trees only & -0.390 & -0.108 & -0.033 & -0.083 \\
Trees \& grass & 0.262 & 0.403 & 0.227 & 0.385 \\
Trees, grass \& shrubs & -0.223 & -0.295 & -0.194 & -0.302 \\
Planting pattern & 30.487 & 30.411 & 30.612 & 30.175 \\
Concentrated & -0.441 & -0.437 & -0.418 & -0.460 \\
In patches & 0.181 & 0.099 & 0.177 & 0.139 \\
Scattered & 0.260 & 0.338 & 0.241 & 0.321 \\
Color variety & 23.865 & 22.991 & 23.969 & 23.540 \\
w/ few other colors & -0.318 & -0.322 & -0.319 & -0.323 \\
w/ many other colors & 0.318 & 0.322 & 0.319 & 0.323 \\
Growth form & 15.021 & 15.727 & $14.452 *$ & -0.391 \\
Natural & -0.362 & -.0354 & -0.321 & \\
\hline
\end{tabular}




\begin{tabular}{lll|ll} 
Trimmed & 0.362 & .0354 & 0.321 & 0.391
\end{tabular}

*Significant at $p<0.05$ level

Table 3.4 lists the relative importance and part-worth utility values of visitors, residents, male, and female respondents. From the results, we can see that both residents and visitors regard plant variety as the most important attribute. Similarly, both sub-groups also regarded growth form as the least important attribute. On the other hand, both male and female respondents agree that plant variety is the most important attribute while growth form is the least important. However, female respondents put a significantly higher relative importance value for growth form compared to male respondents.

Specifically, all sub-groups agree that they prefer urban forests that are dominated by trees and grass, that are scattered or in patches throughout the city. These urban forests are preferred to be mainly green with many other colors and are trimmed.

Table 3.5 shows the results of the conjoint analysis by age group and it can be noted that there are differences in the way they view the various urban forest attributes. Only the 18 to 25 year old group indicated that planting pattern is the most important attribute while the 40 to 49 year old group found planting pattern and plant variety as almost equally important. All groups showed that growth form is the least important attribute with the 18 to 25 and 40 to 49 year old age groups assigning a relative importance value of less than $15 \%$. Lastly, across all age groups, they prefer urban forests that are mainly trees and grass scattered or planted in patches throughout the city, green and colorful and trimmed.

It was mentioned previously that the respondents were well educated but still offers differences in perspectives. As can be seen in Table 3.6, for respondents who attained a college degree at most, plant variety is the most important urban forest attributes while the other two sub-groups had planting pattern as the most important attribute. Respondents who at most 
finished high school, deem plant variety and color variety as almost equally important.

Furthermore, the sub-group who finished high school at most had a significantly lower mean relative importance value while the opposite is true for those respondents who at most finished college. In terms of utility values, these groups follow the overall preference of urban forests described previously.

Table 3.5

Relative importance and utility values for age sub-groups

\begin{tabular}{|c|c|c|c|c|c|}
\hline Attribute/Levels & $\begin{array}{l}18 \text { to } 25 \\
(n=184)\end{array}$ & $\begin{array}{l}26 \text { to } 39 \\
(n=354)\end{array}$ & $\begin{array}{l}40 \text { to } 49 \\
(n=171)\end{array}$ & $\begin{array}{l}50 \text { to } 59 \\
(n=157)\end{array}$ & $\begin{array}{c}60 \text { \& above } \\
(n=98)\end{array}$ \\
\hline Plant variety & 28.105 & 30.217 & 31.310 & 32.465 & 32.869 \\
\hline Trees only & 0.013 & -0.074 & -0.003 & -0.134 & -0.060 \\
\hline Trees \& grass & 0.223 & 0.366 & 0.257 & 0.336 & 0.270 \\
\hline Trees, grass, shrubs & -0.236 & -0.292 & -0.257 & -0.202 & -0.210 \\
\hline Planting pattern & 31.902 & 29.574 & 31.341 & 30.794 & 28.197 \\
\hline Concentrated & -0.326 & -0.414 & -0.434 & -0.625 & -0.444 \\
\hline In patches & 0.126 & 0.102 & 0.176 & 0.299 & 0.158 \\
\hline Scattered & 0.200 & 0.312 & 0.259 & 0.326 & 0.286 \\
\hline Color variety & $25.129 *$ & $25.067 *$ & 22.894 & $20.750 *$ & 23.136 \\
\hline w/ few other colors & -0.373 & -0.303 & -0.351 & -0.277 & -0.311 \\
\hline w/ many other colors & 0.373 & 0.303 & 0.351 & 0.277 & 0.311 \\
\hline Growth form & 14.864 & 15.142 & 14.455 & 15.992 & 15.798 \\
\hline Natural & -0.273 & -0.352 & -0.315 & -0.448 & -0.470 \\
\hline Trimmed & 0.273 & 0.352 & 0.315 & 0.448 & 0.470 \\
\hline
\end{tabular}

*Significant at $p<0.05$ level 
Table 3.6

Relative importance and utility values for educational attainment sub-groups

\begin{tabular}{|c|c|c|c|}
\hline Attribute/Levels & $\begin{array}{l}\text { High School } \\
\quad(n=54)\end{array}$ & $\begin{array}{l}\text { College } \\
(n=418)\end{array}$ & $\begin{array}{l}\text { Graduate } \\
(n=499)\end{array}$ \\
\hline Plant variety & $25.648^{*}$ & $32.000^{*}$ & 29.975 \\
\hline Trees only & -0.035 & -0.073 & -0.045 \\
\hline Trees \& grass & 0.275 & 0.315 & 0.301 \\
\hline Trees, grass \& shrubs & -0.240 & -0.242 & -0.256 \\
\hline Planting pattern & 32.459 & 30.372 & 30.262 \\
\hline Concentrated & -0.146 & -0.472 & -0.452 \\
\hline In patches & -0.023 & 0.236 & 0.113 \\
\hline Scattered & 0.170 & 0.237 & 0.339 \\
\hline Color variety & 25.616 & 23.371 & 23.951 \\
\hline$w /$ few other colors & -0.386 & -0.322 & -0.315 \\
\hline$w /$ many other colors & 0.386 & 0.322 & 0.315 \\
\hline Growth form & 16.277 & 14.257 & 15.812 \\
\hline Natural & -0.268 & -0.400 & -0.338 \\
\hline Trimmed & 0.268 & 0.400 & 0.338 \\
\hline
\end{tabular}

*Significant at $p<0.05$ level

In order to explore differences among visitors, they were also divided into smaller groups based on their trip characteristics and the preferences of each group were observed. The first grouping was based on the timing of their trip to Washington DC and the seasons were the categories of time used in the study since the appearance of urban forests change through these periods. 
Table 3.7

Relative importance and utility values for timing of visit sub-groups.

\begin{tabular}{|c|c|c|c|c|}
\hline Attribute/Levels & $\begin{array}{c}\text { Fall } \\
(n=359)\end{array}$ & $\begin{array}{l}\text { Winter } \\
(n=186)\end{array}$ & $\begin{array}{l}\text { Spring } \\
(n=203)\end{array}$ & $\begin{array}{l}\text { Summer } \\
(n=248)\end{array}$ \\
\hline Plant variety & 29.575 & $37.789 *$ & 28.804 & 28.599 \\
\hline Trees only & -0.114 & -0.193 & -0.075 & 0.126 \\
\hline Trees \& grass & 0.395 & 0.439 & 0.306 & 0.088 \\
\hline Trees, grass \& shrubs & -0.281 & -0.243 & -0.232 & -0.214 \\
\hline Planting pattern & 31.425 & 28.735 & 32.260 & 28.891 \\
\hline Concentrated & -0.471 & -0.423 & -0.403 & -0.436 \\
\hline In patches & 0.098 & 0.192 & 0.097 & 0.250 \\
\hline Scattered & 0.373 & 0.230 & 0.306 & 0.186 \\
\hline Color variety & 22.672 & $16.442 *$ & 23.090 & $30.612 *$ \\
\hline$w /$ few other colors & -0.283 & -0.284 & -0.286 & -0.430 \\
\hline$w /$ many other colors & 0.283 & 0.284 & 0.286 & 0.430 \\
\hline Growth form & 16.328 & 17.034 & 15.846 & $11.898 *$ \\
\hline Natural & -0.337 & -0.582 & -0.302 & -0.286 \\
\hline Trimmed & 0.337 & 0.582 & 0.302 & 0.286 \\
\hline
\end{tabular}

*Significant at $p<0.05$ level

Table 3.7 shows the relative importance and part-worth utility values of the visitors by season. For visitors in the fall and spring, planting pattern is the most important attribute while the rest had plant variety as the most important. Respondents in winter assigned a significantly higher relative importance value to plant variety and a significantly lower value for color variety because they deem it to be the least important. Respondents during summer assigned a 
significantly higher relative importance value for the color variety attribute which they regard as the most important correspondingly. Moreover, this group regard plant variety and planting pattern as almost equal in importance. Fall, spring and summer visitors had growth form as the least important of the four attributes and summer respondents indicated a mean relative importance value for growth form of less than $15 \%$, which means that it is not an important attribute for them in terms of their preferences. Lastly, all groups agreed that they prefer urban forests that are composed of trees and grass, scattered or planted in patches throughout the city, green with many other colors, and trimmed.

Another factor believed to have an impact on visitors' preferences is the frequency of their visit and the length of their stay at a destination. In this study, the visitors were also grouped based on whether they are first timers in the city or repeat visitors; or whether they are day users or stays overnight.

Table 3.8 summarizes the relative importance and utility values for these groups of respondents. First time visitors held planting pattern as the most important attribute while repeat visitors and overnighters view plant variety as the most important attribute. All four groups agreed that growth form is the least important attribute with only the day users assigning a relative importance value of greater than $15 \%$. In terms of the part-worth utility values, the groups share the same preferences for urban forests that are composed mainly of trees and grass, planted either in patches or scattered through the city, mainly green with many other colors and are trimmed.

The last basis for grouping visitors is the purpose of visit and from this, visitors were grouped as those visiting for business purposes including studying and education or training; those that are visiting for leisure or vacation; and those who are visiting family or relatives. 
Table 3.8

Relative importance and utility values by visitors' frequency of visit and length of stay.

\begin{tabular}{lcc|cc}
\hline \multicolumn{1}{c}{ Attribute/Levels } & First timers & Repeaters & Day users & Overnighters \\
& $(n=121)$ & $(n=519)$ & $(n=201)$ & $(n=439)$ \\
\hline Plant variety & 29.580 & 30.830 & 29.364 & 31.224 \\
Trees only & -0.070 & -0.031 & -0.005 & -0.036 \\
Trees \& grass & 0.146 & 0.290 & 0.225 & 0.276 \\
Trees, grass \& shrubs & -0.076 & -0.259 & -0.220 & -0.240 \\
Planting pattern & 32.162 & 30.089 & 29.901 & 30.707 \\
Concentrated & -0.387 & -0.459 & -0.382 & -0.478 \\
In patches & 0.179 & 0.186 & 0.163 & 0.196 \\
Scattered & 0.209 & 0.273 & 0.218 & 0.282 \\
Color variety & 23.954 & 24.108 & 25.068 & 23.623 \\
w/ few other colors & -0.296 & -0.331 & -0.353 & -0.314 \\
w/ many other colors & 0.296 & 0.331 & 0.353 & 0.314 \\
Growth form & 14.304 & 14.973 & 15.667 & -0.400 \\
Natural & -0.265 & -0.386 & -0.295 & 0.295 \\
Trimmed & 0.265 & 0.386 & & 14.446 \\
\hline
\end{tabular}

Table 3.9 enumerates the relative importance and part-worth utility values for these groups of respondents. Those visiting family or relatives and those visiting for leisure regard plant variety as the most important attribute while those visiting for business deem planting pattern as the most important. All groups regard growth form as the least important but only those visiting for business gave it a mean relative importance value of greater than $15 \%$. In terms of the specific levels under each attribute, these groups of respondents prefer the same set of 
attribute levels as the previous visitor subgroups. There were no observed significant differences on the relative importance and part worth utility values for these subgroups.

Table 3.9

Relative importance and utility values by visitors' reason for visit.

\begin{tabular}{lccc}
\hline \multicolumn{1}{c}{ Attribute/Levels } & Business & Leisure & VFR \\
& $(n=91)$ & $(n=411)$ & $(n=117)$ \\
\hline Plant variety & 28.144 & 31.085 & 31.903 \\
Trees only & 0.007 & -0.034 & 0.014 \\
Trees \& grass & 0.226 & 0.227 & 0.331 \\
Trees, grass \& shrubs & -0.232 & -0.193 & -0.345 \\
Planting pattern & 33.150 & 29.799 & 28.821 \\
Concentrated & -0.461 & -0.451 & -.0429 \\
In patches & 0.121 & 0.232 & 0.172 \\
Scattered & 0.340 & 0.219 & 0.257 \\
Color variety & 23.079 & 24.412 & 24.290 \\
w/ few other colors & -0.303 & -0.339 & -0.345 \\
w/ many other colors & 0.303 & 0.339 & 0.422 \\
Growth form & 15.627 & -0.354 & 14.986 \\
Natural & -0.306 & 0.354 & \\
\hline Trimmed & 0.306 & & \\
\hline
\end{tabular}

The results of the study showed that sub-groups based on demographics and trip characteristics offer some differences in their preferences, particularly on the urban forest attribute that they regard as most important. Some groups regard plant variety as the most important while others have planting pattern as most important and there are others who think 
that both are equally most important. Subsequently, all groups were unanimous that growth form was the least important attribute with some groups regarding it as not an important attribute with regards to their preferences. In terms of the specific levels under each attribute, all groups prefer urban forests with the same characteristics. The management implications of these results are discussed further in the succeeding section.

\subsection{Discussion and conclusion}

The four attributes explored in this study are the main attributes that urban forest managers have the capability to manipulate when maintaining such areas. The respondents indicating that plant variety and planting pattern are the most important attributes, give managers an feedback on which urban forest attributes to focus more on, specifically on the establishment or redevelopment of areas devoted for urban forests. Secondary to these two attributes are considerations on color variety and growth form. These findings also suggest that people who enjoy Washington DC take notice of urban forests and have specific points-of-view on its appearance and establishment throughout the city.

The general preference of the respondents indicate that people choose urban forests to be more dominated by trees and grass meaning they are partisan to a more open type of urban forest where there are trees that shade the areas but at the same time have grass that can serve as a natural ground cover where people can enjoy spending time. People want these urban forests to be scattered or planted in patches which adds to the openness that people prefer since they will be accessible to people from all directions and will be located all over the city area. This is challenging on a management point of view especially with most urban forest areas in Washington DC being currently well established. With this in mind, the managers can increase 
the accessibility of the parks and gardens to make it more open and more inviting to most people. Furthermore, managers can also consider identifying areas with a dominantly built up landscape and set aside pockets of land where vegetation can be established.

In terms of increasing color variety, this can also be challenging considering the preference of people are biased towards trees and grass only. There are many other creative ways to add color to urban forests. For one, managers can add flowering plants that do not gain much height as shrubs to keep the openness of the area. Another, is to construct footpaths or small trails, when applicable, and use trail materials that will add color to the area. When there are some small structures like benches, signs, or fences, these can be painted with colors that blend with the natural setting but will add to the color palette. Moreover, during special holidays or events, colorful decorations can be incorporated to the area and this can be done seasonally and annually which can eventually become an attraction to people. Lastly, people's preference to growth form means that constant maintenance need to be done on urban forests regularly especially those places with high human traffic.

\subsection{Limitations and suggestions for future studies}

This study is a novel attempt at understanding the preferences of people on specific characteristics of urban forests and the findings have provided a glimpse at what different groups of people respond to positively when it comes to the characteristics of urban forests they enjoy and experience. Other characteristics that are not included in this study can be explored in future studies to obtain a more accurate picture of the preferred type and appearance of urban forests for a city that is as diverse and as popular as Washington DC. Studies similar to this can be 
conducted at the park level, which is site specific so managers of individual parks or gardens can get a more precise picture of people's preferences.

From a research method standpoint, the methods used for this study can be altered to include more varied survey sites and expand the versions of the survey instrument to include respondents who do not have English as their main language. Differences in language indicates difference in culture so the perspective of such segments of the population also need to be represented and perhaps new insights can be gleaned from them. 


\subsection{References}

Chen, C. (2001). Design for the environmental: a quality-based model for green product development. Management Science, 47, 250-263.

Chiam, M., Soutar, G. \& Yeo, A. (2009). Online and off-line travel packages preferences: A conjoint analysis. International Journal of Tourism Research, 11, 31-40.

Elmendorf, W. F. Willits, F. K., \& Sisidharan, V. (2005). Urban park and forest participation and landscape preference: A review of the relevant literature. Journal of Arboriculture, 31, 311317.

Farber, S., \& Griver, B. (2000). Using conjoint analysis to value ecosystem change. Environmental Science and Technology, 34, 1407-1412.

Green, P. E., \& Srinivasan, V. (1990). Conjoint analysis in marketing: new developments with implications for research and practice. Journal of Marketing, 54, 3-19.

Gustafsson, A. Ekdahl, F., \& Bergman, B. (1999). Conjoint analysis: a useful tool in the design process. Total Quality Management, 10, 327-343.

Katoshevski, R., \& Timmermans, H. (2001). Using conjoint analysis to formulate user-centered guidelines for urban design: the example of new residential development in Israel. Journal of Urban Design, 6, 37-53.

Konijnendijk, C. C. (2008). The forest and the city: The cultural landscape of urban woodland. NY: Springer.

Louviere, J. J. (1988). Analyzing decision making: Metric conjoint analysis. CA: Sage Publications.

Nowak, D. J., Hoehn III, R. E., Crane, D. E., Stevens, J. C., \& Walton, J. T. (2006). Assessing urban forest effects and values, Washington, DC's urban forest. Resource Bulletin NRS-1. 
Newtown Square, PA: U.S. Department of Agriculture, Forest Service, Northern Research Station. 24 p.O' Brien, E. (2006). Social housing and greenspace: a case study in inner London. Forestry, 79, 535-549.

Turpie, J., \& Joubert, A. (2004). The value of flower tourism on the Bokkeveld plateau - a botanical hotspot. Development South Africa, 21, 645-662.

Tyrväinen, L., Silvennoinen, H., \& Kolehmainen, O. (2003). Ecological and aesthetic values in urban forest management. Urban Forestry \& Urban Greening, 1, 135-149.

van Limburg, B. (1998). City marketing: a multi-attribute approach. Tourism Management, 19, 475-477.

Wolf, K. L. (2005). Trees in the small city retail business district: comparing resident and visitor preferences. Journal of Forestry, 103, 390-395.

Won, D., Hwang, S., \& Kleiber, D. (2009). How do golfers choose a course? A conjoint analysis of influencing factors. Journal of Park and Recreation Administration, 27, 1-16. 


\title{
CHAPTER 4
}

\section{People's attitudes towards urban forests in Washington DC as related to satisfaction and loyalty}

\author{
Abstract \\ The study uses a combination of analysis tools in exploring the attitudes of various groups of \\ people on the urban forest of Washington DC for the main purpose of producing insights that can \\ be useful for the management and development of these resources. A year-long survey yielded \\ respondents who reported that they offer differing attitudes towards urban forests and their \\ familiarity with these places influence the way they appreciate and perceive them. Furthermore, \\ it is also observed that the respondents are relatively aware of the uses and functions of urban \\ forests in the city and that it contributes positively and significantly to their satisfaction and \\ loyalty. The study was also successful at using a combination of analysis tools in describing the \\ dimensions of people's attitudes towards the urban forests of Washington DC. Lastly, the \\ management implications of the study results were also discussed.
}

Keywords: urban tourism, factor analysis, structural equation modelling 


\subsection{Introduction}

In recent decades, urban forests have rapidly cemented their status as an essential part of the built landscape and this is primarily due to the myriad of studies conducted looking into their significant impact on the aesthetics of cities, as well as their contribution to the socio-economic conditions of the area (Konijnendijk, 2008). There are studies that look at urban forests and their role in contributing to the local economy (More, Stevens, \& Allen, 1988; Price, 2003; Wolf, 2005) and there are also studies that look more closely at the social values of urban forests (Nowak et al., 2006; Tyrväinen et al., 2006; Wolf, 2003).

This study, focuses on investigating the differences in the attitude of groups of people towards the urban forests of Washington DC and its influence on visit satisfaction and place loyalty. Specifically, the study aims to explore the general attitude of residents and visitors on the urban forests of Washington DC, based on the cognitive, affective and behavioral dimensions. Also, the study aims to describe similarities and differences in the attitudes of groups of people; examine the relationship among dimensions of attitude towards urban forests, and explain the implications of these in the context of management.

\subsection{Literature review}

\subsubsection{Urban forests and people}

Research on the role of nature as part of experiencing the urban environment is not wanting. Studies conducted by Bostedt and Mattson (1995); Hansen-Møller and Oustrup (2004); Kuvan (2005); and Bryant (2006) are just some of the growing number of investigative efforts to know and understand how natural landscapes, particularly vegetation, add to the benefits of leisure activities. Some of these studies looked into greenspaces with a horticultural focus while 
others explored various forms of urban forests and their contribution to human health, urban outdoor recreation, and visual aesthetics. With the concept of sustainable development prevailing in these past years, the study on nature-human interaction in the urban ecosystem is expected to continue. Scientists, urban planners, landscape managers and health care specialists have proven that forests and other forms of vegetation in urban areas influence the well-being of people. Visitors and residents alike enjoy the amenities that these natural features offer. Paquot (2005) noted that nature in cities is not a new concept but an ideology that has manifested throughout history. He cited historical accounts where botanists of the early $20^{\text {th }}$ century were clamoring for the establishment of gardens and parks to serve as venues for nature education, a place where children can know, learn and respect nature and its principles and processes. The re-emergence of this long-time ideology is brought about by problems on pollution and urbanization.

Studies on how people support, perceive and benefit from urban forests are also common due perhaps to the tangible and practical conclusions that these studies provide. $\mathrm{Yu}, \mathrm{Li}$, and $\mathrm{Li}$ (2006) studied the historical development and management of greenways in China's rapidly urbanizing cities and found that the management of greenways in China is rooted to the people's culture. They added that because the people have benefited from the maintenance of these greenways, they have protected and adapted their practices to suit the changing needs of these areas. This particular study highlights the connection between the public, who are the users and beneficiaries of urban forest services, and the management.

On the other hand, in an economic point of view, Wolf (2005) looked into how having trees in streets contribute to the retail business district of a city in the United States, and from the results, she observed that people are more likely to stay near or enter business establishments proximal to tree-lined areas where both visitors and residents agree that street trees lining retail 
establishments add to the general appeal of the place and influences their willingness to spend time and money to the stores nearby. Furthermore, from a management point of view, studying people's perceptions and attitudes about urban forests elicit useful information that can serve as basis for urban forest programs particularly those that are geared towards landscape aesthetics and human well-being. Zhang, Hussain, Deng, and Letson (2007) explored the attitude and support of local people towards programs focusing on the management and development of urban forests. Their study characterized the segment of the population who tends to harbor a positive attitude towards urban forests through its demographics.

Moreover, other studies like Solecki and Weich's (1995) investigated the role of urban parks in socialization of local residents. On the other hand, some of these studies also cited some negative impacts that urban forests bring to the city. Among those mentioned include the dispersal of pollen, which causes allergies to many people, clogged storm water drainage due to tree debris and the constant danger of branches and tree trunks toppling and causing damage to vehicles, houses and buildings.

Another key study by Smardon (1998), revealed that people have a generally positive perception and attitude about urban forests mainly because of their therapeutic, recreational and economic services. Specifically, the study highlighted that people prefer well-groomed urban forests with a pleasant aesthetic. However, it was also noted from the study that the positive perception towards urban forests is limited to a certain extent as long as these resources do not interfere with the daily social processes that people participate in urban areas.

These demonstrate that studies on urban forests and vegetation are not conducted mainly to learn more about the plants thriving in this setting. The prevailing focus of studies in urban forestry is relating the urban vegetation and other natural features to the general welfare of 
people. The structure, composition, arrangement and extent of urban forests are explored based on their impacts to people and this is due to the direct contact between people and these natural features. Researchers in this area of study always find interesting issues about human-nature interaction in urban areas that are worth addressing. Generally, their findings enlighten not only their peers but also the general public on the complexity and inherent beauty of this relationship. More importantly, such studies contribute significantly in the formulation of objectives and strategies in the management of urban forests that is in tune with the needs of the people.

\subsubsection{Relationship of attitude, satisfaction and loyalty}

Over the past few decades, studies have probed the attitude of two groups of people who experience large cities. These groups, residents and visitors are investigated differently where a majority of studies involving the former is about eliciting their insights on development of tourism resources that are either existing (Andriotis \& Vaughan, 2003; Jurowski \& Gursoy, 2004; Sheldon \& Var, 1984;) or still yet to be developed (Allen, Hafer, Long, \& Perdue, 1993; Andereck \& Vogt, 2000; Mason \& Cheyne, 2000). The latter, on the other hand, is studied to determine their attitude towards changes in terms of resource development and management in places they visit (Kiely-Brocato, 1980; Weaver \& Lawton, 2004). However, visitor attitudes were mostly studied to understand behavior and motivations (Eagles, 1992; Swanagan, 2000). A common element that affects attitude of people towards a resource is the level of their knowledge about urban forests, particularly its uses and importance.

The collection of studies on exploring the awareness, the level of knowledge and understanding of people on urban forests has proven fruitful in the body of literature on this subject. Studies have shown that people fully recognize that urban forests contribute significantly to the environmental and social aspects of city life (Chen, 2006; Nowak, Hoehn, Crane, Stevens, 
\& Walton, 2006; Tyrväinen, 2006; Wolf, 2003). Therefore, as shown by the findings of these studies, knowledge is a primary element that dictates the way people think about or perceive urban forests. Oftentimes, a positive perspective on urban forests is seen on its aesthetic, leisure and recreational uses (Elmendorf, 2005; Hansen-Møller \& Oustrup, 2004; Price, 2003; Smardon, 1988; Solecki \& Weich, 1995). Therefore, to test whether knowledge of people on the uses of urban forests influence their beliefs on the leisure importance of the resource, the following hypotheses are presented:

$\mathrm{H}_{1}$ - Knowledge on the uses of parks and gardens positively relate to the leisure value of urban forests.

$\mathrm{H}_{2}$ - Knowledge on the uses of street trees positively relate to the leisure value of urban forests.

However, the influence of people's extent of knowledge on urban forests as it relates to their satisfaction and loyalty of the city has not been thoroughly explored. It can be assumed, deducting from the findings of previous studies, that a person with a sufficient level of knowledge and understanding on the uses of urban forests will positively correlate to their satisfaction and loyalty to the city that houses the resource. Thus, the following hypotheses are given:

$\mathrm{H}_{3}-$ Knowledge on the uses of parks and gardens has a direct positive influence on the satisfaction and loyalty on urban forests and the city.

$\mathrm{H}_{4}-$ Knowledge on the uses of street trees has a direct positive influence on the satisfaction and loyalty on urban forests and the city.

Most common studies that look into satisfaction and loyalty of people are concentrated on visitors particularly tourists. These studies are focused in the field of marketing since such 
studies aim to examine the factors behind people's satisfaction, which is a motivation to return to a place or to advertise it to their family, friends or peers. On a more conceptual level, a study delved into defining and describing the relationship of place-based understanding, identity and attitude based on a survey of literature. It was highlighted in this study that attitudes are composed of cognitive, affective and behavioral parts. If people collect knowledge about an object or resource and evaluate the information to form judgment, specific beliefs and eventually behavior can manifest through this process (Stedman, 2002). Thus, the last hypothesis to be explored in this study is given by:

$\mathrm{H}_{5}$ - Positive beliefs in the leisure value of urban forests leads to positive satisfaction and loyalty on urban forests and the city.

These hypotheses are tested in this study to contribute to the exploration of the link between urban forests and urban tourism in a venue where the former is a predominant feature and resource but is not placed at the forefront of tourism marketing. The findings of this study is aimed at providing insights on possible management directions that future urban forest programs to be created for the city as well as provide an understanding on people's attitudes towards urban forests in a city as important as Washington DC.

\subsection{Methods}

\subsubsection{Study Area}

The choice of Washington DC as the study site is based on several reasons, one of which is its unique status as the capital of the United States and a popular tourist destination. Another reason is its character and landscape, having a significant portion of its land devoted for urban forests in the form of parks, gardens and tree-lined streets. In fact, Nowak et al. (2006) cited that 
the city is popularly known as a "city within a park". Therefore, studies such as this that intermittently elicit feedback from the users of its urban forest are used to guide management and future urban forest development programs. Data collection was specifically conducted in the following sites: United States Botanic Garden (USBG), United States National Arboretum (USNA), National Mall (area in front of the Lincoln Memorial, tidal basin, and the area in front of the Smithsonian Institute museums).

\subsubsection{Data collection}

Face-to face interviews using a self-administered questionnaire were conducted to collect data. The survey was conducted at the study sites mentioned previously from October 2009 to September 2010 where the surveyors visited the sites twice a month during weekends from Friday to Sunday. On these days, data collection was done from 10 am to $5 \mathrm{pm}$, which is the prime time for visitors and residents who are roaming around the city.

Purposive sampling was used in choosing prospective respondents and each was given a brief background of the study objectives prior to answering the questionnaire. During data collection, each respondent was asked to score each statement using a 5-point Likert scale whether they strongly agree (5 points) or strongly disagree (1 point) with each statement. Furthermore, background information and trip characteristics of the respondents were also collected.

\subsubsection{Questionnaire design and data analysis}

The first portion of the questionnaire contained 23 statements related to expressing attitudes and perception towards urban forests following the framework that attitudes are composed of cognitive, affective and behavioral components as it connects to a person's leisure 
experience. As seen in Table 4.1, the statements with its corresponding codes used in the analysis covers the dimensions of people's attitude towards urban forests.

\section{Table 4.1}

Summary of perception statements used for the study

\begin{tabular}{|c|c|}
\hline Code & Statement \\
\hline atti1 & I believe that urban forests are part of the appeal of Washington DC \\
\hline atti2 & I believe that urban forests give Washington DC a more natural appearance \\
\hline atti3 & Parks, gardens and street trees make going around the city interesting \\
\hline atti4 & Urban forests give unique scents and colors \\
\hline atti5 & Parks and gardens attract birds and other animals that interest people \\
\hline atti6 & Urban forests tell us of seasonal changes \\
\hline atti7 & Parks, gardens and street trees make the city more relaxing for people \\
\hline atti8 & I feel rejuvenated after visiting parks and gardens \\
\hline atti9 & Street trees give a feeling of security because it separates pedestrians from traffic \\
\hline atti10 & Street trees and plants along sidewalks help in pedestrian mobility \\
\hline atti11 & Trees and plants in the National Mall make it look natural \\
\hline atti12 & Parks and gardens are good to look at when they are well kept \\
\hline atti13 & Parks and gardens are places in the city where I do recreational activities \\
\hline atti14 & Crowds in parks and gardens add to my enjoyment of these areas \\
\hline atti15 & Parks and gardens of Washington DC are among the things that I enjoy visiting in the city \\
\hline atti16 & Visiting parks and gardens increase my curiosity on trees and other plants \\
\hline atti17 & I enjoy taking pictures of places inside parks and gardens \\
\hline atti18 & I am impressed by the greenery of Washington DC \\
\hline atti19 & My leisure/recreation experience is enhanced by the urban forests of the city \\
\hline atti20 & I am satisfied with the appearance of the urban forests in the city \\
\hline atti21 & I will tell my relatives and friends to visit Washington DC's parks and gardens \\
\hline
\end{tabular}


atti23 I am satisfied with my visit here

This scale was subjected to exploratory factor analysis to determine its underlying dimensions. Comparisons on the mean scores obtained from sub-groups of the sample were compared using $t$ tests and ANOVA following the assumptions of normality and homogeneity of variance. Finally, structural equation modelling (SEM) is used to investigate the relationship among the dimensions of people's attitudes.

\subsection{Results and Discussion}

\subsubsection{Sample descriptives}

The survey yielded 1,146 completed questionnaires from a total of 3,210 people who were asked to participate to the study making the response rate equal to $35.7 \%$. Among the primary reasons for non-response were not having time to participate and not having good skills reading in English. After data organization, the number of questionnaires used for analysis was further reduced to 1,090 , which pegs the response rate at $34 \%$. The reduction was due to culling out incomplete responses and respondents giving one rating for all statements. Table 4.2 shows the demographic breakdown of the sample. Based on the results, the biggest portion of the sample is aged 26 to 39 years old (35.8\%), and more than half of the sample (53.6\%) is below 40 years. Furthermore, a vast majority of the sample $(94.2 \%)$ has at least a college degree indicating a relatively well-educated group of respondents. Moreover, a little over half (52.1\%) of the sample are females and about two-thirds (65.6\%) are visitors to Washington DC.

The sample was further grouped according to their frequency of visit and length of stay. Subsequently, the subsample of visitors was further classified into first timers, repeat visitors, 
day users and overnighters. The majority of visitors $(81.3 \%)$ are repeat visitors and $67.9 \%$ spent at least a night in the city while $32.1 \%$ are in the city just for the day. Lastly, in terms of the reason for visit, $38.1 \%$ of the respondents were in the city on business, $46.5 \%$ for leisure, and $15.4 \%$ were visiting family and relatives.

Table 4.2

Demographics and trip characteristics of the sample

\begin{tabular}{|c|c|c|}
\hline \multirow[t]{2}{*}{ Variable } & \multicolumn{2}{|c|}{ Proportion of the sample } \\
\hline & Frequency $(n)$ & Percentage $(\%)^{*}$ \\
\hline \multicolumn{3}{|l|}{ Age } \\
\hline 18 to 25 & 192 & 17.8 \\
\hline 26 to 39 & 385 & 35.8 \\
\hline 40 to 49 & 199 & 18.5 \\
\hline 50 to 59 & 180 & 16.7 \\
\hline 60 and above & 120 & 11.2 \\
\hline \multicolumn{3}{|l|}{ Educational attainment } \\
\hline High School & 63 & 5.8 \\
\hline College & 459 & 42.4 \\
\hline Graduate & 561 & 51.8 \\
\hline \multicolumn{3}{|l|}{ Gender } \\
\hline Male & 518 & 47.9 \\
\hline Female & 563 & 52.1 \\
\hline \multicolumn{3}{|l|}{ Type of respondent } \\
\hline Residents & 375 & 34.4 \\
\hline Visitors & 715 & 65.6 \\
\hline
\end{tabular}




\begin{tabular}{lcc}
\hline -First time visitors & 132 & 18.8 \\
-Repeat visitors & 572 & 81.3 \\
-Day users & 225 & 32.1 \\
-Overnight visitors & 476 & 67.9 \\
-Visiting on business & 372 & 38.1 \\
-Visiting for leisure & 455 & 46.5 \\
-Visiting family \& relatives (VFR) & 150 & 15.4 \\
\hline
\end{tabular}

* The valid percent values were used to exclude cases where there are missing data.

\subsubsection{Exploratory factor analysis (EFA)}

Using SPSS, the suitability of the data for factor analysis was first conducted and it was observed that the Kaiser-Meyer-Oklin value is 0.934 and the Bartlett's test of Sphericity is significant $(p<.000)$ rendering the dataset suitable.

Table 4.3

Summary results of factor analysis

\begin{tabular}{|c|c|c|c|c|c|c|}
\hline \multirow[b]{2}{*}{$\begin{array}{l}\text { Factor (Proportion): } \\
\text { Scale name \& items }\end{array}$} & \multirow[b]{2}{*}{$\begin{array}{c}\mathrm{M} \\
(N=1090)\end{array}$} & \multirow[b]{2}{*}{ SD } & \multicolumn{4}{|c|}{ Rotated (varimax) factors } \\
\hline & & & $\begin{array}{c}\text { Factor } \\
1\end{array}$ & $\begin{array}{c}\text { Factor } \\
2\end{array}$ & $\begin{array}{c}\text { Factor } \\
3\end{array}$ & $\begin{array}{c}\text { Factor } \\
4\end{array}$ \\
\hline \multicolumn{7}{|l|}{ Factor 1: Knowledge on parks and garden uses } \\
\hline I believe that parks and gardens are part of the appeal of & 4.31 & .767 & .586 & -.034 & .210 & .425 \\
\hline \multicolumn{7}{|l|}{ Washington $D C$} \\
\hline I believe that parks and gardens give Washington DC a & 4.37 & .712 & 608 & .144 & .094 & .393 \\
\hline \multicolumn{7}{|l|}{ more natural appearance } \\
\hline Parks and gardens make going around the city interesting & 4.52 & .650 & .681 & .081 & .150 & .297 \\
\hline Urban forests give unique scents and colors & 4.29 & .710 & .661 & .161 & .307 & .151 \\
\hline Parks and gardens attract birds and other animals that & 4.29 & .747 & .599 & .202 & .375 & -.061 \\
\hline interest people & & & & & & \\
\hline
\end{tabular}




\begin{tabular}{lllllll}
\hline Urban forests tell us of seasonal changes & 4.38 & .679 & $\mathbf{. 6 4 2}$ & .188 & .246 & .054 \\
Parks and gardens trees make the city more relaxing for & 4.62 & .581 & $\mathbf{. 6 9 6}$ & .053 & .050 & .234 \\
$\quad$ people & & & & & & \\
$\quad$ feel rejuvenated after visiting parks and gardens & 4.42 & .744 &. $\mathbf{5 3 7}$ & .136 & .374 & .160 \\
Factor 2: Knowledge on street tree uses & & & & & & \\
Street trees give a feeling of security because it separates & 3.75 & .928 & .278 & $\mathbf{. 7 1 9}$ & .183 & .081 \\
$\quad$ pedestrians from traffic & & & & & & \\
Street trees and plants along sidewalks help in pedestrian & 3.46 & .958 & .145 & $\mathbf{. 8 1 0}$ & .172 & .112 \\
$\quad$ mobility & & & & & & \\
Street trees and plants in the National Mall make it look & 4.14 & .850 & .333 & $\mathbf{. 5 5 3}$ & .055 & .324 \\
$\quad$ natural
\end{tabular}

\section{Factor 3: Leisure value of urban forests}

Urban forests are places in the city where I do

$\begin{array}{llllllll}4.15 & .854 & .312 & .165 & \mathbf{. 5 0 3} & .144\end{array}$

recreational activities

Urban forests of Washington DC are among the things

4.14

.801

$.318 \quad .625$ that I enjoy visiting in the city

Visiting parks and gardens increase my curiosity on trees

3.87

.960

.262

.135

.710 and other plants

I enjoy taking pictures of urban forests

$\begin{array}{lllllllll}4.12 & .886 & .093 & .219 & .515 & .51\end{array}$

\section{Factor 4: Satisfaction and loyalty}

I am impressed by the urban forests of Washington DC

$\begin{array}{lllll}4.17 & .807 & .177 & .095 & .229\end{array}$

.730

My leisure/recreation experience is enhanced by the

$4.29 \quad .712$

.361

.007

.425

.508 urban forests of the city

I am satisfied with the appearance of the urban forests in the city

I will tell my relatives and friends to visit Washington

DC's parks and gardens 


\begin{tabular}{|c|c|c|c|c|c|c|}
\hline I am satisfied with my visit here & 4.44 & .639 & .253 & .162 & .115 & .644 \\
\hline Eigenvalues & & & 8.40 & 1.14 & 1.47 & 1.57 \\
\hline$\%$ of variance & & & 36.52 & 6.84 & 6.42 & 4.98 \\
\hline Cumulative \% & & & & 43.36 & 49.78 & 54.76 \\
\hline Standardized Cronbach's $a$ & & & .865 & .729 & .701 & .846 \\
\hline
\end{tabular}

Note: The statements: (atti12) Urban forests are good to look at when they are well kept; and (atti14) Crowds in parks and gardens add to my enjoyment of these areas were excluded for further analysis because of the former had almost equal factor loadings (Factor $1=0.388$; Factor $2=0.381$ ) for two factors and the latter failed to satisfy the reliability test for scale.

Results of the EFA are summarized in Table 4.3 and it shows that there are four factors derived with eigenvalues over $1(8.40,1.14,1.47$, and 1.57). These factors explain the $36.52 \%$, $6.84 \%, 6.42 \%$, and $4.98 \%$ of the variance, respectively. The solution explained a total of $54.76 \%$ of the variance. Each factor is labeled as follows: factor 1 - knowledge of parks and garden uses; factor 2 - knowledge of street tree uses; factor 3 - leisure value of urban forests; and factor 4 satisfaction and loyalty. The number of scale items under each factor are 8, 3, 4, and 6, respectively. Two items were removed from the analysis because one item had almost equal loadings on two factors and the other failed to satisfy the reliability test of scale. Cronbach's alpha values for the four factors are: $.865, .729, .701$, and .846 , respectively.

\subsubsection{Mean scores comparison among sample sub-groups}

Overall, the mean scores given by the respondents for all four factors are given in Table 4.4, indicating that the respondents rated knowledge of parks and garden uses the highest followed by satisfaction and loyalty, leisure value of urban forests and finally knowledge on street tree uses. The sample was then divided into sub-groups based on demographics and trip characteristics and compared based on each group's mean scores on the factors established previously. Table 4.4 presents the results of $t$ tests comparing visitors versus residents as well as first time visitors and repeat visitors. 
Results show the influence of familiarity in the appreciation of a resource or tourism attraction as shown by the tendency of residents and repeat visitors to give higher mean scores on the factors particularly on their knowledge of urban forest use and the leisure value of forests. Other visitor sub-groups based on reason for visit and length of stay were tested and the subgroups did not reveal any significant differences in their mean scores on the factors analyzed. Table 4.4

Comparison between first time and repeat visitors; residents and visitors

\begin{tabular}{|c|c|c|c|c|c|c|c|}
\hline \multirow[b]{2}{*}{ Factor } & \multirow{2}{*}{$\begin{array}{l}\text { Overall } \\
\text { Mean } \\
\text { Score }\end{array}$} & \multicolumn{3}{|c|}{ Visitors } & \multicolumn{3}{|c|}{ Type of respondent } \\
\hline & & $\begin{array}{l}\text { First-timers } \\
\qquad(n=132)\end{array}$ & $\begin{array}{c}\text { Repeaters } \\
(n=572)\end{array}$ & $t$ value & $\begin{array}{l}\text { Visitors } \\
(n=715)\end{array}$ & $\begin{array}{l}\text { Residents } \\
(n=375)\end{array}$ & $t$ value \\
\hline $\begin{array}{l}\text { Knowledge on parks } \\
\text { and garden uses }\end{array}$ & 4.40 & 4.24 & 4.40 & $-3.12^{* *}$ & 4.36 & 4.47 & $-3.37^{* *}$ \\
\hline $\begin{array}{l}\text { Knowledge on street } \\
\text { tree uses }\end{array}$ & 3.58 & 3.59 & 3.60 & -0.17 & 3.60 & 3.55 & 1.07 \\
\hline $\begin{array}{l}\text { Leisure value of urban } \\
\text { forest }\end{array}$ & 4.07 & 3.92 & 4.06 & $-2.28^{*}$ & 4.03 & 4.14 & $-2.88^{* *}$ \\
\hline $\begin{array}{l}\text { Satisfaction and } \\
\text { Loyalty }\end{array}$ & 4.27 & 4.23 & 4.25 & 0.75 & 4.25 & 4.31 & -1.85 \\
\hline
\end{tabular}

${ }^{* *}$ Significant at $p<0.001$, two-tailed; ${ }^{*}$ Significant at $p<0.05$, two-tailed

However, sub-groups based on age showed that the younger group of respondents tend to give lower mean scores compared to their older counterparts (Table 4.5). Three of the four 
factors: knowledge on parks and garden uses, leisure value of urban forests and satisfaction and loyalty, were given significantly lower mean scores by the youngest age group, 18 to 25 years old, compared to the mean scores of the rest of the sub-groups.

Table 4.5

Summary of mean attitude scores by age sub-group

\begin{tabular}{|c|c|c|c|c|c|}
\hline \multirow[b]{2}{*}{ Factor } & \multicolumn{5}{|c|}{ Age sub-group } \\
\hline & $\begin{array}{l}18 \text { to } 25 \\
(n=192)\end{array}$ & $\begin{array}{l}26 \text { to } 39 \\
(n=385)\end{array}$ & $\begin{array}{l}40 \text { to } 49 \\
(n=199)\end{array}$ & $\begin{array}{l}50 \text { to } 59 \\
(n=180)\end{array}$ & $\begin{array}{c}60 \& \text { above } \\
(n=120)\end{array}$ \\
\hline $\begin{array}{l}\text { Knowledge on parks } \\
\text { and garden uses }\end{array}$ & $4.25^{*}$ & 4.39 & 4.43 & 4.46 & 4.53 \\
\hline $\begin{array}{l}\text { Knowledge on street } \\
\text { tree uses }\end{array}$ & 3.50 & 3.56 & 3.65 & 3.59 & 3.64 \\
\hline $\begin{array}{l}\text { Leisure value of urban } \\
\text { forest }\end{array}$ & $3.90^{*}$ & 4.09 & 4.10 & 4.12 & 4.10 \\
\hline Satisfaction and Loyalty & $4.12^{*}$ & 4.30 & 4.29 & 4.30 & 4.35 \\
\hline
\end{tabular}

Table 4.5 also shows the summary of mean scores while Table 4.6 presents the ANOVA table indicating the factors that have significant differences. It can be deduced from the results that older age groups have more experience and knowledge on urban forests particularly on its uses and leisure value are generally more appreciative of it. Their age has given them more opportunities to interact with urban forests, experience it and learn more about it. Thus, more 
knowledge and experience increases people's understanding of the role that urban forests play in the city's overall image as well as to the individual's personal well-being.

Table 4.6

One-way analysis of variance of mean attitude scores by age sub-group

\begin{tabular}{|c|c|c|c|c|c|c|}
\hline Variable & & $\begin{array}{l}\text { Sum of } \\
\text { Squares }\end{array}$ & \multicolumn{2}{|r|}{ Mean } & $\boldsymbol{F}$ & Sig. \\
\hline Knowledge on parks and & Between Groups & 6.903 & 4 & 1.726 & 6.998 & .000 \\
\hline \multirow[t]{2}{*}{ garden uses } & Within Groups & 264.123 & 1071 & .247 & & \\
\hline & Total & 271.026 & 1075 & & & \\
\hline Knowledge on street tree & Between Groups & 2.734 & 4 & .683 & 1.354 & .248 \\
\hline \multirow[t]{2}{*}{ uses } & Within Groups & 540.630 & 1071 & .505 & & \\
\hline & Total & 543.364 & 1075 & & & \\
\hline Leisure value of urban & Between Groups & 6.398 & 4 & 1.599 & 4.015 & .003 \\
\hline \multirow[t]{2}{*}{ forest } & Within Groups & 426.678 & 1071 & .398 & & \\
\hline & Total & 433.076 & 1075 & & & \\
\hline \multirow[t]{3}{*}{ Satisfaction and Loyalty } & Between Groups & 5.767 & 4 & 1.442 & 4.867 & .001 \\
\hline & Within Groups & 317.250 & 1071 & .296 & & \\
\hline & Total & 323.017 & 1075 & & & \\
\hline
\end{tabular}

Furthermore, the respondents were also subdivided into sub-groups based on survey location as well as by season to investigate whether respondents sampled at urban forest attractions (USNA, USBG) have differences in perceptions with those who are sampled at the National Mall, and to explore the influence of season on people's perception on urban forests as 
it changes over time. Table 4.7 summarizes the mean scores given by respondents grouped by survey location and Table 4.8 gives the results of the ANOVA done for the same sub-groups. Table 4.7

Summary overall mean scores of respondents grouped by survey location Survey location

\begin{tabular}{|c|c|c|c|}
\hline \multirow[t]{2}{*}{ Factor } & USNA & USBG & National Mall \\
\hline & $(n=379)$ & $(n=339)$ & $(n=372)$ \\
\hline
\end{tabular}

Knowledge on parks and garden uses

Knowledge on street tree uses

Leisure value of urban forest

Satisfaction and Loyalty $4.49^{\mathrm{a}}$

3.59

$4.22^{\mathrm{a}}$

$4.35^{\mathrm{c}}$ $4.40^{\mathrm{a}, \mathrm{b}}$

$4.30^{\mathrm{b}}$

3.59

3.57

${ }^{\mathrm{a}, \mathrm{b}}$ Significant at $p<0.001 ;{ }^{\mathrm{c}}$ Significant at $\mathrm{p}<0.05$

Looking at Table 4.7, it is observed that respondents surveyed at the USNA consistently gave higher mean scores in all four factors with statistically significant differences noted for knowledge on parks and garden uses, leisure value of forests, and satisfaction and loyalty. Relatively, those respondents sampled at the USBG also gave higher mean scores on all four factors compared to the respondents who were sampled at the National Mall. This validates that people who tend to visit and enjoy urban forest attractions in Washington DC are more aware of its importance and use.

Table 4.8 
One-way analysis of variance of mean scores by survey location sub-group

\begin{tabular}{|c|c|c|c|c|c|c|}
\hline Variable & & $\begin{array}{l}\text { Sum of } \\
\text { Squares }\end{array}$ & $d f$ & & $\boldsymbol{F}$ & Sig. \\
\hline Knowledge on parks and & Between Groups & 7.114 & 2 & 3.557 & 14.531 & 0.000 \\
\hline \multirow[t]{2}{*}{ garden uses } & Within Groups & 266.083 & 1087 & 0.245 & & \\
\hline & Total & 273.197 & 1089 & & & \\
\hline Knowledge on street tree & Between Groups & 0.135 & 2 & 0.068 & 0.133 & 0.875 \\
\hline \multirow[t]{2}{*}{ uses } & Within Groups & 551.016 & 1087 & 0.507 & & \\
\hline & Total & 551.151 & 1089 & & & \\
\hline Leisure value of urban & Between Groups & 15.523 & 2 & 7.762 & 19.894 & 0.000 \\
\hline \multirow[t]{2}{*}{ forest } & Within Groups & 424.094 & 1087 & 0.507 & & \\
\hline & Total & 439.617 & 1089 & & & \\
\hline \multirow[t]{3}{*}{ Satisfaction and Loyalty } & Between Groups & 3.744 & 2 & 1.872 & 6.280 & 0.002 \\
\hline & Within Groups & 323.991 & 1087 & 0.298 & & \\
\hline & Total & 327.735 & 1089 & & & \\
\hline
\end{tabular}

To further investigate differences in perceptions, visitor and resident respondents were grouped by season and by survey location and corresponding comparisons were also made. The succeeding tables show only the significant results observed. Table 4.9 shows the $t$ test results comparing visitors and residents who were sampled at the National Mall. Residents who were sampled at the National Mall gave higher mean scores for all four factors compared to the visitors. Significantly higher scores were noted on two factors namely: knowledge of parks and garden uses as well as leisure value of urban forests. Similar comparisons made for the USNA and USBG sites did not yield significant results. 
Table 4.9

Comparison between residents and visitors sampled at the National Mall

\begin{tabular}{|c|c|c|c|}
\hline \multirow[b]{2}{*}{ Factor } & \multicolumn{3}{|c|}{ National Mall respondents } \\
\hline & $\begin{array}{l}\text { Visitors } \\
(n=267)\end{array}$ & $\begin{array}{l}\text { Residents } \\
(n=105)\end{array}$ & $t$ value \\
\hline Knowledge on parks and garden uses & 4.26 & $4.39^{*}$ & -2.19 \\
\hline Knowledge on street tree uses & 3.56 & 3.61 & -0.656 \\
\hline Leisure value of urban forest & 3.90 & $4.05^{*}$ & -2.02 \\
\hline Satisfaction and Loyalty & 4.19 & 4.29 & -1.47 \\
\hline
\end{tabular}

${ }^{*}$ Significant at $p<0.05$, two-tailed

Comparisons made between visitors and residents grouped by season is summarized in

Table 4.10. Only respondents surveyed during summer and fall yielded significant differences.

As indicated in the table, residents have higher mean scores on all four factors, and for summer

respondents, knowledge on parks and garden uses and leisure value of urban forests are the

factors that have significantly different mean scores while for fall residents only knowledge on

street tree uses did not give significantly different mean scores between residents and visitors.

Such findings indicate that respondents are particularly aware of the importance of urban forests

on seasons when they typically use these as venues for recreational activity and therefore has an

effect on their level of satisfaction and their loyalty to the city.

Table 4.10 
Comparison between residents and visitors grouped by season

\begin{tabular}{|c|c|c|c|c|c|c|}
\hline \multirow[b]{2}{*}{ Factor } & \multicolumn{3}{|c|}{ Summer } & \multicolumn{3}{|c|}{ Fall } \\
\hline & $\begin{array}{l}\text { Visitors } \\
(n=171)\end{array}$ & $\begin{array}{l}\text { Residents } \\
\qquad(n=83)\end{array}$ & $t$ value & $\begin{array}{l}\text { Visitors } \\
(n=236)\end{array}$ & $\begin{array}{l}\text { Residents } \\
(n=168)\end{array}$ & $t$ value \\
\hline $\begin{array}{l}\text { Knowledge on parks and } \\
\text { garden uses }\end{array}$ & 4.33 & $4.50^{*}$ & -2.62 & 4.37 & $4.52^{*}$ & -3.17 \\
\hline $\begin{array}{l}\text { Knowledge on street tree } \\
\text { uses }\end{array}$ & 3.54 & 3.56 & -0.268 & 3.58 & 3.59 & -0.15 \\
\hline $\begin{array}{l}\text { Leisure value of urban } \\
\text { forest }\end{array}$ & 3.93 & $4.21^{*}$ & -3.25 & 4.01 & $4.18^{*}$ & -2.83 \\
\hline Satisfaction and Loyalty & 4.28 & 4.32 & -0.544 & 4.20 & $4.33^{*}$ & -2.48 \\
\hline
\end{tabular}

*Significant at $p<0.05$, two-tailed

Respondents grouped by season were also subdivided by survey location and comparisons of each segment of respondents were made. Significant differences were observed for fall, winter and summer respondents and their scores are summarized in Tables 4.11, 4.13 and 4.15 respectively with the ANOVA tables given in Tables 4.12, 4.14 and 4.16 correspondingly. Based on the mean scores seen on Table 4.11, it was observed that fall respondents at the National Mall gave the lowest mean score in terms of their knowledge on parks and garden uses compared to the respondents from USNA and USBG. Conversely, fall respondents at the USNA gave the highest mean score among the three sub-groups of respondents in terms of their perceptions on the leisure value of urban forests. Finally, in general, 
USNA and USBG fall respondents gave higher mean scores to three out of the four factors compared to their National Mall counterparts.

Table 4.11

Summary mean scores given by fall respondents grouped by survey location

\begin{tabular}{|c|c|c|c|}
\hline \multirow[b]{2}{*}{ Factor } & \multicolumn{3}{|c|}{ Survey location } \\
\hline & $\begin{array}{l}\text { USNA } \\
(n=210)\end{array}$ & $\begin{array}{l}\text { USBG } \\
(n=114)\end{array}$ & $\begin{array}{l}\text { National Mall } \\
\qquad(n=80)\end{array}$ \\
\hline Knowledge on parks and garden uses & 4.48 & 4.44 & $4.28^{*}$ \\
\hline Knowledge on street tree uses & 3.64 & 3.49 & 3.56 \\
\hline Leisure value of urban forest & $4.22^{*}$ & 3.95 & 3.90 \\
\hline Satisfaction and Loyalty & 4.31 & 4.22 & 4.17 \\
\hline
\end{tabular}

${ }^{*}$ Significant at $p<0.05$, two-tailed

Table 4.12

ANOVA table for mean scores from fall respondents grouped by survey location

\begin{tabular}{|c|c|c|c|c|c|c|}
\hline Variable & & Sum of & $d f$ & Mean & $\boldsymbol{F}$ & Sig. \\
\hline Knowledge on parks and & Between Groups & 2.513 & 2 & 1.257 & 5.654 & 0.004 \\
\hline \multirow[t]{2}{*}{ garden uses } & Within Groups & 89.121 & 401 & 0.222 & & \\
\hline & Total & 91.634 & 403 & & & \\
\hline Knowledge on street tree & Between Groups & 1.680 & 2 & 0.840 & 1.725 & 0.180 \\
\hline
\end{tabular}




\begin{tabular}{llrrrrr}
\hline uses & Within Groups & 195.269 & 401 & 0.487 & & \\
& Total & 196.948 & 403 & & & \\
& Between Groups & 9.179 & 2 & 4.589 & 12.336 & 0.000 \\
Leisure value of urban & Within Groups & 149.189 & 401 & 0.372 & & \\
forest & Total & 158.368 & 403 & & & \\
& Between Groups & 1.315 & 2 & 0.658 & 2.393 & 0.093 \\
Satisfaction and Loyalty & Within Groups & 110.199 & 401 & 0.275 & & \\
& Total & 111.514 & 403 & & & \\
\hline
\end{tabular}

The succeeding two tables show the differences in mean scores given by winter respondents subdivided by survey location and as indicated in Table 4.13 , it is observed that USNA respondents gave a significantly low mean score compared to the other subgroups in terms of their perceptions related to their knowledge on street tree uses. On the other hand, the respondents from the National Mall gave a significantly low mean score in terms of their perceptions on the leisure value of urban forests.

Table 4.13

Summary mean scores given by winter respondents grouped by survey location

\begin{tabular}{|c|c|c|c|}
\hline \multirow[b]{2}{*}{ Factor } & \multicolumn{3}{|c|}{ Survey location } \\
\hline & $\begin{array}{l}\text { USNA } \\
(n=30)\end{array}$ & $\begin{array}{l}\text { USBG } \\
(n=112)\end{array}$ & $\begin{array}{l}\text { National Mall } \\
\qquad(n=65)\end{array}$ \\
\hline Knowledge on parks and garden uses & 4.42 & 4.39 & 4.23 \\
\hline Knowledge on street tree uses & $3.25^{*}$ & 3.62 & 3.44 \\
\hline
\end{tabular}


Leisure value of urban forest

Satisfaction and Loyalty
4.14

4.36
4.15

4.21

${ }^{*}$ Significant at $p<0.05$, two-tailed

Table 4.14

ANOVA table for mean scores from winter respondents grouped by survey location

\begin{tabular}{|c|c|c|c|c|c|c|}
\hline Variable & & $\begin{array}{l}\text { Sum of } \\
\text { Squares }\end{array}$ & \multicolumn{2}{|r|}{ Mean } & $\boldsymbol{F}$ & Sig. \\
\hline Knowledge on parks and & Between Groups & 1.308 & 2 & 0.654 & 2.062 & 0.130 \\
\hline \multirow[t]{2}{*}{ garden uses } & Within Groups & 64.689 & 204 & 0.317 & & \\
\hline & Total & 65.997 & 206 & & & \\
\hline Knowledge on street tree & Between Groups & 3.675 & 2 & 1.837 & 3.719 & 0.026 \\
\hline \multirow[t]{2}{*}{ uses } & Within Groups & 100.782 & 204 & 0.494 & & \\
\hline & Total & 104.457 & 206 & & & \\
\hline Leisure value of urban & Between Groups & 2.445 & 2 & 1.223 & 3.229 & 0.042 \\
\hline \multirow[t]{2}{*}{ forest } & Within Groups & 77.240 & 204 & 0.379 & & \\
\hline & Total & 79.685 & 206 & & & \\
\hline \multirow[t]{3}{*}{ Satisfaction and Loyalty } & Between Groups & 0.915 & 2 & 0.458 & 1.239 & 0.292 \\
\hline & Within Groups & 75.379 & 204 & 0.370 & & \\
\hline & Total & 76.295 & 206 & & & \\
\hline
\end{tabular}

Table 4.15 summarizes the mean scores given by summer respondents grouped by survey site and it shows that respondents from USNA gave significantly higher mean scores in terms of their perception on their knowledge of parks and garden uses, the leisure value of urban forests, 
and their satisfaction and loyalty. On the other hand, respondents from the National Mall gave a significantly low score concerning their perception on their knowledge of parks and garden uses as well as their satisfaction and loyalty compared to the other two subgroups of respondents.

Table 4.15

Summary mean scores given by summer respondents grouped by survey location

\begin{tabular}{|c|c|c|c|}
\hline \multirow[b]{2}{*}{ Factor } & \multicolumn{3}{|c|}{ Survey location } \\
\hline & $\begin{array}{l}\text { USNA } \\
(n=89)\end{array}$ & $\begin{array}{l}\text { USBG } \\
(n=65)\end{array}$ & $\begin{array}{l}\text { National Mall } \\
\qquad(n=100)\end{array}$ \\
\hline Knowledge on parks and garden uses & $4.52^{\mathrm{a}}$ & $4.39^{\mathrm{a}, \mathrm{b}}$ & $4.27^{\mathrm{b}}$ \\
\hline Knowledge on street tree uses & 3.57 & 3.60 & 3.50 \\
\hline Leisure value of urban forest & $4.27^{\mathrm{c}}$ & 3.97 & 3.84 \\
\hline Satisfaction and Loyalty & $4.42^{\mathrm{a}}$ & $4.29^{\mathrm{a}, \mathrm{b}}$ & $4.18^{\mathrm{b}}$ \\
\hline
\end{tabular}

${ }^{\mathrm{a}, \mathrm{b}}$ Significant at $p<0.05 ;{ }^{\mathrm{c}}$ Significant at $\mathrm{p}<0.001$

Table 4.16

ANOVA table for mean scores from summer respondents grouped by survey location

\begin{tabular}{llrrrrr}
\hline \multicolumn{1}{c}{ Variable } & & Sum of & Mean & Sig. \\
& & Squares & & Square & & \\
\hline Knowledge on parks and & Between Groups & 3.129 & 2 & 1.565 & 6.806 & 0.001 \\
garden uses & Within Groups & 57.698 & 251 & 0.230 & & \\
& Total & 60.827 & 253 & &
\end{tabular}




\begin{tabular}{|c|c|c|c|c|c|c|}
\hline Knowledge on street tree & Between Groups & 0.471 & 2 & 0.235 & 0.470 & 0.626 \\
\hline \multirow[t]{2}{*}{ uses } & Within Groups & 125.776 & 251 & 0.501 & & \\
\hline & Total & 126.246 & 253 & & & \\
\hline Leisure value of urban & Between Groups & 8.956 & 2 & 4.478 & 11.419 & 0.000 \\
\hline \multirow[t]{2}{*}{ forest } & Within Groups & 98.427 & 251 & 0.392 & & \\
\hline & Total & 107.383 & 253 & & & \\
\hline \multirow[t]{3}{*}{ Satisfaction and Loyalty } & Between Groups & 2.552 & 2 & 1.276 & 4.936 & 0.008 \\
\hline & Within Groups & 64.898 & 251 & $0 . .259$ & & \\
\hline & Total & 67.450 & 253 & & & \\
\hline
\end{tabular}

The subgroup comparisons provided notable insights on the general tendency of change in the perception of various groups of people on the four factors explored in this study. The results of the comparisons reinforces the notion that people who generally have a level of familiarity with a resource like urban forests tend to appreciate its leisure value and translates to a more favorable satisfaction on the resource. This is exemplified by residents giving higher mean scores compared to visitors. The results of the comparisons also highlighted that influence that seasons have on the perceptions of people on urban forests. During seasons when urban forests are more vibrant, people tend to have increased awareness to it. Similarly, those respondents who were surveyed at attractions directly tied to urban forests such as the USNA and USBG, exhibited a higher level of awareness and appreciation to it.

The succeeding section uses structural equation modelling to further investigate the relationships among the factors generated in this section of the study. Data from the whole sample is used to test the model.

\subsubsection{Structural equation model (SEM)}


Figure 4.2 illustrates the model tested in this analysis including the scale items for each factor. The four factors, namely: knowledge of urban forests; knowledge of street trees; leisure value of urban forests and satisfaction and loyalty, were generated from the results of the factor analysis and are treated as latent variables in the analysis. As previously mentioned, atti 12 and 14 were removed from further analysis.

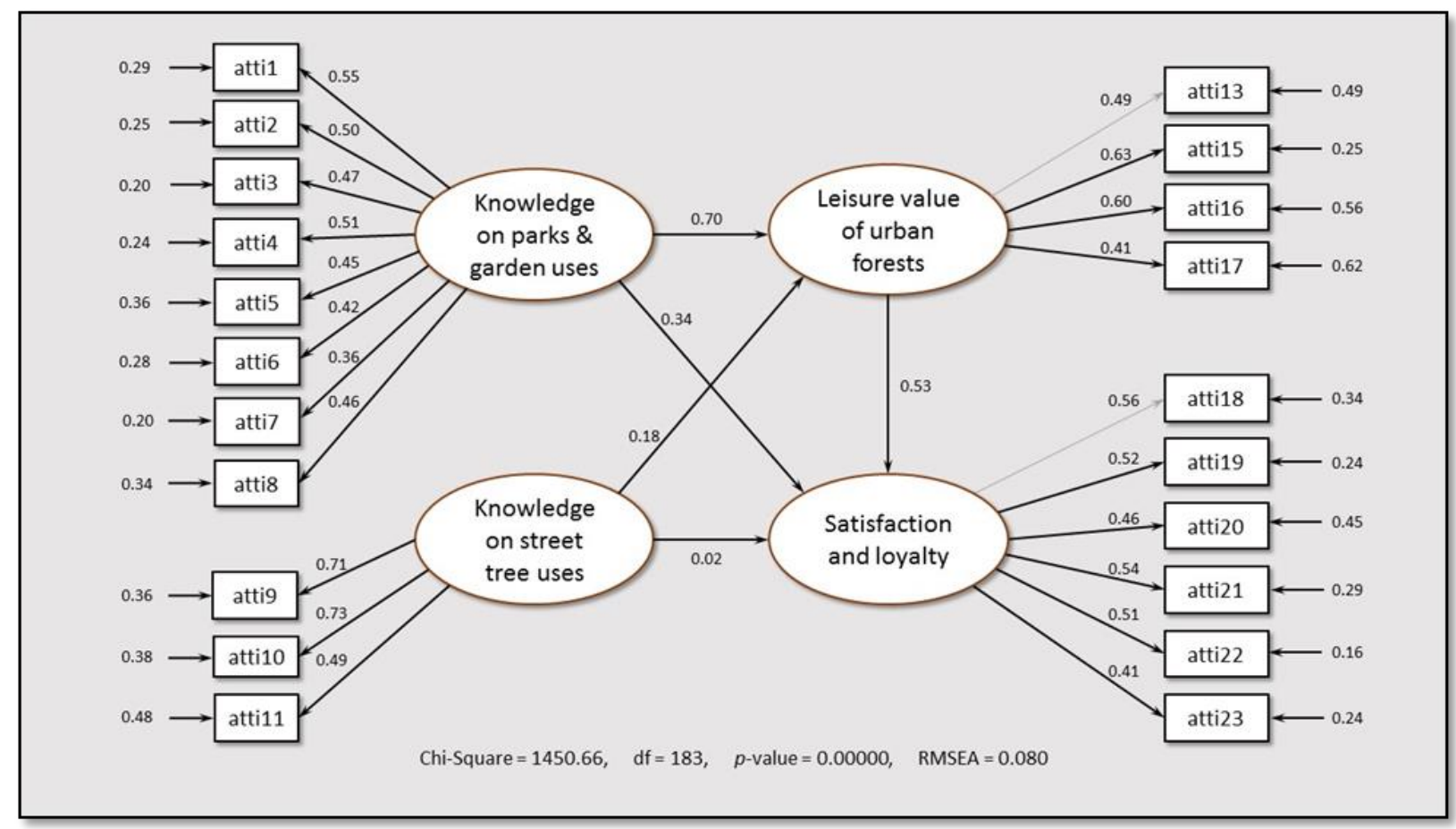

Figure 4.2 Structural model showing the relationship of the variables used in the study

Collectively, it is hypothesized that satisfaction and loyalty to the city in general and the urban forests in particular is influenced directly by individuals' knowledge on the uses of the urban forests and street trees. Moreover, it is also assumed that these two factors influence peoples' attitudes towards the value of urban forests as a leisure and recreational venue, which in turn, affects satisfaction and loyalty.

In terms of the relationships of the latent variables, Table 4.7 summarizes the results generated using LISREL and it shows that the assumed paths relating the four latent variables as shown in the structural model were significant at $p<0.05$ and at $p<0.1$ and in a positive 
direction. Specifically, it shows that $\left(\mathrm{H}_{1}\right)$ : knowledge on the uses of parks and gardens positively influence the leisure value of urban forests $(t=13.91, p<0.1)$. Also, $\left(\mathrm{H}_{2}\right)$ knowledge on the uses of street trees positively influence the leisure value of urban forests $(t=4.37, p<0.05)$.

Furthermore, $\left(\mathrm{H}_{3}\right)$ knowledge on the uses of parks and gardens has a direct and positive influence on satisfaction and loyalty on urban forests and the city $(t=5.69, p<0.1)$; and similarly, $\left(\mathrm{H}_{4}\right)$ knowledge of street tree uses has a direct and positive influence on satisfaction and loyalty on urban forests and the city $(t=0.54, p<0.05)$. Lastly, $\left(\mathrm{H}_{5}\right)$ the leisure value of urban forests has a positive influence on the satisfaction and loyalty on urban forests and the city $(t=7.62, p<0.1)$. Looking at the value of the standardized coefficients, it can be observed that some relationships are relatively strong $\left(\mathrm{H}_{1}=0.70 ; \mathrm{H}_{4}=0.53\right)$ while others are relatively weak $\left(\mathrm{H}_{2}=0.18 ; \mathrm{H}_{4}=\right.$ 0.02). Also note that in Figure 4.2, items with gray arrows, and in Table 4.7, the items that do not have $t$-values are estimated for fixed parameters in the model, which is true for items atti18 and atti13.

Correspondingly, the standardized estimates computed for the path coefficients between two variables can be interpreted as the amount of change in the standard deviation of one variable (dependent) given one unit of change in the standard deviation of another variable (independent). For example, according to Table 4.7, the coefficient between the dependent variable leisure value and the independent variable knowledge on parks and gardens uses is 0.70 , which means that one standard deviation change in this variable corresponds to a 0.70 change in the standard deviation of leisure value (Deng et al., 2010).

Table 4.7

Summary of standardized path coefficients and model fit statistics

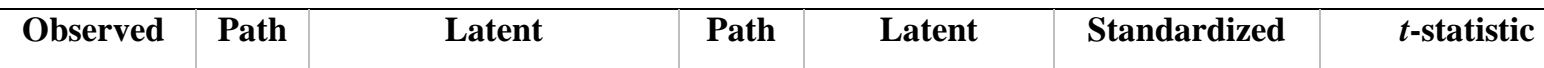




\begin{tabular}{|c|c|c|c|c|c|c|}
\hline variables & & variables & & variables & estimate & \\
\hline atti1 & $\leftarrow \leftarrow$ & \multirow{9}{*}{$\begin{array}{l}\text { Knowledge } \\
\text { on parks and gardens }\end{array}$} & & & .55 & $26.06^{\mathrm{a}}$ \\
\hline atti2 & $\leftarrow \leftarrow$ & & & & .50 & $25.80^{\mathrm{a}}$ \\
\hline atti3 & $\leftarrow \leftarrow$ & & & & .47 & $26.34^{\mathrm{a}}$ \\
\hline atti4 & $\leftarrow \leftarrow$ & & & & .51 & $26.40^{\mathrm{a}}$ \\
\hline atti5 & $\leftarrow \leftarrow$ & & & & .45 & $20.63^{a}$ \\
\hline & & & & & & \\
\hline atti6 & $\leftarrow \leftarrow$ & & & & .42 & $21.92^{\mathrm{a}}$ \\
\hline atti7 & $\leftarrow \leftarrow$ & & & & .36 & $22.00^{\mathrm{a}}$ \\
\hline atti8 & $\leftarrow \leftarrow$ & & & & .46 & $21.63^{\mathrm{a}}$ \\
\hline atti9 & $\leftarrow \leftarrow$ & \multirow{4}{*}{ Knowledge on street } & & & .71 & $25.39^{\mathrm{a}}$ \\
\hline atti10 & $\leftarrow \leftarrow$ & & & & .73 & $25.39^{\mathrm{a}}$ \\
\hline & & & & & & \\
\hline atti11 & $\leftarrow \leftarrow$ & & & & .49 & $18.36^{\mathrm{a}}$ \\
\hline atti13 & $\leftarrow \leftarrow$ & \multirow{4}{*}{$\begin{array}{l}\text { Leisure value of urban } \\
\text { forests }\end{array}$} & & & .49 & N/A \\
\hline atti15 & $\leftarrow \leftarrow$ & & & & .63 & $17.78^{\mathrm{a}}$ \\
\hline atti16 & $\leftarrow \leftarrow$ & & & & .60 & $15.68^{\mathrm{a}}$ \\
\hline atti17 & $\leftarrow \leftarrow$ & & & & .41 & $12.42^{\mathrm{a}}$ \\
\hline atti18 & $\leftarrow \leftarrow$ & \multirow{7}{*}{ Satisfaction and loyalty } & & & .56 & N/A \\
\hline atti19 & $\leftarrow \leftarrow$ & & & & .52 & $21.52^{\mathrm{a}}$ \\
\hline atti20 & $\leftarrow \leftarrow$ & & & & .46 & $17.05^{\mathrm{a}}$ \\
\hline & & & & & & \\
\hline atti21 & $\leftarrow \leftarrow$ & & & & .54 & $21.10^{\mathrm{a}}$ \\
\hline atti22 & $\leftarrow \leftarrow$ & & & & .51 & $23.13^{\mathrm{a}}$ \\
\hline \multirow[t]{4}{*}{ atti23 } & $\leftarrow \leftarrow$ & & & & .41 & $19.12^{\mathrm{a}}$ \\
\hline & & $\begin{array}{l}\text { Knowledge on urban } \\
\text { forest uses (H1) }\end{array}$ & $\rightarrow \rightarrow$ & Leisure value & .70 & $13.91^{\mathrm{b}}$ \\
\hline & & $\begin{array}{l}\text { Knowledge on street } \\
\text { tree uses (H2) }\end{array}$ & $\rightarrow \rightarrow$ & Leisure value & .18 & $4.37^{\mathrm{a}}$ \\
\hline & & Knowledge of urban & $\rightarrow \rightarrow$ & Satisfaction & .34 & $5.69^{\mathrm{b}}$ \\
\hline
\end{tabular}




\begin{tabular}{|c|c|c|c|c|c|}
\hline & forest uses (H3) & & and loyalty & & \\
\hline & $\begin{array}{l}\text { Knowledge of street } \\
\text { tree uses (H4) }\end{array}$ & $\rightarrow \rightarrow$ & $\begin{array}{l}\text { Satisfaction } \\
\text { and loyalty }\end{array}$ & .02 & $0.54^{\mathrm{a}}$ \\
\hline & Leisure value (H5) & $\rightarrow \rightarrow$ & $\begin{array}{l}\text { Satisfaction } \\
\text { and loyalty }\end{array}$ & .53 & $7.62^{b}$ \\
\hline & & \multicolumn{4}{|c|}{ Model fit statistics } \\
\hline$\chi^{2}$ & & \multicolumn{4}{|c|}{1450.66} \\
\hline$\chi^{2} / d . f$. & & \multicolumn{4}{|c|}{7.93} \\
\hline SRMR & & \multicolumn{4}{|c|}{.06} \\
\hline RMSEA & & \multicolumn{4}{|c|}{.08} \\
\hline NFI & & \multicolumn{4}{|c|}{.96} \\
\hline NNFI & & \multicolumn{4}{|c|}{.96} \\
\hline CFI & & \multicolumn{4}{|c|}{.96} \\
\hline
\end{tabular}

${ }^{\mathrm{a}} p$ value $<0.05 ;{ }^{\mathrm{b}} p$ value $<0.10$ Note: $\chi^{2}-$ Model chi-square; $\chi^{2} / d . f .-$ Normed chi-square; NFI - Normed-fit index; NNFI - Non-Normed fit index; CFI - Comparative fit index; SRMR - Standardized root mean square residual; RMSEA - Root mean square error of approximation.

The overall model fit of the conceptual model can be described in several ways. It shows the extent on which the scale items represent the latent variables of the model. The lower part of Table 4.7 shows the values for a number of absolute and incremental fit indices. The $\chi^{2}$ value (1450.66 with 183 degrees of freedom) is statistically significant at $p<0.001$, which indicates a failure to fit the model proposed in the study. Other absolute fit indices were computed such as the normed chi-square equal to 7.93, which is above the threshold value of 3 and reinforcing the previous result. On the other hand, the RMSEA and the SRMR are equal to 0.08 and 0.06 , respectively and these values indicate an acceptable level of fit for both measures (Hooper, Coughlan, \& Mullen, 2008). 
Due to a fairly large sample size $(N=1090)$, corresponding incremental fit tests were also explored, namely: the NFI, NNFI, and CFI. Similarly, Table 4.7 lists the value for these measures and are all equal to 0.96 , which is slightly above the threshold level of 0.95 , validating a fairly acceptable fit for the proposed model (Hu \& Bentler, 1999). Moreover, following Hu and Bentler's two-index guidelines on determining model fit: (1) NNFI is 0.96 and SRMR is lower than 0.09; and (2) CFI is 0.96 and SRMR is less than 0.90, reinforces the model having an acceptable fit to the observed data.

\subsection{Conclusions}

As highlighted by this study, various segments of the sample have varying attitudes on how urban forests affect their experiences while enjoying Washington DC. The general positive outlook on the statements based on the mean scores given by the respondents validates the people's awareness and appreciation of the presence of the city's urban forests and the services they provide. In general, statements related to the appearance of the urban forest, the influence of the urban forests to the people's leisure experiences, and their satisfaction were strongly agreed upon by the whole group. This shows that Washington DC offers a counterbalance to its innate cultural and historical charm as the nation's capital. Its urban forests, manifested in the street trees, gardens and parks scattered throughout the area is not unnoticed and in fact has become part of its appeal.

Comparison among subgroups of respondents offered distinct differences particularly on how groups of people who are more familiar with the city tends to give higher mean scores. The same is true for older respondents, who by virtue of their age have collected more experiences 
interacting with nature in either an urban or rural setting. In almost all factors, the older the respondent, the higher the scores given on the factors involved in the study.

Using SEM, the study was able to describe the interrelationship among the factors that comprise the cognitive, affective and behavioral dimensions of people's attitudes in the context of urban forests. It is notable to validate the key role of knowledge in positively influencing the perceived leisure value of urban forests which ultimately leads to higher satisfaction. Thus, with education and more experience with urban forests, people's appreciation and satisfaction of such areas improve. A higher satisfaction level would mean more support towards the management and development of these areas.

On a management aspect, the need to maintain well-kept areas such as parks, gardens and including street trees can gain support towards these resources. Designing and incorporating programs that will provide opportunities to learn more about the functions, benefits, and uniqueness of urban forests in Washington DC can enhance the city's image to include a more nature-related appeal. Currently, visitors put urban forests secondary to the historical and cultural resources of the city. It is undeniable that the popularity of the museums, memorials and galleries is unlikely to diminish, but adding urban forest attractions widen the versatility of the tourism offerings of the city. Invigorated initiatives to highlight urban forests as attractions, that can also be enjoyed for free, can elevate the status of the city as a destination. At present, the residents hold the advantage of knowing the extra value that urban forests have in experiencing Washington DC. Having stated this, there are two things that can be derived from it: 1) tourism managers can harness the residents as a potentially effective means of advertising the urban forest attractions of the city; and 2) city and tourism managers can work together to develop a means of dispersing tourism use from highly concentrated sites such as the National Mall to 
some peripheral attractions such as the National Arboretum, Rock Creek Park, and Kenilworth Aquatic Gardens. These places are underutilized and relatively not popularly advertised as main attractions, mainly because these places are at the moment fairly inaccessible to visitors, especially those who are not familiar with the city. In return, increase in tourism activity in these areas will eventually generate more support towards their management and development.

Overall, the study was successful in cementing the connection between urban tourism and urban forests in an urban center such as Washington DC. It provided city and urban planners and managers substantial evidence that the mindset of their clientele, the local people and the visitors are influenced by these natural resources. Thus, it is imperative that supporting urban forest programs that relate to tourism should be included as one of the priorities in city management.

\subsection{Limitations and suggestions for future research}

Despite the useful insights gleaned from the study, it is not without its share of limitations. One key limitation of the study is the variety of survey sites to ensure a more accurate representation of the users of urban forests in Washington DC. Sites such as transportation hubs, commercial establishments, and hotels can be places where additional respondents can be encouraged to participate. There were efforts to address this limitation in the study but for security reasons, the survey was not allowed to be conducted in such areas. In line with this, people who enjoy Washington DC are not limited to domestic visitors. A relatively significant proportion of its visitors are foreign and not all are conversant in the English language. In fact, this is one of the factors that hindered certain individuals to participate in the study. Therefore, it is suggested that a more varied location of survey sites can be integrated to further improve the variety of respondents captured in future studies. Also, the use of 
multilingual questionnaires on such and related studies on similar areas can capture the perspectives of foreign visitors.

In terms of the analysis tools used in the study, further comparisons can be made by combining specific demographic and trip characteristics of the respondents. By doing this, future researchers can zero in on more specific segments of the population and glean insights on their attitudes. 


\subsection{References}

Allen, L. R., Hafer, H. R., Long, P. T., \& Perdue, R. R. (1993). Rural residents' attitudes toward recreation and tourism development. Journal of Travel Research, 31, 27-33.

Andereck, K. L., \& Vogt, C. A. (2000). The relationship between residents' attitudes toward tourism and tourism development options. Journal of Travel research, 39, 27-36.

Andriotis, K., \& Vaughan, R. D. (2003). Urban residents' attitudes toward tourism development: The case of Crete. Journal of travel research, 42, 172-185.

Barrett, P. (2007). Structural equation modelling: Adjudging model fit. Personality and Individual Differences, 42, 815-824.

Bostedt, G. \& Mattson, L. (1995). The value of forests for tourism in Sweden. Annals of Tourism Research, 22, 671-680.

Bryant, M. M. (2006). Urban landscape conservation and the role of ecological greenways at local and metropolitan scales. Landscape and Urban Planning, 76, 23-44.

Chen, B., Bao, Z., \& Zhu, Z. (2006). Assessing the willingness of the public to pay to conserve urban green space: The Hangzhou city, China case. Journal of Environmental Health, 69, 26-30.

Deng, J., Araño, K. G., Pierskalla, C., \& McNeel, J. (2010). Linking urban forests and urban tourism: A case of Savannah, Georgia. Tourism Analysis, 15, 167-181.

Eagles, P. F. (1992). The travel motivations of Canadian ecotourists. Journal of Travel Research, 31, 3-7.

Elmendorf, W. F. Willits, F. K., \& Sisidharan, V. (2005). Urban park and forest participation and landscape preference: A review of the relevant literature. Journal of Arboriculture, 31, 311317. 
Hansen-Møller, J., \& Oustrup, L. (2004). Emotional, physical/functional and symbolic aspects of an urban forest in Denmark to nearby residents. Scandinavian Journal of Forest Research, 19(Suppl. 4), 56-64.

Hooper, D., Coughlan, J., \& Mullen, M. (2008). Structural equation modelling: Guidelines for determining model fit. Electronic Journal of Business Research Methods, 6, 53-60.

Hu, L. T., \& Bentler, P. M. (1999). Cutoff criteria for fit indexes in covariance structure analysis: Conventional criteria versus new alternatives. Structural equation modeling: a multidisciplinary journal, 6, 1-55.

Kiely-Brocato, K. (1980). An assessment of visitor attitudes toward resource use and management. The Journal of Environmental Education, 11, 29-36.

Konijnendijk, C. C. (2008). The forest and the city: The cultural landscape of urban woodland. New York: Springer.

Jurowski, C., \& Gursoy, D. (2004). Distance effects on residents' attitudes towards tourism. Annals of Tourism Research, 31, 296-312.

Mason, P., \& Cheyne, J. (2000). Residents' attitudes to proposed tourism development. Annals of Tourism Research, 27, 391-411.

More, T. A., Stevens, T. \& Allen, P. G. (1988). Valuation of urban parks. Landscape and Urban Planning, 15, 139-152.

Nowak, D. J., Hoehn III, R. E., Crane, D. E., Stevens, J. C., \& Walton, J. T. (2006). Assessing urban forest effects and values, Washington, DC's urban forest. Resource Bulletin NRS-1. Newtown Square, PA: U.S. Department of Agriculture, Forest Service, Northern Research Station. 24 p. 
O’ Brien, E. (2006). Social housing and greenspace: a case study in inner London. Forestry, 79, 535-549.

Paquot, T. (2005). City and nature, a missed opportunity? Diogenes, 52, 65-74.

Price, C. (2003). Quantifying the Aesthetic benefits of urban forestry. Urban Forestry \& Urban Greening, 1, 123-133

Sheldon, P. J., \& Var, T. (1984). Resident attitudes to tourism in North Wales. Tourism Management, 5, 40-47.

Smardon, R. C. (1988). Perception and aesthetics of the urban environment; Review of the role of vegetation. Landscape and Urban Planning, 15, 85-106.

Solecki, W. D. \& Weich, J. M. (1995). Urban parks: green spaces or green walls?. Landscape and Urban Planning, 32, 93-106.

Stedman, R. C. (2002). Toward a social psychology of place: Predicting behavior from placebased cognitions, attitude and identity. Environment and Behavior, 34, 561-581.

Swanagan, J. S. (2000). Factors influencing zoo visitors' conservation attitudes and behavior. The Journal of Environmental Education, 31, 26-31.

Tyrväinen, L., Mäkinen, K., \& Schipperijn, J. (2006). Tools for mapping social values of urban woodlands and other green areas. Landscape and Urban Planning, 79, 5-19.

Weaver, D. B., \& Lawton, L. J. (2004). Visitor attitudes toward tourism development and product integration in an Australian urban-rural fringe. Journal of travel research, 42, 286296.

Wolf, K. L. (2003). Ergonomics of the city: Green infrastructure and social benefits. In C. Kollin (Ed.), Engineering Green: Proceedings of the 2003 National Urban Forest Conference (pp. 141-143). Washington DC: American Forests. 
Wolf, K. L. (2005). Business district streetscapes, trees, and consumer response. Journal of Forestry, 103, 396-400.

Yu, K., Li, D., \& Li, N. (2006). The evolution of greenways in China. Landscape and Urban Planning, 76, 223-239.

Zhang, Y., Hussain, A., Deng, J., \& Letson, N. (2007). Public attitudes towards urban trees and supporting urban tree programs. Environment and Behavior, 39, 797-814. 


\title{
CHAPTER 5
}

Characterizing visitors' and residents' movement and its implications on urban forest and tourism management in Washington DC

\begin{abstract}
Understanding the interaction between people and city resources is a key element in achieving balanced planning and management. This portion of the study provided a glimpse at the general movement of people in Washington DC using survey data collected for one year. Respondents showed a variety of movement preferences and patterns that vary among residents and visitors as well as through different seasons. Insights gained from the study highlighted future needs and direction of urban forests and tourism management which, in turn, emphasizes the connection between the two entities.
\end{abstract}

Keywords: Kernel density, tourist flow, tourism seasonality 


\subsection{Introduction}

Studying the movement of people in a place such as a city can have many practical applications. Generally, tracing movement of units whether animals or humans can provide vital information on the way they interact with their environment (Zhao, Forer, \& Harvey, 2008). Management of resources is poised to benefit from understanding more on how people relate to their surroundings. Such information can be used in designing and layout of particular resources that the general public use such as centers for commerce, social services, transportation, recreation and others in urban areas.

For the tourism industry, there have been many attempts to study and represent spatial movement information by researchers who believe that it can serve as an important input in planning and locating various tourism resources such as attractions, accommodation, venues for tourism activities in addition to other city resources. Furthermore, having this information can be strategic in terms of designing tourism itineraries as products to offer visitors. In this regard, this study is targeted to characterize the patterns of movement of a segment of Washington DC's population in relation to the major cultural and natural attractions of the city such as monuments, memorials, museums, parks, and gardens. This study also illustrates the location where people have most interaction with urban forests to be used in influencing its management.

The concept of distance from a tourism point of view has generally been viewed and explored by research as the element that separates people and the destinations. There is a body of literature that looked into distance as a factor in decision making behavior of tourists (Nicolau, 2008; Sirakaya \& Woodside, 2005; Zalatan, 1996). As a factor influencing the decision to travel, distance is complemented by other factors such as income, mode of transport and accessibility that people also consider. One valuation method used to quantify the benefits accrued from 
leisure travel is based on distance: the travel cost method (Rosenthal, Loomis, \& Peterson, 1984; Loomis, 2006). Furthermore, distance is one of the primary factors driving the movement tendencies of people within an area.

There is a group of study that investigated the manner in which people travel and visit multi-destinations at a country level (Seguí-Llinás \& Capellà-Cervera, 2006) or at the level of a specific destination (Debbage, 1991). Similarly, there is one study that delved into travel behavior as influenced by the layout of a city as dictated by land use (Kockelman, 1997). Another study established and characterized the movement of tourists in a very busy city destination such as Hong Kong (McKercher \& Lau, 2008). It is regarded as one of the more indepth studies conducted because it developed a set of generalized movement patterns of tourists based on trip diary data. Among the patterns identified ranged from a no movement pattern to single distant stops, multiple stops, and local exploration to a combination of the last three. This study was aimed at understanding how tourists interact with the destination attractions where the information can be used to formulate market segments, develop itineraries or tour products that can be offered to tourists. Most of the studies mentioned above generally explore the connection between people's motivations, tendencies and demographics with the attractions in the destination; and those do not give particular emphasis to a certain type of attraction.

However, none of these studies looked into the movement patterns of people at a seasonal level because most of the studies described above looked at the duration of stay as the temporal base. This study is an attempt to explore the mobility, spatial pattern, and distribution of people at a popular city destination like Washington DC and relate its implications to the management of urban forests and urban tourism, which is both a city resource and an attraction. Furthermore, seasonal differences and similarities in the variables mentioned is observed and discussed. 


\subsection{Methods}

\subsubsection{Study area and data collection}

Washington DC was the study site chosen because it is a destination that offers different types of attractions that can cater to the various needs of visitors. The city is very popular for its historical and cultural attractions such as the museums, memorials, monuments and historical places. Moreover, the city also boasts of its reputation as one of the cities in the United States with a significant amount of urban forest in terms of area. These urban forests are comprised of parks, gardens and tree-lined streets that are located throughout the city. Thus, the study investigates the interaction that people have with the city's urban forests as they utilize the historical and cultural attractions of the city; and by doing so, can give useful information to urban forest managers in developing management and maintenance strategies for the upkeep of these resources and help identify tourism opportunities tied to urban forests.

The study employed a self-administered questionnaire as the data collection tool. Surveys were conducted at three specific sites: United States Botanic Garden, United States National Arboretum, and the National Mall (area in front of the Lincoln Memorial, tidal basin, and the area in front of the Smithsonian Institute museums). Respondents were approached and asked to complete the questionnaire. The survey period lasted from October 2009 to September 2010 collecting data twice a month. Surveys were conducted on weekends from Friday to Sunday where two surveyors stationed themselves at the sites listed previously and asked people to participate in the survey from 10 am to $5 \mathrm{pm}$. Purposive sampling was used to determine respondents for the study and the surveyors were tasked to explain and answer concerns about the questionnaire whenever respondents have issues completing it. 


\subsubsection{Questionnaire design and data analysis}

The questionnaire has two main portions, the first portion elicits information on the respondents' itinerary in terms of the places they have visited and the ones they still intend to visit during the day. It also included questions on their mode of moving around the city as well as the activities they have done and plan to do. The second portion of the questionnaire collected background and trip characteristic information from the respondents. Data analysis consisted of characterizing the sample; describing the distribution of visitors and residents by season; and identification of movement patterns of sub-groups.

Kernel density analysis using ArcGIS 10.3 is used to interpret and illustrate concentrations of respondents in relation to the location of urban forests in Washington DC. This method of density analysis was used because it accounts for the number of visits that respondents indicate at a specific point. Lastly, management implications on the findings of the study are discussed.

In further describing the movement of people within the city, the study uses the general log-linear analysis tool in the Statistical Package for the Social Sciences (SPSS) software. General log-linear models are used to analyze categorical data that is assumed to have a Poisson distribution (Agresti, 2002). To apply this method of analysis, the attractions in Washington DC were grouped based on the ward in which they are located. For example looking at a zoomed in map of Washington DC in Figure 5.1, the attractions National Cathedral and National Zoo will be grouped together in ward 3 and correspondingly, Dupont Circle, National Geographic Museum and Georgetown Waterfront Park will be grouped together in ward 2. The movement patterns will be based on people going from one ward to another based on the attractions that they visit. 


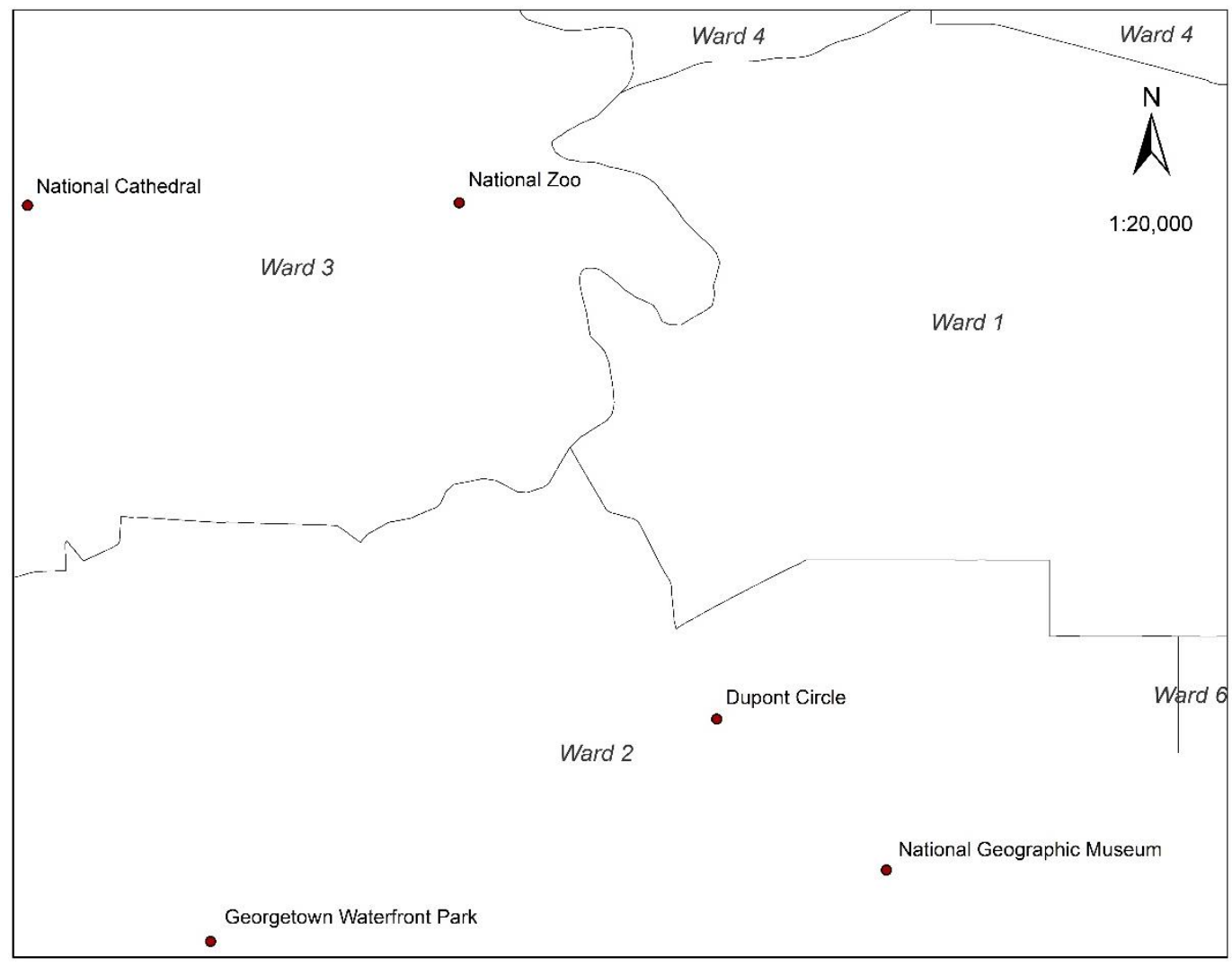

Figure 5.1. Map illustrating grouping of attractions by ward

The movement of people will be defined in this study as the geographic space between an attraction or set of attractions in one ward to another ward, thus a sequence of attractions visited in one ward and then to another is referred to as spatial movement. For visitor $i$, spatial movement $\left(M_{i}\right)$ is represented by the group of wards visited in their itinerary. $W_{i n}$ represents the wards visited by visitor $i$ at steps $n$.

$$
M_{i}=\left(W_{i 1}, W_{i 2}, \ldots, W_{i n}\right)
$$

A significant movement pattern will be those wards that denote strong interactions between each other in a particular movement sequence. For example, to test whether the movement pattern where a visitor visited the National Zoo in ward 3 and then visited the National Geographic museum in ward 2, let the variable $W_{l}$ be the first destination of the visitor 
and $W_{2}$ be the second destination. The saturated model for this two-ward movement pattern is given by:

$$
\log m_{i j}=\mu+\lambda_{i}^{W_{1}}+\lambda_{j}^{W_{2}}+\lambda_{i j}^{W_{1} W_{2}}
$$

Where $m_{i j}$ is the expected frequencies of the movement pattern; $\lambda_{i}^{W_{1}}$ is the main effect of

variable $W_{1} ; \lambda_{j}^{W_{2}}$ is the main effect of variable $W_{2}$; and $\lambda_{i j}^{W_{1} W_{2}}$ is the interaction effects of the two variables. The interaction effect parameter $\lambda_{i j}^{W_{1} W_{2}}$ will be set to zero to test whether there is an interaction between variables $W_{l}$ and $W_{2}$, then the expected frequencies, $m_{i j}^{\prime}$ will be calculated using the equation:

$$
\log m_{i j}^{\prime}=\mu+\lambda_{i}^{W_{1}}+\lambda_{j}^{W_{2}}
$$

Comparison between $\log m_{i j}$ and $\log m_{i j}^{\prime}$ will then be tested using the likelihood ratio Chisquare statistic where an interaction between the variables are deemed significant if the value of the likelihood ratio is significantly large at a $p$-value of 0.05 or less (Xia, 2007).

\subsection{Results}

\subsubsection{The sample}

The study used 1,143 completed questionnaires for the analysis out of 3,210 total respondents who participated in the study making the response rate equal to $35.6 \%$. Nonparticipants gave the following reasons for non-response: 1) no time to do the survey and 2) do not have a good grasp of English to complete the questionnaire properly. All the respondents who answered the questionnaire were versed on the study objectives and given proper instructions in completing the questionnaire. 
As listed on Table 5.1, more than one-third of the respondents are between 26 to 30 years old (35.7\%), and when combined with the 18 to 25 year old respondents make up $53.4 \%$ of the sample. Furthermore, the sample can be described as well-educated with $94 \%$ having a college degree with $51.8 \%$ having post-graduate degrees. There are slightly more female respondents $(52.1 \%)$ than males $(47.9 \%)$. In terms of the time of visit, $36.8 \%$ of the respondents were in the city during the fall season and the smallest portion of the respondents participated during winter with only $19.3 \%$. Finally, $34.3 \%$ of the sample are residents and $65.7 \%$ are visitors.

The visitors were also classified based on their length of stay, reason for visit, and frequency of visit to the city. Based on these parameters, $19.1 \%$ of the visitors are first timers and $80.9 \%$ are repeat visitors while $32 \%$ are day users and $68 \%$ are over nighters. In terms of the reason of visit, $64.4 \%$ were visiting for leisure, $19.2 \%$ were visiting family and relatives and the rest are in the city for business.

Table 5.1

Demographics and trip characteristics of the sample

\begin{tabular}{|c|c|c|}
\hline \multirow[t]{2}{*}{ Variable } & \multicolumn{2}{|c|}{ Proportion of the sample } \\
\hline & Frequency $(n)$ & Percentage $(\%)^{*}$ \\
\hline \multicolumn{3}{|l|}{ Age } \\
\hline 18 to 25 & 193 & 17.7 \\
\hline 26 to 39 & 389 & 35.7 \\
\hline 40 to 49 & 200 & 18.3 \\
\hline 50 to 59 & 184 & 16.9 \\
\hline 60 and above & 125 & 11.5 \\
\hline \multicolumn{3}{|l|}{ Educational attainment } \\
\hline High School & 66 & 6.0 \\
\hline
\end{tabular}




\begin{tabular}{|c|c|c|}
\hline College & 464 & 42.2 \\
\hline Graduate & 569 & 51.8 \\
\hline \multicolumn{3}{|l|}{ Gender } \\
\hline Male & 527 & 47.9 \\
\hline Female & 573 & 52.1 \\
\hline \multicolumn{3}{|l|}{ Timing of visit } \\
\hline Fall & 421 & 36.8 \\
\hline Winter & 221 & 19.3 \\
\hline Spring & 243 & 21.3 \\
\hline Summer & 258 & 22.6 \\
\hline \multicolumn{3}{|l|}{ Type of respondent } \\
\hline Residents & 392 & 34.3 \\
\hline Visitors & 751 & 65.7 \\
\hline -First time visitors & 137 & 19.1 \\
\hline -Repeat visitors & 580 & 80.9 \\
\hline -Day users & 229 & 32.0 \\
\hline -Overnight visitors & 487 & 68.0 \\
\hline -Visiting on business & 113 & 16.4 \\
\hline -Visiting for leisure & 444 & 64.4 \\
\hline -Visiting family \& relatives (VFR) & 132 & 19.2 \\
\hline
\end{tabular}

* The valid percent values were used to exclude cases where there are missing data.

\subsubsection{Getting around the city}

One aspect of movement that was focused on in this study is the manner at how visitors moved around the city. Table 5.2 summarizes the different ways of going around the city as well as the corresponding number of respondents who used it. 
Table 5.2

Ways of getting around Washington DC

\begin{tabular}{|c|c|c|c|c|c|c|c|}
\hline \multirow[t]{2}{*}{ Group } & \multicolumn{7}{|c|}{ Number of respondents } \\
\hline & Bus & Metro & Taxi & $\mathrm{Car}^{*}$ & Bike & Walk & Tour \\
\hline Overall & 135 & 573 & 77 & 572 & 65 & 538 & 23 \\
\hline \multicolumn{8}{|l|}{ Time of visit } \\
\hline Fall & 46 & 187 & 17 & 250 & 26 & 169 & 8 \\
\hline Winter & 22 & 126 & 18 & 99 & 6 & 134 & 10 \\
\hline Spring & 34 & 128 & 30 & 98 & 17 & 112 & 3 \\
\hline Summer & 33 & 132 & 12 & 125 & 16 & 123 & 2 \\
\hline Residents & 64 & 182 & 18 & 240 & 48 & 157 & 0 \\
\hline Visitors & 71 & 391 & 59 & 332 & 17 & 381 & 23 \\
\hline First timers & 25 & 76 & 9 & 30 & 4 & 88 & 6 \\
\hline Repeaters & 44 & 298 & 47 & 289 & 12 & 280 & 15 \\
\hline Day users & 9 & 90 & 3 & 149 & 2 & 73 & 1 \\
\hline Overnighters & 59 & 281 & 54 & 169 & 14 & 295 & 20 \\
\hline
\end{tabular}

*Private car or vehicle

As shown in Table 5.2, the most popular ways of going around the city is the subway system called the Metro, followed by private vehicle and walking. Conversely, the least popular means of going around is by package tours followed by riding a bicycle and taking the taxi. It is important to note that people use multiple means of getting around the city, therefore the total of these counts do not equal the number of respondents. Based on the season, riding the Metro and walking consistently ranked as a preferred means of going around while tour packages is the least preferred. It can be observed, however that visitors in the fall prefer using their private cars while winter visitors preferred walking. Furthermore, residents' top choice for getting around the 
city is by private car and the least is the package tours. Visitors, on the other hand, had the Metro as the most popular and the bicycle as the least popular way of going around the city. First timers get around by walking or using the Metro while repeat visitors use the Metro or their private cars. Understandably, day users have their private cars as the primary means of getting around because they need a means to leave the destination within the day while overnighters walk or ride the Metro. Lastly, tours include all types where visitors ride a bus, trolley, or Segway but excludes bike and walking tours, which are classified into different variables.

\subsubsection{Distribution of visits by respondent sub-groups}

Density analysis in ArcGIS was used to represent the distribution of respondents in the city based on the information they provided regarding their itineraries. Specifically, the kernel density tool was used to generate several maps where comparisons are made. Figure 5.2 shows the overall distribution of the respondents' visits based on the data collected. The map shows the overall boundary of Washington DC as well as the boundary of the city's wards. The city is subdivided into eight wards and each is considered as an administrative unit which is the basis of management. Furthermore, the green areas on the map shows the location and coverage of the city's urban forests which includes gardens, parks and other spaces covered with a variety of vegetation. The areas covered by colors that range from red to purple or blue represent the results of the kernel density analysis. As seen on the map, the respondents visited several attractions during their stay in the city and majority of the most visited places are within the National Mall area where most of the museums, memorials and monuments are located. The areas that are colored red have low density (less than 5) in terms of the number of visits while areas shaded in blue and purple are the places with high density (40 or more) of visits. In this case, we can see 
that only wards 4 and 8 are the ones that the respondents did not visit while wards 2, 6 and 5 have a relatively high concentration of visits.

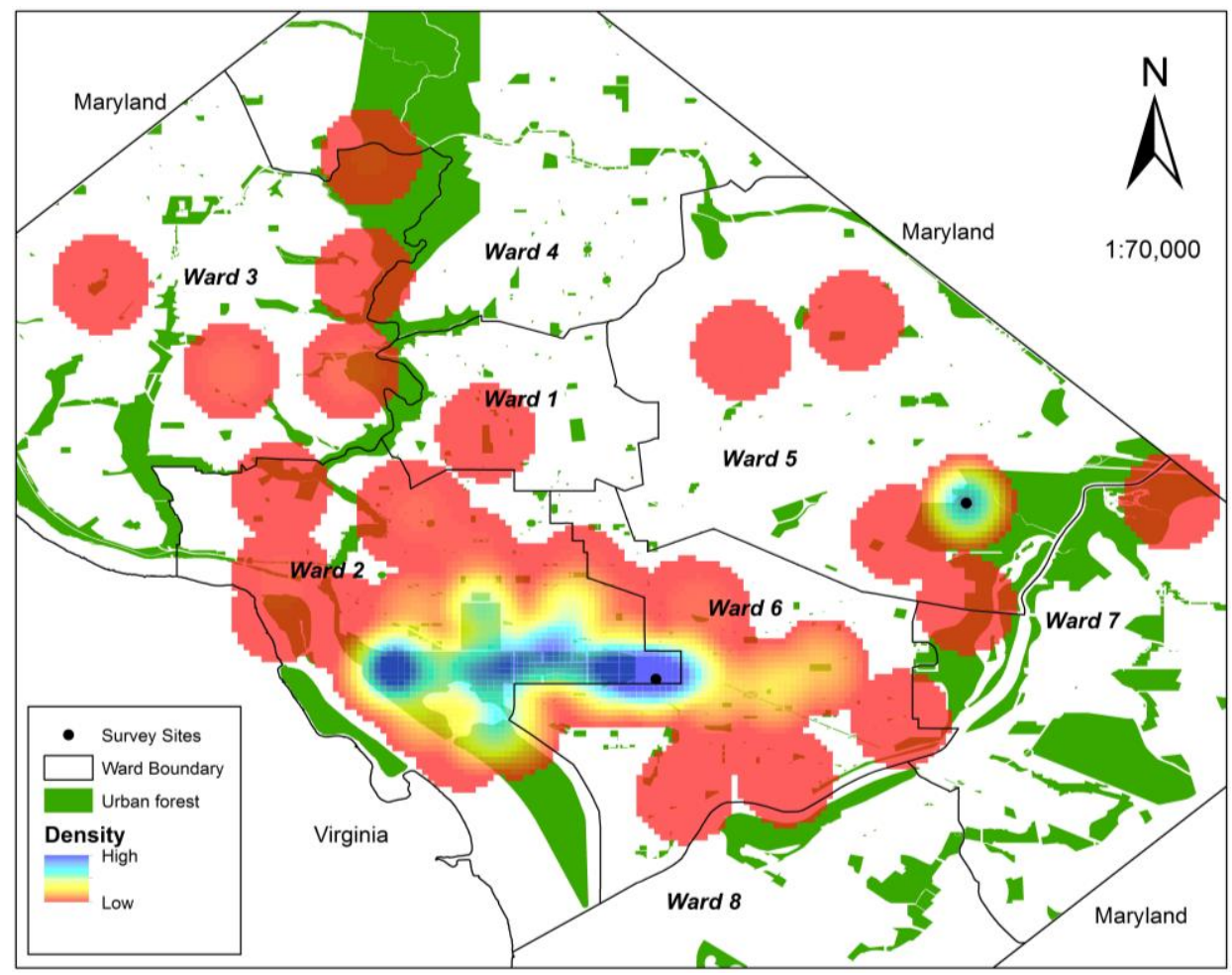

Figure 5.2 Density map of respondents' visit throughout Washington DC.

Looking at the wards surrounding wards 2 and 6, we can see that there was one attraction visited in ward 1, which is Meridian Park. Similarly, visitors only visited the Kenilworth Aquatic Gardens in ward 7. Wards 3 and 5 had a few attractions that people visited and these are: the National Zoo, National Cathedral, Hillwood Museum, Rock Creek, and Turtle Parks for the former; and the National Arboretum, National Shrine of the Immaculate Conception, Langston Golf Course, Franciscan Monastery, and Lincoln's cottage for the latter. It is important to note, however that in all the maps shown in the results, the survey sites: USNA (in ward 5) and USBG (in ward 2) have very high visitation numbers and will show very high densities (blue to purple spots). 
On the other hand, focusing on wards 2 and 6 , we can see that the most popular attractions are located within these two areas with the former having more attractions than the latter. Ward 2 has the White House, the various Smithsonian museums, the major memorials, Georgetown, and the Tidal Basin as its main attractions while ward 6 has the US Capitol, Eastern Market, Union Station, and the Nationals' Ballpark as its popular attractions.

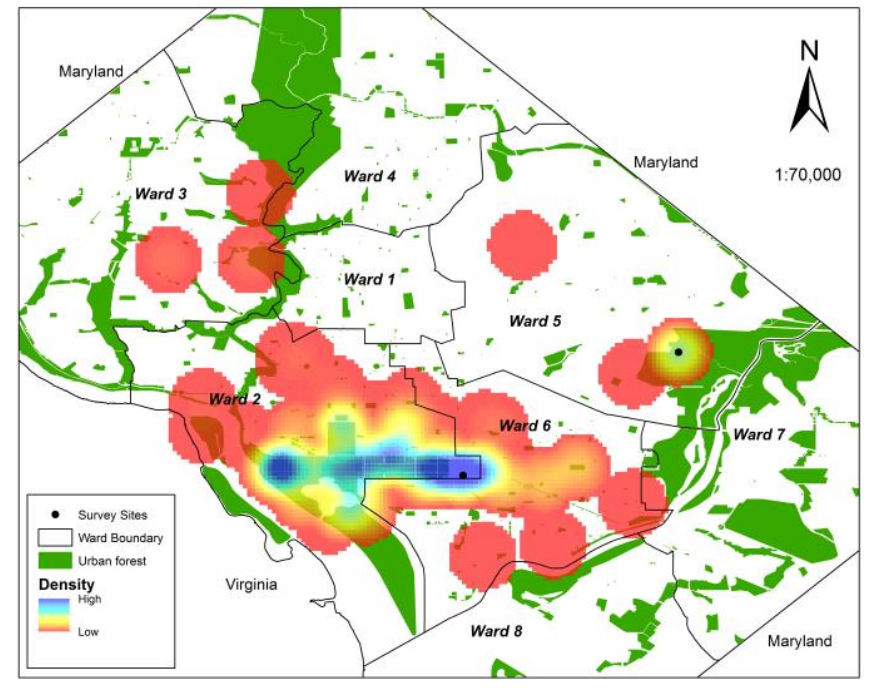

(a) Visitors

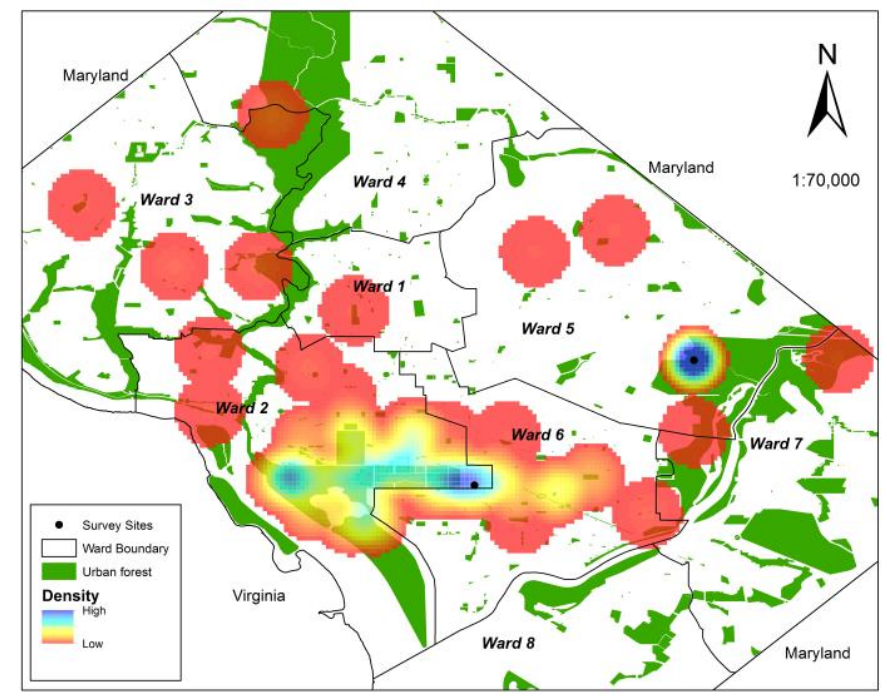

(b) Residents

Figure 5.3 Density maps comparing visitors and residents 
Referring to Figure 5.3, it can be noted that both groups of respondents are similar in terms of the general concentration of visits. However, one glaring difference is the higher concentration of visits made by residents to the USNA as indicated by a deep blue shade in ward 5 of the map. Conversely, visitors' itineraries are concentrated around the National Mall where most museums and memorials are as indicated by several spots of blue on the map. The study also analyzed the differences in the concentrations of visits by season as shown in Figure 5.4.

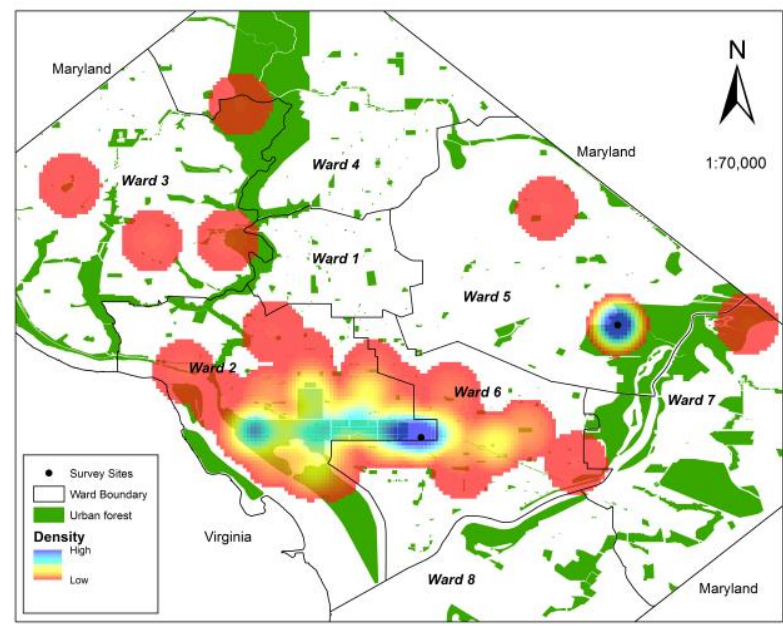

(a) Fall

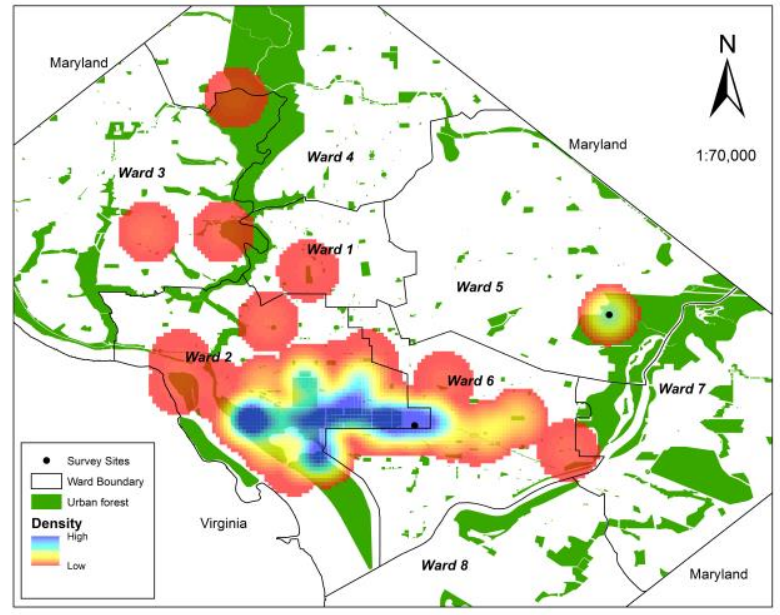

(c) Spring

Figure 5.4 Density maps of different seasons

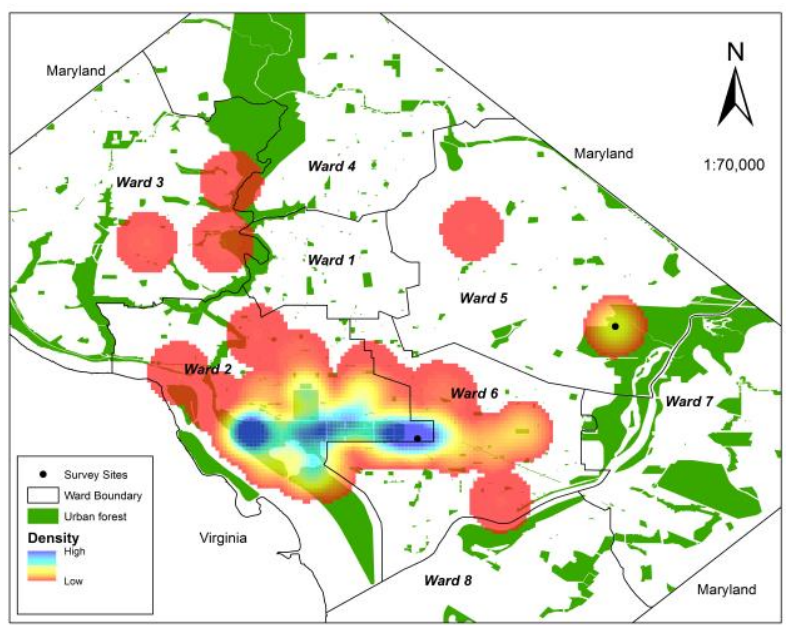

(b) Winter

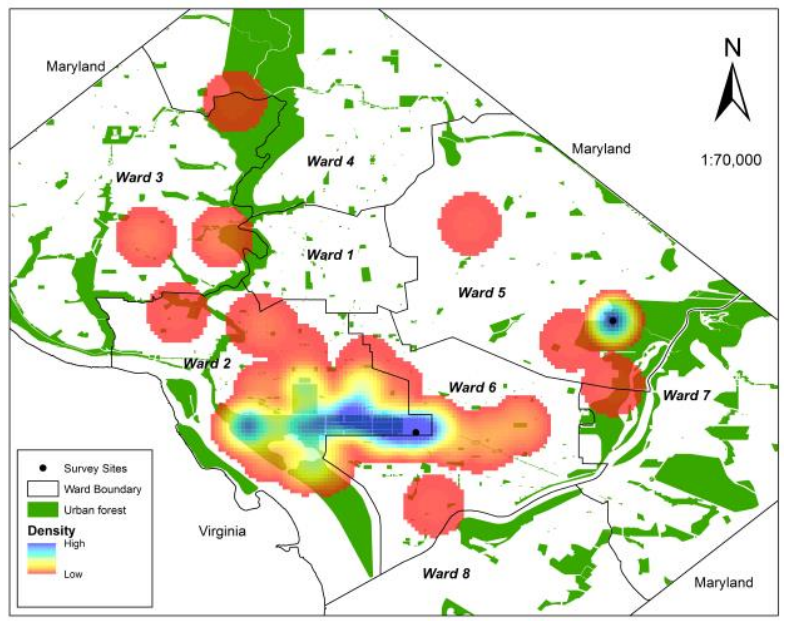

(d) Summer 
Examining the maps in Figure 5.4, we can observe that there are variations in the densities of visits. While the National Mall consistently rank as the most visited area, the degree of concentration varies among the attractions located there. It can be seen that in the spring season higher concentrations of visits are found in the tidal basin, which is slightly south of the National Mall, which can be attributed to the cherry trees blossoming during this season.

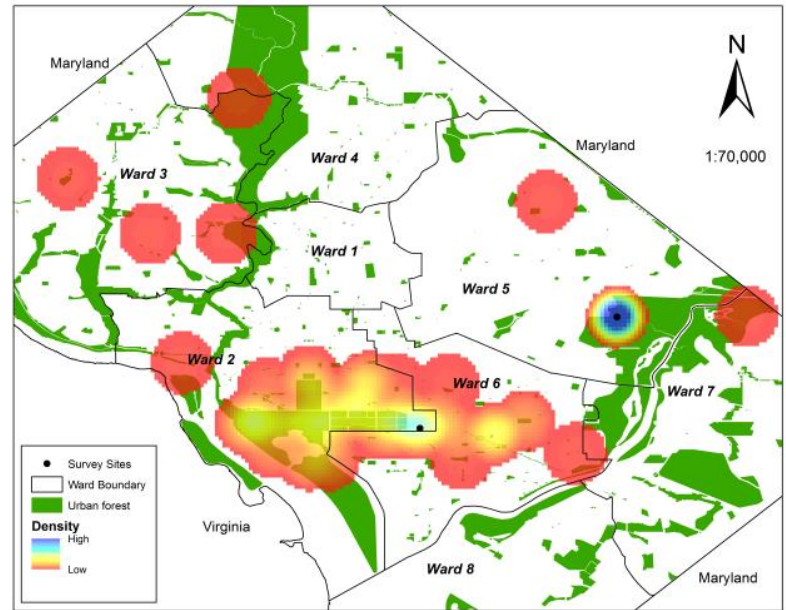

(a) Fall

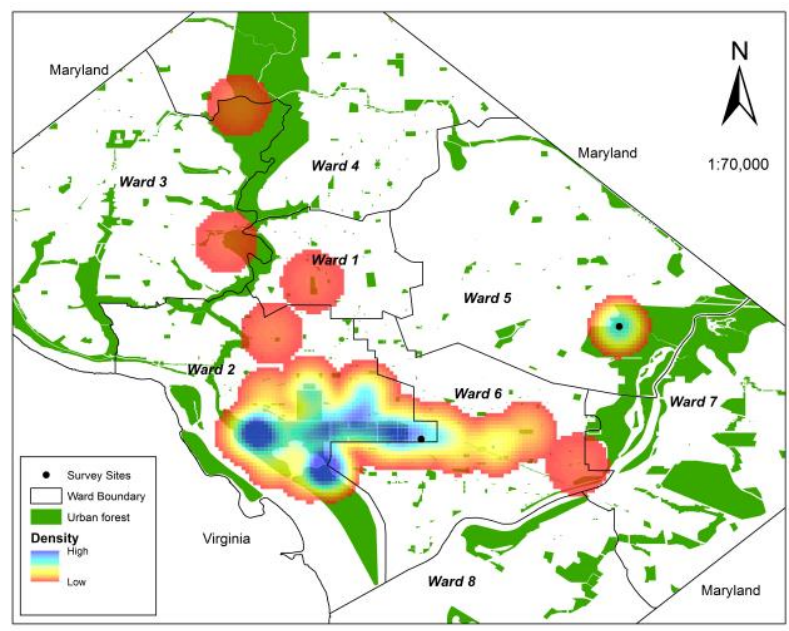

(c) Spring

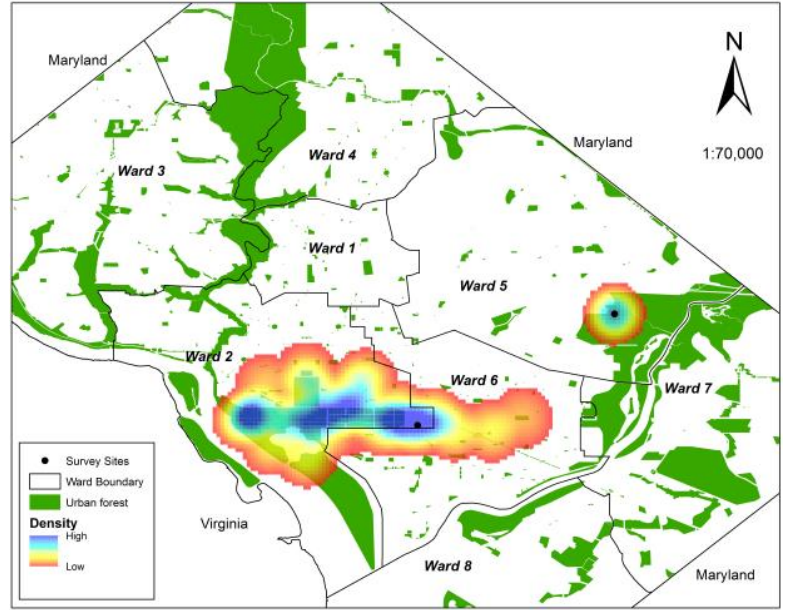

(b) Winter

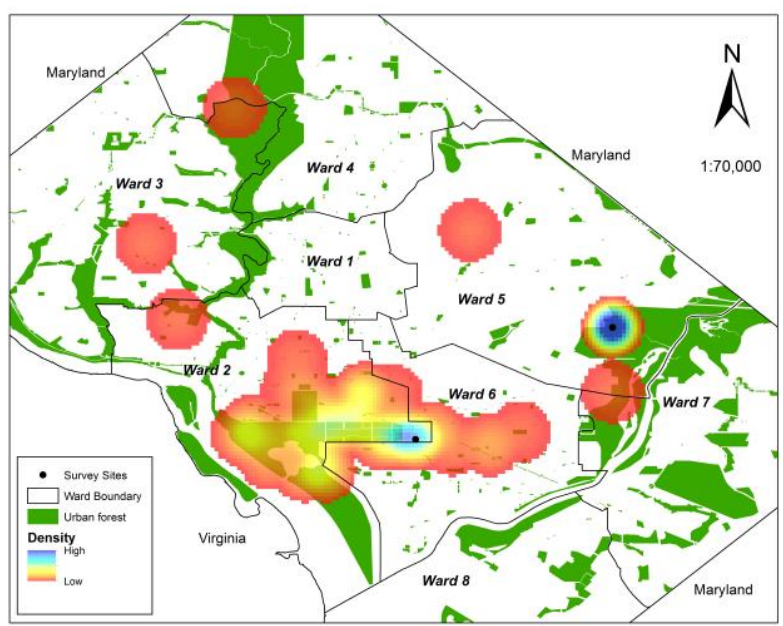

(d) Summer

Figure 5.5 Density maps of residents' visits by season 
Another notable difference is the concentration of visits at the USNA, the attractions with a high density in ward 5. The highest concentration of visits to this place is in the fall, summer and spring, which lends to the fact that this attraction has a potential to draw more people for the most part of the year.
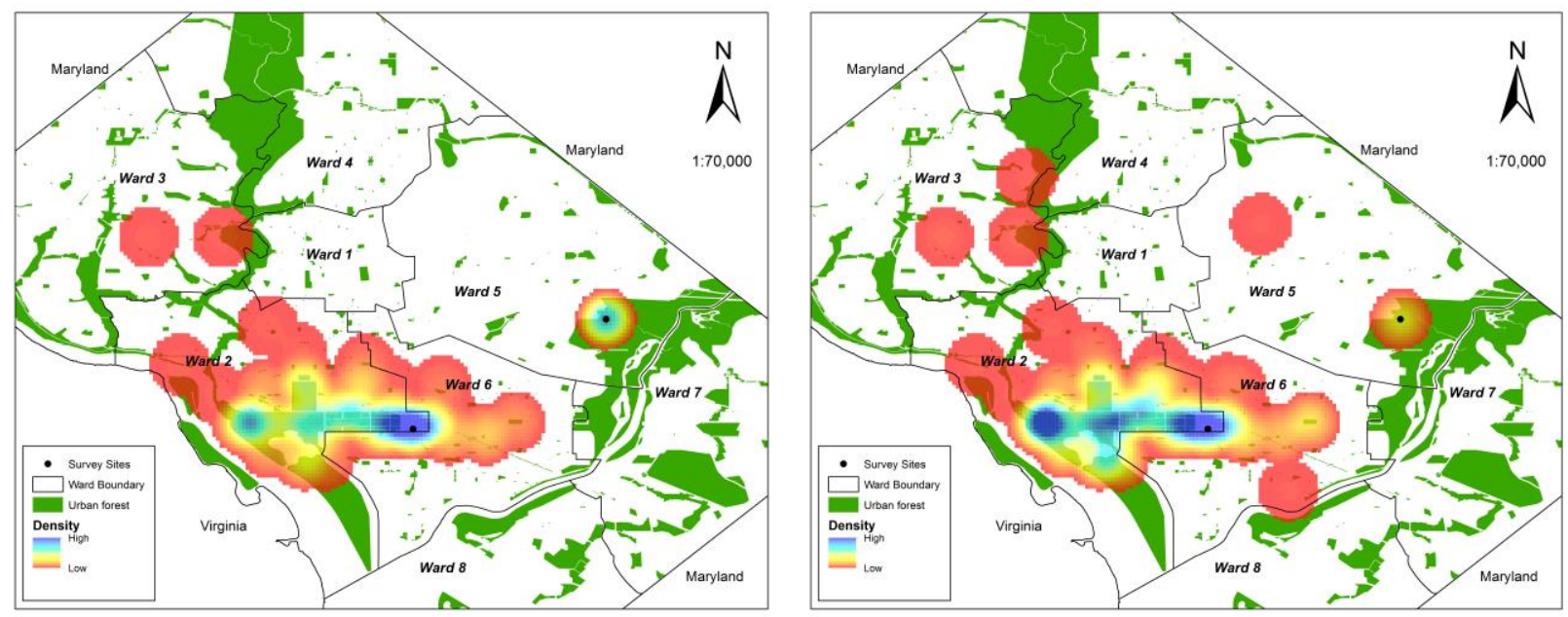

(a) Fall

(b) Winter
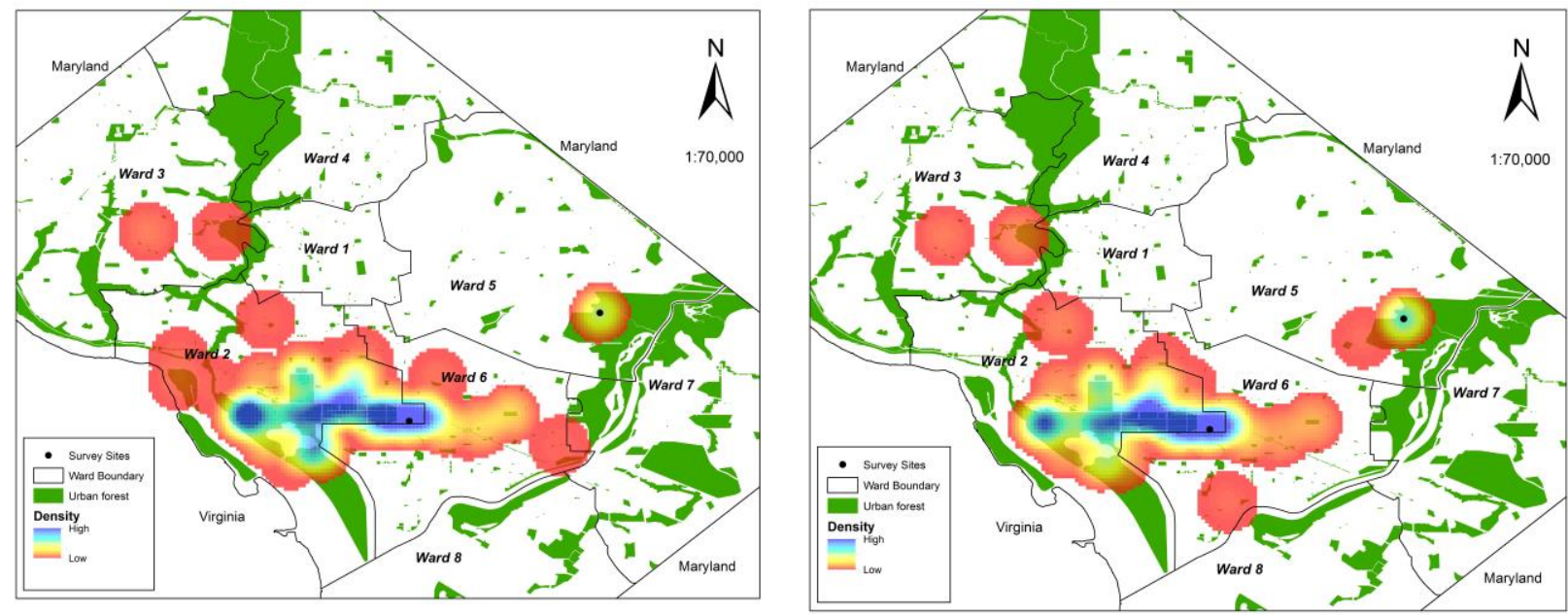

(c) Spring

(d) Summer

Figure 5.6. Density maps of visitors' visits by season

Further analysis of the data looks into differences in the concentration of visits made by residents and visitors in different seasons. Figures 5.5 and 5.6 shows the density maps of the 
visits made by these groups of respondents. From the maps in Figure 5.5, we can see that during the winter season, the respondents limited their visits to within the National Mall area with the exception of the visits at the USNA while during the other seasons, residents tend to spread out the places they visit which extends to attractions located in ward 3, 5 and 7 which includes Rock Creek Park, the USNA and the Kenilworth Aquatic Gardens.

Figure 5.6, on the other hand shows the density of visits made by visitors in different seasons. Compared to the maps shown for residents, visitors tend to converge on several points within the National Mall area. For the fall season, three dark blue spots can be seen and these are where the Lincoln memorial, the USBG and the USNA are located. For the winter season, visitors tend to concentrate on the memorials, monuments and museums around the National Mall, which includes the Washington Monument, Lincoln Memorial, National Museum of Natural History, Jefferson Memorial, Roosevelt Memorial and the White House. The concentration of visits is more evident in the spring and summer seasons which denotes a higher number of visits coinciding with the peak season for visiting the city of Washington DC.

Comparing the four seasonal maps of residents and visitors, we can see that the residents have specific attractions that they visit during the different seasons. The USNA appears to be a consistent preference regardless of the season mainly because some residents visit the area for recreational activities such as hiking, biking, running and jogging. The arboretum provides an ideal place for recreation that is away from the throngs of visitors. Other attractions that get a lot of visits are the Lincoln memorial, the tidal basin, and the USBG.

The sub-group of visitors are further subdivided based on their purpose of visit: business, leisure and visiting family and relatives (VFR) and the visits are compared. As shown in Figure 5.7, all three groups are similar in terms of the places they visited along the National Mall. Slight 
differences can be seen in the choices of places to visit in the peripheral areas where visitors with families and relatives include places with religious significance in their itineraries like the National Cathedral, the National Shrine of the Immaculate Conception, Congressional Cemetery and Mt. Olivet Cemetery. On the other hand, visitors on business and leisure concentrated more on the typical cultural and historical attractions.

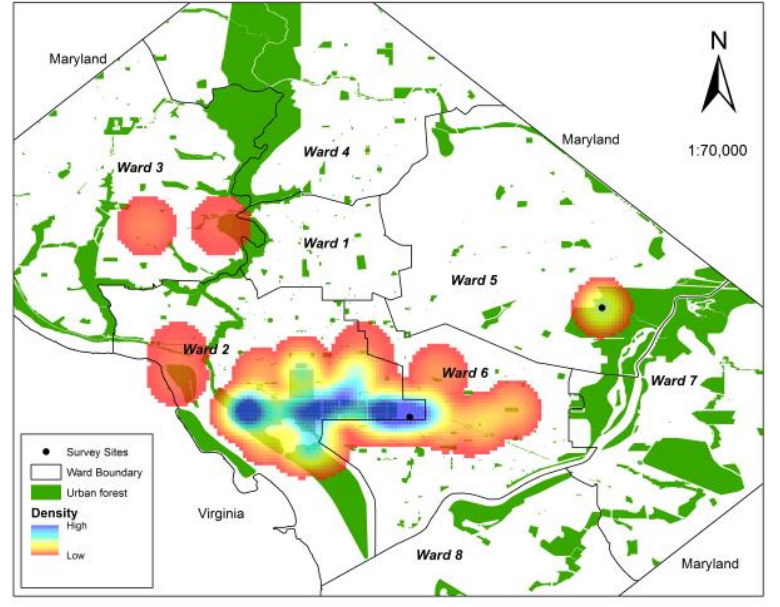

(a) Business

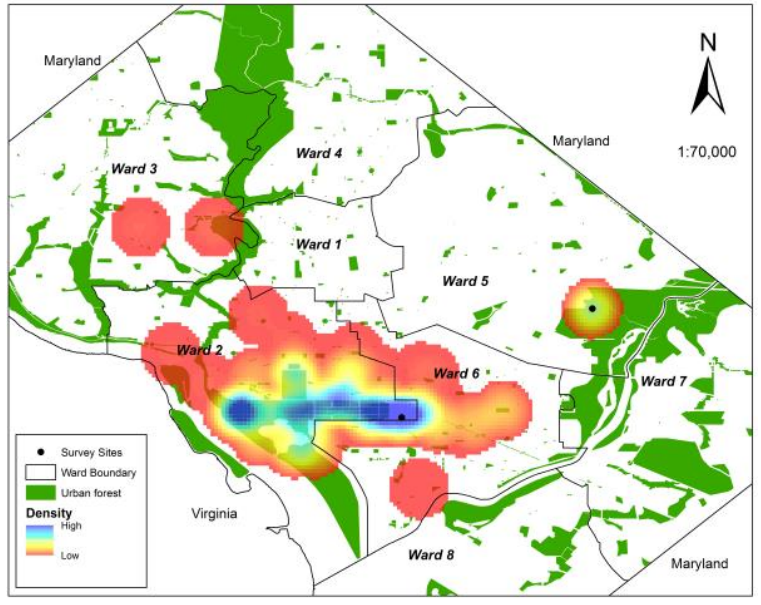

(b) Leisure

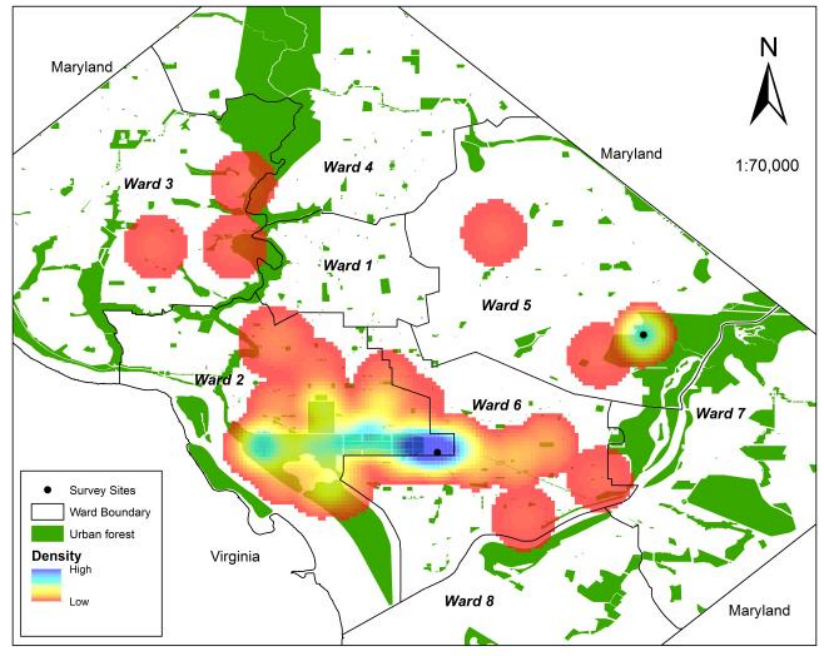

(c) VFR

Figure 5.7 Density maps by reason of visit 
Collectively, the maps indicate the general common trends in the distribution of visitors among the attractions in Washington DC. It illustrated the common visitor hotspots for different groups of respondents as well as the differences in the less popular attractions that groups of people visit. One thing that the maps emphasizes is the role of season in determining the itineraries of people going around the city. More favorable seasonal conditions, that is relatively cooler temperatures with relatively few rainy days, lead to more dispersed movement of people and better chances for lesser known attractions to be visited.

In terms of the visits to urban forests, it is observed that the National Mall is a high traffic area for people and there are a lot of parks and gardens in the city that have the potential to be tapped as future attractions. The Kenilworth Aquatic Garden is an example of an underutilized attraction. With proper development of visitor programs coupled with marketing, this can be used to add to the unique attractions of the city as well as a means to help decongest tourist hotspots. Lastly, the high density values observed at the USNA and USBG can attributed to the fact that these are the survey sites for the study and should be interpreted with caution.

\subsubsection{Movement patterns of people in Washington DC}

To further understand the movement of people within the city, the study used the general $\log$ linear model expressed in Equation 5.3 to identify significant movement patterns at the ward level. The results of this analysis provides information on the flow that people generally follow when moving within the city. Out of the eight wards, there are only six wards that the respondents visited and Tables 5.3 summarizes the parameter estimates for movement involving 2 to 3 wards.

Based on the results presented on Table 5.3, there are six two-ward patterns that are significant at $p<0.001$ and there are three three-ward patterns that are significant at $p<0.001$. 
There are no four destination combinations that are statistically significant. To visualize these patterns, Figure 5.8 provides a map showing the direction of movement.

The maps in Figure 5.8 is a visual representation of the spatial movement of the respondents in the study. It can be seen that three of the movements in (a) involving wards 2, 6 and 5 goes in both directions while the movement between ward 3 goes only in one direction. For (b), the three combinations for wards 2, 6 and 5 expressed by the respondents are all significant.

Table 5.3

Parameter estimates on movement patterns analyzed

\begin{tabular}{|c|c|c|c|c|}
\hline $\mathbf{W}_{1}$ & $\mathbf{W}_{2}$ & $\mathbf{W}_{3}$ & Count & $p$-value \\
\hline \multicolumn{5}{|l|}{ Two wards } \\
\hline Ward 2 & Ward 6 & & 171 & 0.000 \\
\hline Ward 6 & Ward 2 & & 129 & 0.000 \\
\hline Ward 5 & Ward 2 & & 90 & 0.000 \\
\hline Ward 5 & Ward 6 & & 82 & 0.000 \\
\hline Ward 2 & Ward 5 & & 7 & 0.000 \\
\hline Ward 3 & Ward 2 & & 7 & 0.000 \\
\hline \multicolumn{5}{|l|}{ Three wards } \\
\hline Ward 5 & Ward 6 & Ward 2 & 51 & 0.000 \\
\hline Ward 5 & Ward 2 & Ward 6 & 18 & 0.000 \\
\hline Ward 2 & Ward 6 & Ward 5 & 11 & 0.000 \\
\hline
\end{tabular}




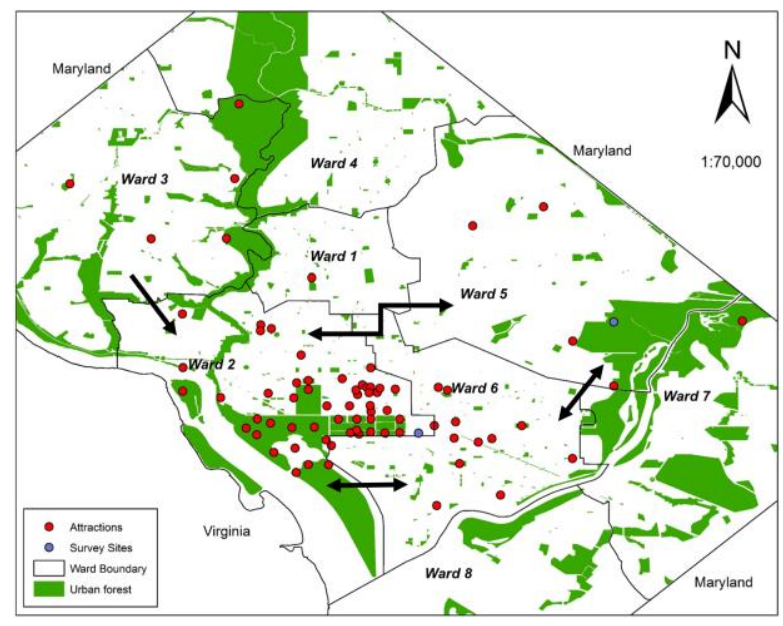

(a) Two-ward movements

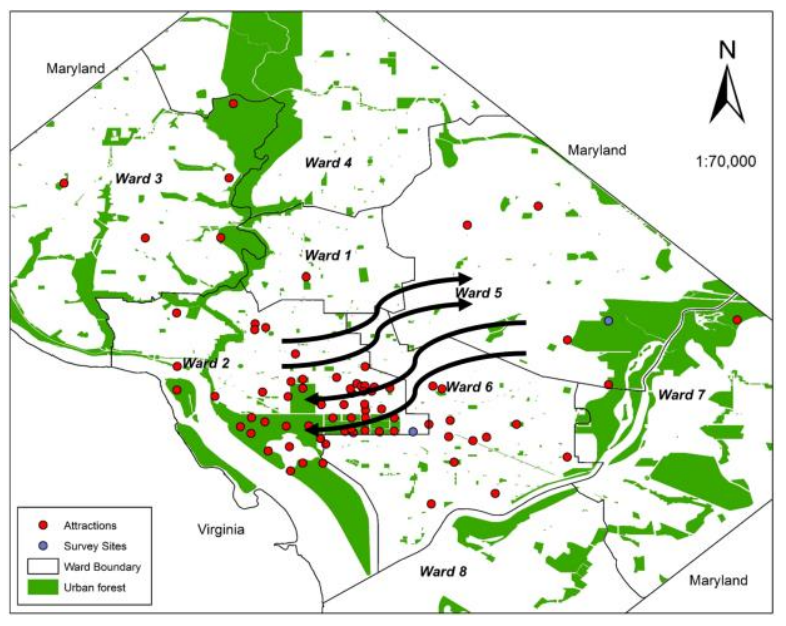

(b) Three-ward movements

Figure 5.8. Spatial movement patterns

\subsection{Discussion and conclusions}

As mentioned before, understanding movement of entities in an area provides information on its interactions with its surroundings. The results of the study was successful in providing a glimpse at the way people go around and move within a city destination such as Washington DC. In fact, knowing that for most groups of people walking, riding the Metro and driving their own vehicle are the most popular way of going around Washington DC proves that the city is relatively easy to explore by individuals or small groups. Walking and driving gives opportunities for the people to visually consume the cityscape. For urban forest managers this means that people can continue to interact with urban forests while they are in transit going from one location to another. For this reason, particular focus can be given towards maintenance of the urban forests that are located near roads and trails especially on areas that are busy routes. Aesthetically, people gravitate towards urban forests that are well groomed and maintained so intensive maintenance should be sustained in high traffic areas. Regular replacement planting, pruning and trimming can produce appealing spaces for people. With regards to the aspect of 
safety, dealing with vegetation that can hamper mobility of people as well as cause some form of discomfort should be integral to the management of urban forests.

In terms of tourism management, the enhancement of existing and designing new walking tour routes that can take people to lesser crowded areas may appeal to some groups of visitors. Provision of places for people to rest can help in making routes more popular. These rest areas can not only be in the form of benches and sheds but also in the form of kiosks, food trucks, and cafes with outdoor seating and multi-purpose booths.

The unpopularity of using buses and bicycles in going around Washington DC is an untapped potential. The main reasons behind this are the time inefficiency and safety. Buses are generally challenging to a visitor who is not familiar with the city. In addition, the bus schedule usually causes issues that leads to time lost in transit, which for a visitor can be a cause of dissatisfaction. Developing free trip planning or bus tracking apps can help visitors follow the bus schedules more efficiently. For bicycles on the other hand, urban planners and tourism managers can design and promote bike routes that are both safe and scenic. Once developed, it should be coupled with an extensive information dissemination initiative.

The hotspots shown by the kernel density maps identified areas in the city with high concentrations of people and how it changes over the seasons. Understandably, it shows that visitors are very mobile and cover a variety of attractions in the city during their stay. The results reinforced the popularity of the national mall mainly due to the attractions being clustered around this area. All year round most publicized events happen in or around the area pulling people to congregate. Another observation highlighted by the study is the presence of lesser known attractions that are underutilized from a tourism perspective mainly because such attractions are 
situated in the periphery of the city. The residents clearly gave proof that their familiarity of the city is an advantage in enjoying the "hidden gems" of Washington DC.

Relating the location of urban forests and the intensity of human activity in the city, one can discern that the National Mall requires the most intensive management, which recently prompted the city to implement the improvement of the area's water drainage so the turf areas get watered more efficiently. A number of respondents during the survey noted that the damage to turf areas caused by the high traffic of people needs to be addressed. Both residents and visitors touted the National Mall as the country's "backyard", thus requiring a more groomed appearance to the general public.

Moreover, the maps showed that there are parks that are not frequently enjoyed by visitors at the moment. The U. S. National Arboretum is located east of the National Mall and is regarded by most residents as their "go to" place for recreation away from the crowd. Most visitors who get to enjoy the arboretum are those that are accompanied by residents. Another similar place that has an anonymity status is the Kenilworth aquatic gardens, which incidentally is just across the Anacostia River from the arboretum. Both attractions can be packaged together for an "off the beaten path" alternative for visitors who seek novel experiences. Consequently, more exposure of these areas would eventually translate to more support to their research and educational initiatives as well as to its management and conservation.

The spatial movement part of the study provided a picture on the wards of the city where people visit and spend time. The presence of two wards in the city that did not elicit a visit from the respondents indicate that there is a need to expand the movement of people through the city. One major reason behind this is that these wards are dominated by residential facilities. Wards 1 , $3,5,7$, and 8 have areas that are developed for apartment complexes, houses, schools, and other 
non-tourism related facilities such as military installments, hospitals and places of worship.

Despite this, such areas need not be excluded entirely from tourism activity because these areas offer unique appeal. For example, the architecture of the buildings can be highlighted particularly the old houses, schools, and places of worship can provide a rich source of interesting vistas in the city. Also, urban forest managers should similarly take care of residential parks and gardens for the benefit of the local people. Providing well maintained urban forests encourage them to recreate in their neighborhood and not contribute to the congestion of the mall and its surroundings.

Overall information gained from this study will help get planners and managers closer to a better understanding of the manner in which people interact with the resources of the city, and this serves as input to future development of programs and projects geared towards the improvement of services and facilities for both residents and visitors to Washington DC.

\subsection{Suggestions for future research}

Future studies on this aspect of urban tourism can be done at various scales and levels and recent studies have focused on a micro-scale specifically looking into actual movement patterns of people visiting destinations. In the case of Washington DC, this might not hold useful given the clustered arrangement of its attractions. The ward level used in this study is too wide to detect more specific movement patterns. A different GIS base level can be explored to determine an appropriate level to which spatial movement can be traced to provide more useful information. Moreover, the temporal element can be incorporated into future studies to investigate the time spent on these attractions. In terms of the actual mobility of the people, this 
can further be explored using appropriate and unobtrusive tracking methods appropriate for social research.

The sample can expanded in future studies because this particular study was limited by the number of survey sites as well as the language used on the questionnaire. Adding other survey sites such as transportations hubs, hotels and other similar areas may capture segments of the population that this study failed to capture. In addition, given the big proportion of visitors coming to Washington DC having first languages other than English, it can be valuable to create surveys in a few different languages also to capture the perspectives of these visitors. 


\subsection{References}

Agresti, A. (2002). Categorical data analysis (2nd Ed). New York: Wiley-Interscience, 314.

Debbage, K. G. (1991). Spatial behavior at a Bahamian resort. Annals of Tourism Research, 18, 251-268.

Kockelman, K. M. (1997). Travel behavior as function of accessibility, land use mixing, and land use balance: evidence from San Francisco Bay Area. Transportation Research Record: Journal of the Transportation Research Board, 1607, 116-125.

Loomis, J. (2006). A comparison of the effect of multiple destination trips on recreation benefits as estimated by travel cost and contingent valuation methods. Journal of Leisure Research, $38,46$.

McKercher, B. \& Lau, G. (2008). Movement patterns of tourists within a destination. Tourism Geographies, 10, 355-374.

Nicolau, J. L. (2008). Characterizing tourists' sensitivity to distance. Journal of Travel Research, 47, 43-52.

Nowak, D. J., Hoehn III, R. E., Crane, D. E., Stevens, J. C., \& Walton, J. T. (2006). Assessing urban forest effects and values, Washington, DC's urban forest. Resource Bulletin NRS-1. Newtown Square, PA: U.S. Department of Agriculture, Forest Service, Northern Research Station. 24 p.

Rosenthal, D. H., Loomis, J. B., \& Peterson, G. L. (1984). The travel cost model: concepts and applications. General Technical Report, Rocky Mountain Forest and Range Experiment Station, USDA Forest Service, (RM-109).

Seguí-Llinás, M., \& Capellà-Cervera, J. E. (2006). Spanish package holiday tourism to China: Spatial patterns and tourist attractions. Tourism Geographies, 8, 233-252. 
Sirakaya, E., \& Woodside, A. G. (2005). Building and testing theories of decision making by travelers. Tourism management, 26, 815-832.

Xia, J. (2007). Modelling the spatial-temporal movement of tourists. Retrieved from RMIT University Research repository.

Zalatan, A. (1996). The determinants of planning time in vacation travel. Tourism Management, 17, 123-131.

Zhao, J., Forer, P., \& Harvey, A. S. (2008). Activities, ringmaps and geovisualization of large human movement fields. Information visualization, 7, 198-209. 


\section{CHAPTER 6}

Linking urban forests and urban tourism through people's preferences, perception, and spatial movement

\subsection{Introduction}

As exemplified by the facets of this study, the link between urban forests and urban tourism is a rich source of knowledge that can be gained through research. The results of the study present evidence that these two entities are related and complementary. Therefore, managing one means taking the other one into serious consideration which ultimately lends to urban tourism being an integrated field that includes not only the built environment but also the natural landscape in the city setting. The following section discusses the findings of this study in the context of the four aspects of urban tourism and forest management namely: planning, maintenance, marketing, and development. Each section delves into each aspect covering the four components of the study.

\subsection{On urban forest and urban tourism planning and development}

The planning process of any utilizable resource regardless of its setting requires accurate and reliable background and baseline information that serves as a springboard for the planning team for discussion and development of strategies. The information gathered from this study can definitely qualify as baseline information in the form of feedback from the beneficiaries of both tourism and urban forests. The people's inputs influence formulation of management objectives which ultimately dictates the strategies created. Knowing and understanding what the people think and their behavior help generate ideas on new tourism products in terms of attractions and/or itineraries. In the case of Washington DC, it can be seen that the city is not only 
appreciated as a cultural, and historical center but also a destination where nature can be appreciated and enjoyed. Furthermore, knowing how the people perceive urban forests and how it affects their experiences of the city can bring forward new ideas for the development of these resources in lieu of tourism.

It is undeniable that the museums, memorials and historic places are popular crowd drawers and have continued to do so through the decades, but there are nature related attractions that are slowly becoming more popular year after year. The National Cherry Blossom Festival is one example where visitation is generally increasing over the past 10 years (Destination DC, 2013). The event is generally centered at the location of hundreds of cherry trees lining the tidal basin and Washington monument areas and typically lasts from a couple of weeks to a month. The historical and cultural aspects of the festival are always highlighted during the event however little has been emphasized on the biological and ecological side of the cherry trees which are at the core of the festival. Furthermore, other sites where cherry trees abound are not given their due, and this is where the knowledge of familiarity held by the residents of DC can play a key role. It was gleaned from the comments made by the respondents in the study that the beauty of cherry trees can be enjoyed in other places like the US national arboretum and Anacostia Park. Thus this information can be used in planning future events for the festival given that the organizers plan to expand the event.

Knowledge on people's preferences on the attributes of urban forests can help planners assess the current structure, composition and appearance of the city's natural landscape and make adjustments or improvements accordingly. The study found that people, in general, prefer wellmaintained parks and gardens with a relatively good variety of plants that can break the monotony of green. Having this information, development initiatives can be designed to make 
the species selection of the plants to be established more inclusive of non-traditional plants that can offer variety to people. This is particularly important because the most high traffic area of the city, the National Mall, is regarded by people as the "nation's backyard". Horticultural and arboricultural system designed to establish and maintain the urban forests of the city can also be influenced by the feedback elicited by the study in terms of people's perception and preferences. The fact that experts know that people are sensitive and aware on the conditions of the urban forests in Washington DC, make their responsibilities more challenging and exciting in terms of developing the resource in a more socially responsive manner.

Lastly, having information on the distribution and movement of people within the city, with respect to the location of urban forests can assist in planning the schedule of maintenance activities that will minimally impact the public. Managers can also use this as an opportunity to educate the public on the importance of maintenance activities conducted in urban forests to increase their support and understanding of such activities. In terms of development, planners of both tourism and urban forest management can cooperate in designing programs to help in diluting the concentrations of people, so their experiences and satisfaction are enhanced by encountering less crowds. Moreover, they can also develop safer walking or biking routes for people to take that will not only showcase less popular attractions but also provide a more aesthetic means of exploring the city, not to mention being away from crowds and heavy traffic.

\subsection{On maintenance of urban forests and tourism facilities}

In terms of maintenance activities, this study primarily reinforced the role and influence of urban forests to the way people view and enjoy the city of Washington DC. This is important because it gives credence to the support needed by agencies managing the city's urban forests. 
Studies like this validate the investment put into this resource's management and development by looking at the relative importance that both residents and visitors put into urban forests as part of the city's character. Specifically, the results of this study helps present the challenges that maintenance programs face and push the implementers to come up with means to do their activities without much negative impacts to the people. Furthermore, their maintenance programs become more relevant and responsive to the needs of the people by gaining knowledge on people's perception and preferences.

The timing of implementing maintenance program can also be influenced by the results of the study. Obtaining an accurate picture on the concentrations and movement of visitors throughout the seasons assists in achieving an informed decision-making process in determining the timing of such activities. Similarly, if maintenance activities coincide with high level of visits, managers can devise plans to divert people or contingency plans to ensure that the negative impacts of conducting these activities are at a minimum. To achieve this, constant and proactive coordination must be established and sustained by the agencies involved in the management of urban forests and tourism.

\subsection{On marketing of urban forests as tourism attractions}

As mentioned previously, the study results collectively uncovers opportunities for adding to the marketing of Washington DC as a city attraction. It is obvious that the city has enough resources to establish and sustain a new set of attractions centered on its urban forests. By doing so, the city can position itself on a different niche. According to the visitor statistics released by Washington.org recently, tourism is one of the industries that consistently and significantly 
contribute to the local economy, thus it is in this interest that managers of the city consider an expansion in its tourism capabilities (Destination DC, 2013).

Washington DC has a few lesser known attractions it can market to draw visitors. The US National Arboretum is at present still considered a hidden gem in terms of its tourism potential. The development of the Arboretum can be done in the next five years but this should be done through careful planning because it is considered by most residents as their refuge away from crowds. Thus, its development must consider this carefully, so the welfare of the residents are preserved. Among the specific attractions that the Arboretum has to showcase include its Azalea Collection, which blooms in spring; the Bonsai and Penjing Museum which houses centuries old miniature trees, an herb garden, the original US Capitol pillars, and miles of biking and walking trails.

Its neighbor across the Anacostia River, the Kenilworth Aquatic Gardens is another diamond in the rough. Just by reading its name, one can readily see its uniqueness and could pique the interest of any visitor looking for something new to experience in the city. The garden boasts of areas planted with lotus, lilies and other aquatic plants. It has a nursery and a boardwalk that provides a glimpse of the unique ecosystem of the Anacostia River.

Rock Creek Park to the north of the National Mall, is yet another lesser known attraction that can be a potential visitor draw. Its facilities include a planetarium, nature center, tennis center, golf course, and boating facilities in addition to the trails they have for walking, bicycling and horseback riding.

These attractions have seasonal and year-round facilities that can encourage visitation and provide novel experiences to their clientele. A suggested marketing strategy for these is a gradual introduction to visitors where it can serve as venues for small events that do not attract 
large crowds. This way, the areas' carrying capacity is not jeopardized and management is not overwhelmed.

\subsection{Conclusions}

Multi-faceted studies such as this are important in collectively investigating different elements of a resource or field of research. However, careful planning and design is needed to implement efficient and effective data collection and analysis. If conducted properly, it provides a myriad of useful insights that can be practically applied in management or in decision making. This study has validated the connection between an industry and a resource in a city as significant as Washington DC. It elicited valuable feedback and insights on the perspectives and behavior of the people in the city. However, further studies that can complement and reinforce the findings of this study are encouraged to capture a more accurate scenario of the dynamic character of Washington DC's populace, both visitors and residents. In developing similar studies, consultations and proper coordination with agencies involved in the administration of the resources in the study can ensure better focus and can facilitate data collection, organization and analysis, thus avoiding some of the limitations of the study mentioned in previous chapters.

Future endeavors along these lines need to be encouraged and supported because it

provides opportunities for investigation and exploration of the city's programs and resources that serve as a feedback collecting mechanism.

From the perspective of the agencies managing the survey sites used in the study (USNA, USBG and National Mall), the findings justifies the continuous management and development of such areas for scientific, recreational, cultural, aesthetic, and even historical uses because such 
places have proven its capacity to significantly contribute in the tourism activity in the city as well as in educating the general public on the uses and importance of urban forests. 


\subsection{References}

Destination DC. (2013). Visitor Statistics. Retrieved on May 22, 2015 from

http://washington.org/press/DC-information/washington-dc-visitor-research.

U.S. Travel Association (2015). Travel Facts. Retrieved on May 26, 2015 from

https://www.ustravel.org/marketing/national-travel-and-tourism-week/talking-points-and-

facts. 
Questionnaire No.

Survey Site:

Date:

\title{
WEST VIRGINIA UNIVERSITY Recreation, Parks and Tourism Program
}

\author{
Research Study on \\ Perception, Attitudes and Preferences on Urban Forests \\ and Spatial Movement of People in Washington D.C.
}

\section{RESIDENT Survey Questionnaire}

Approved by the West Virginia University Institutional Review Board (IRB) 
We want to look at how residents see the attractions and urban forests in the city and how they enjoy it for recreation. The survey takes about 10 minutes to finish and if, for any reason, you feel you do not want to answer an item, just leave it blank and proceed to the next. Rest assured that ALL INFORMATION collected will be KEPT CONFIDENTIAL and will be used FOR ACADEMIC PURPOSES ONLY.

\section{Part I. Your Itinerary for Today}

Please put $\checkmark$ opposite the places you VISITED and put $\mathbf{X}$ on the ones you PLAN TO VISIT.

Museums
\begin{tabular}{|l|l|l|}
\hline Holocaust museum & & \\
\hline Museum of the American Indian & & \\
\hline Museum of American History & & \\
\hline Museum of Natural History & & \\
\hline National Gallery of Art & & \\
\hline National Air and Space museum & & \\
\hline National Aquarium & & \\
\hline
\end{tabular}

Memorials/Monuments
\begin{tabular}{|l|l|l|}
\hline Jefferson memorial & & \\
\hline Korean War memorial & & \\
\hline Lincoln memorial & & \\
\hline Roosevelt memorial & & \\
\hline Vietnam Veterans memorial & & \\
\hline Washington monument & & \\
\hline World War II memorial & & \\
\hline
\end{tabular}

Parks and gardens
\begin{tabular}{|l|l|l|}
\hline Constitution Gardens & & \\
\hline Lafayette park & & \\
\hline Lincoln park & & \\
\hline National Arboretum & & \\
\hline Gallery of Art Sculpture Garden & & \\
\hline Potomac park & & \\
\hline US Botanic Gardens & & \\
\hline
\end{tabular}

Historic places
\begin{tabular}{|l|l|l|}
\hline Arlington National Cemetery & & \\
\hline Chinatown & & \\
\hline Eastern Market & & \\
\hline Ford's Theater & & \\
\hline Library of Congress & & \\
\hline US Capitol & & \\
\hline White House & & \\
\hline
\end{tabular}

Other areas, Please specify: $\quad \checkmark / x$

\begin{tabular}{|l|l|l|}
\hline & & \\
\hline & & \\
\hline & & \\
\hline
\end{tabular}

\begin{tabular}{|l|l|l|}
\multicolumn{1}{c|}{$\checkmark / \boldsymbol{x}$} \\
\hline & & \\
\hline & & \\
\hline & & \\
\hline
\end{tabular}

\section{NUMBER THE ITEMS WITH THE $\checkmark / \times$ MARKS IN THE ORDER OF HOW YOU WOULD VISIT THEM}

1. In total, how much time will you or did you spend in these areas for today? hrs

2. What is/are your mean(s) of getting around the city and getting to these areas? Check $(\checkmark)$ all that apply

$\square$ Bus

$\square$ Metro

$\square$ Taxi/Cab $\square$ Car (Own/Rental/Carpool)

$\square$ Bicycle/Motorbike/Segway

$\square$ Walking/Stroll

$\square$ Others, please specify

3. What recreational activities did you and your group do or plan to do for today? Check $(\checkmark)$ all that apply
$\square$ Stroll
$\square$ Take family/friends around the city
$\square$ Biking
$\square$ Sports activities
$\square$ Jog
$\square$ Picnic

$\square$ Others, please specify 


\section{Part II. Preferences on City Attractions}

The following are sets of attractions in Washington D.C. that people enjoy; please score each combination according to how enjoyable you think these are to you. Scores can be identical if you like two or more of the combinations. Please go over them carefully before scoring.

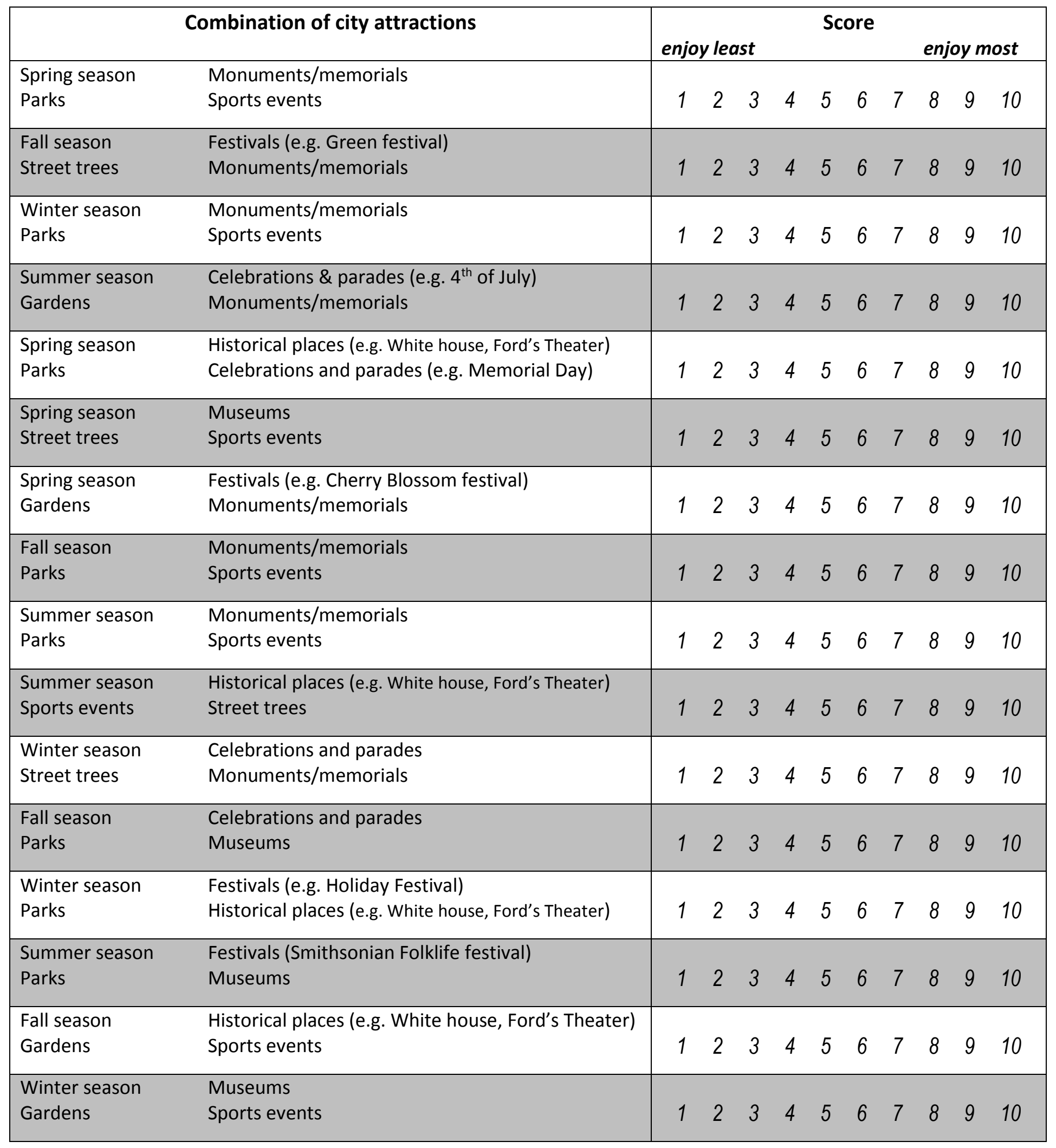




\section{Part III. Attitude towards Urban Forests}

For the purpose of this study, an URBAN FOREST is defined as:

The land in and around areas ranging from small communities to city centers, that is occupied or potentially occupied by trees, other plants and associated natural resources. These areas include public and private property, transportation and utility corridors.

Below are statements about urban forests in Washington D.C. and please indicate how much you agree or disagree with each statement by encircling the number.

\section{Statements}

Strongly
Disagree

Disagree

Neutral

Agree

Strongly

Agree

1. I believe that urban forests are part of the appeal of Washington D.C.

$\begin{array}{lllll}1 & 2 & 3 & 4 & 5\end{array}$

2. I believe that urban forests give Washington D.C. a 1

2

3

4

more natural appearance

3. Parks, gardens and street trees make going around

1

2

3

4

5 the city interesting

4. Urban forests give unique scents and colors

1

5. Parks and gardens attract birds and other animals

1

2

3

that interest people

23

$4 \quad 5$

6. Urban forests tell us of seasonal changes

1

23

7. Parks, gardens and street trees make the city more relaxing for people

2

3

4

8. I feel rejuvenated after visiting parks and gardens

9. Street trees give a feeling of security because they separate pedestrians from traffic

1

$2 \quad 3$

3

34

$4 \quad 5$

$4 \quad 5$

10. Street trees and plants along sidewalks help in pedestrian mobility

11. Trees and plants at the National Mall make it look natural

12. Parks, gardens and street trees are good to look at when they are well kept

12

3

$4 \quad 5$

13. Parks and gardens are places in the city where I do recreational activities

1

2

3

4

5

14. Crowds in parks and gardens add to my enjoyment of these areas

15. Urban forests of Washington D.C. are among the things that I enjoy visiting in the city

16. Visiting parks and gardens increase my curiosity of trees and other plants

1

1

1

1

12

1

2

2

3

3

4

5

2

3

4

5

5

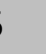

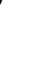

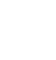


17. I enjoy taking pictures of places inside parks and gardens
1
2

1

1

1

1

1

1

1

1

$(2$

2

3

4

5

20. I am satisfied with the appearance of the urban forests in the city

21. I will tell my relatives and friends to visit Washington D.C.'s parks and gardens

\section{Urban forests make Washington D.C. a better place} to visit

23. I am satisfied with my stay here

\section{Part IV. Preferences on the Appearance of Urban Forests}

Here, you will be given a short description of how urban forests may look like in an area. Score each according to your preference; again scores can be identical if you like two or more sets equally. Please go through each set carefully before scoring.

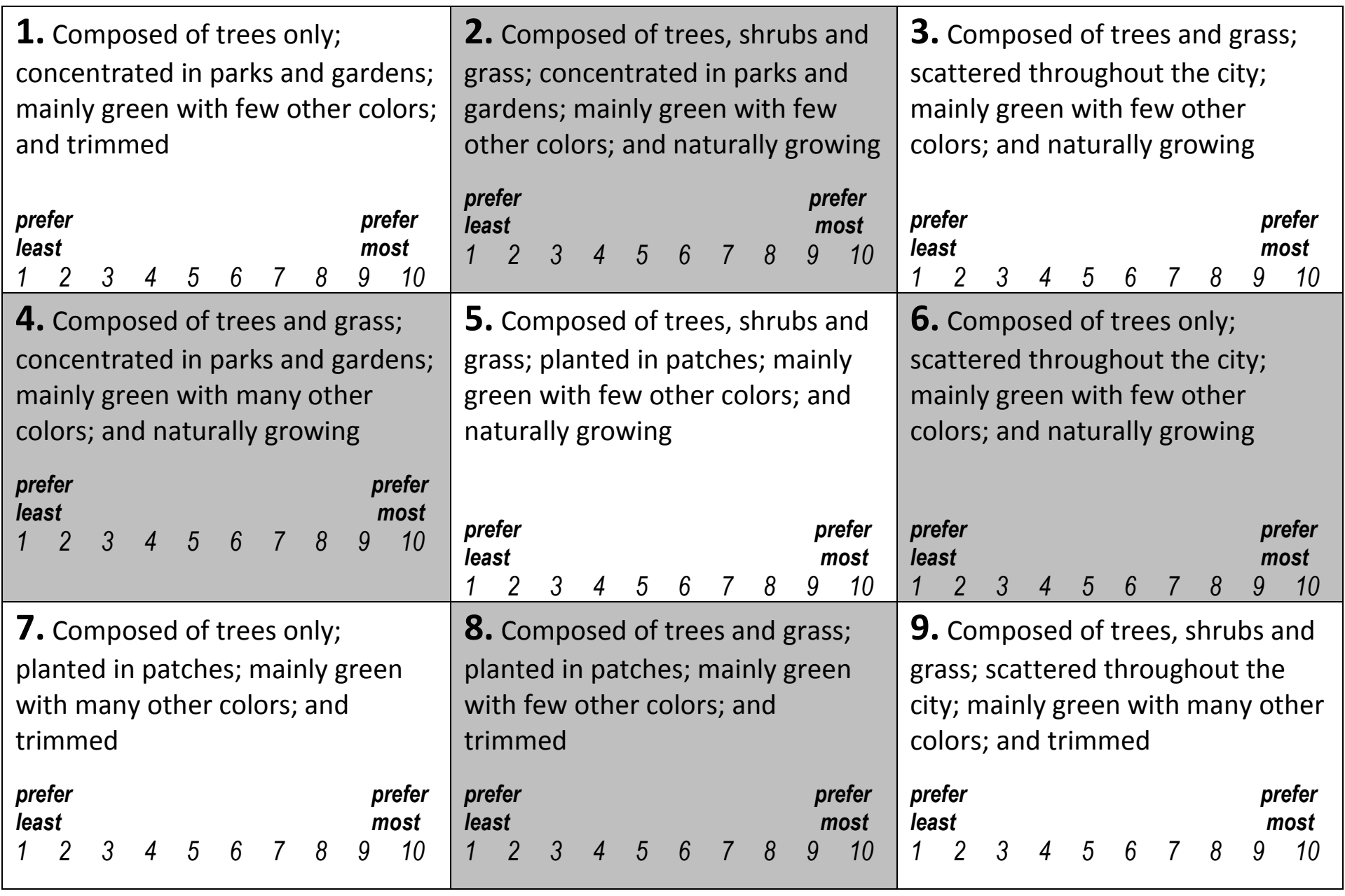




\section{Part V. Background Information}

1. How long have you been living in Washington D.C.? years

2. Are you a U.S. citizen? $\square$ Yes $\square$ No. If NO, what is your citizenship?

3. What is your primary reason for going around Washington D.C. today? Please check $(\checkmark)$ ONE $\square$ Personal errands (grocery shopping, etc.) $\square$ Work $\square$ Leisure/Recreation $\square$ Eating/Dining out

$\square$ Other, please specify

4. Including yourself, how many people are with you now?

5. How are they related to you? Please check $(\checkmark)$ ONE $\square$ Spouse/Partner $\square$ Family $\square$ Friends $\square$ Family \& Friends $\square$ Colleagues/Co-worker $\square$ Other, specify

6. Sex: $\square$ Male $\square$ Female

7. Age: years

8. Education level attained. Please check $(\checkmark)$ ONE that applies to you:
$\square$ High School
$\square$ Graduate
$\square$ College
$\square$ Other, please specify

9. Estimated annual family income (in US \$). Please check $(\checkmark)$ ONE

$\square$ less than $\$ 20,000$

$\square \$ 60,000$ to $\$ 79,999$

10. Line of work: $\square \$ 20,000$ to $\$ 39,999$

$\square \$ 80,000$ to $\$ 99,999$ $\square \$ 40,000$ to $\$ 59,999$

$\square \$ 100,000$ and above

Please write any other comments you may have related to this study

Thank you very much for participating!!

Your contribution is greatly appreciated!! (Occupation)

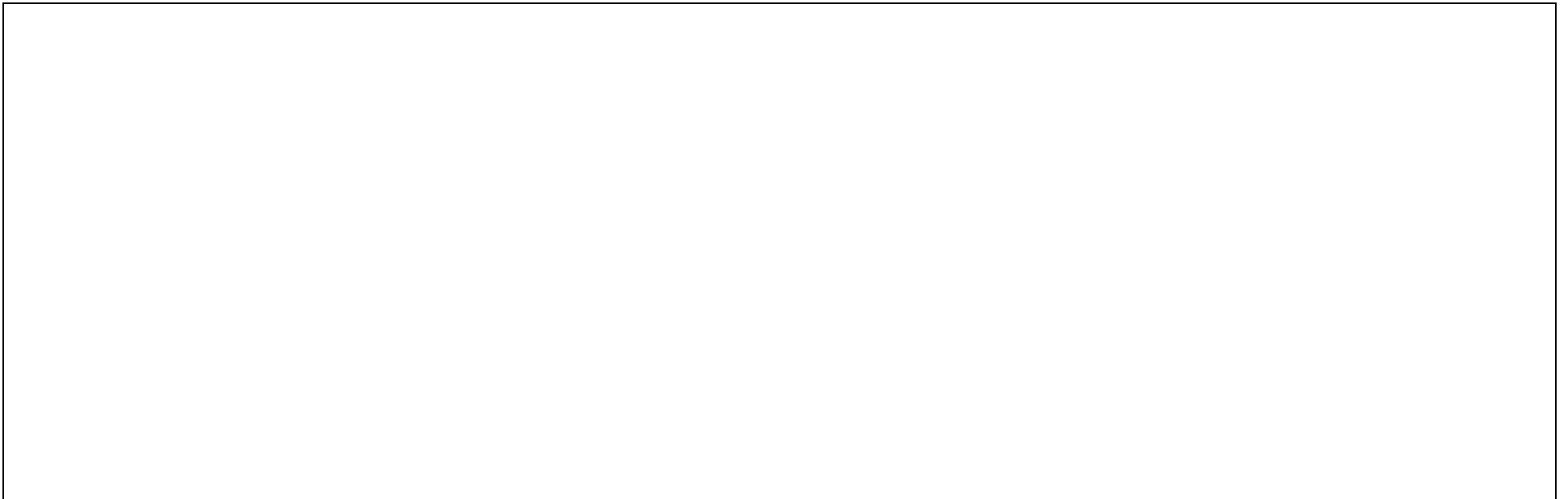




\title{
APPENDIX 2
}

Questionnaire No.

Survey Site:

Date:

\section{WEST VIRGINIA UNIVERSITY Recreation, Parks and Tourism Program}

\author{
Research Study on \\ Perception, Attitudes and Preferences on Urban Forests \\ and Spatial Movement of People in Washington D.C.
}

\section{VISITOR Survey Questionnaire}

Approved by the West Virginia University Institutional Review Board (IRB) 
We want to look at how visitors see the attractions and urban forests in the city and how they enjoy it for recreation. The survey takes about 10 minutes to finish and if, for any reason, you feel you do not want to answer an item, just leave it blank and proceed to the next. Rest assured that ALL INFORMATION collected will be KEPT CONFIDENTIAL and will be used FOR ACADEMIC PURPOSES ONLY.

\section{Part I. Your Itinerary for Today}

Please put $\checkmark$ opposite the places you VISITED and put $\mathrm{X}$ on the ones you PLAN TO VISIT.

\begin{tabular}{|l|l|l|} 
Museums & $\checkmark / x$ \\
\hline Holocaust museum & & \\
\hline Museum of the American Indian & & \\
\hline Museum of American History & & \\
\hline Museum of Natural History & & \\
\hline National Gallery of Art & & \\
\hline National Air and Space museum & & \\
\hline National Aquarium & & \\
\hline
\end{tabular}

\begin{tabular}{|c|c|}
\hline Memorials/Monuments & $\checkmark / x$ \\
\hline Jefferson memorial & \\
\hline Korean War memorial & \\
\hline Lincoln memorial & \\
\hline Roosevelt memorial & \\
\hline Vietnam Veterans memorial & \\
\hline Washington monument & \\
\hline World War II memorial & \\
\hline
\end{tabular}

Parks and gardens
\begin{tabular}{|l|l|l|}
\hline Constitution Gardens & & \\
\hline Lafayette park & & \\
\hline Lincoln park & & \\
\hline National Arboretum & & \\
\hline Gallery of Art Sculpture Garden & & \\
\hline Potomac park & & \\
\hline US Botanic Gardens & & \\
\hline
\end{tabular}

Historic places
\begin{tabular}{|l|l|l|}
\hline Arlington National Cemetery & & \\
\hline Chinatown & & \\
\hline Eastern Market & & \\
\hline Ford's Theater & & \\
\hline Library of Congress & & \\
\hline US Capitol & & \\
\hline White House & & \\
\hline
\end{tabular}

\begin{tabular}{|c|c|}
\hline Other areas, Please specify: & $\checkmark / x$ \\
\hline & \\
\hline & \\
\hline & \\
\hline
\end{tabular}

\begin{tabular}{|l|l|l|}
\multicolumn{1}{c}{$\checkmark / x$} \\
\hline & & \\
\hline & & \\
\hline & & \\
\hline
\end{tabular}

\section{NUMBER THE ITEMS WITH THE $\checkmark / \times$ MARKS IN THE ORDER OF HOW YOU WOULD VISIT THEM}

1. In total, how much time will you or did you spend in these areas for today? hrs

2. What is/are your mean(s) of getting around the city and getting to these areas? Check $(\checkmark)$ all that apply

$\square$ Bus

$\square$ Metro

$\square$ Taxi/Cab

\section{$\square$ Bicycle/Motorbike/Segway}

$\square$ Walking/Stroll

$\square$ Sightseeing tour, please specify

$\square$ Car (Own/rental/Carpool)

$\square$ Others, please specify

3. What recreational activities did you and your group do or plan to do for today? Check $(\checkmark)$ all that apply
$\square$ Stroll
$\square$ Biking
$\square$ Sight seeing
$\square$ Take pictures
$\square$ Picnic
$\square$ Watch show or movies

Others, please specify 


\section{Part II. Preferences on City Attractions}

The following are sets of attractions one can enjoy at different seasons in Washington D.C. Please score each combination according to how enjoyable you think these are to you. Scores can be identical if you like two or more of the combinations. Please go over them carefully before scoring.

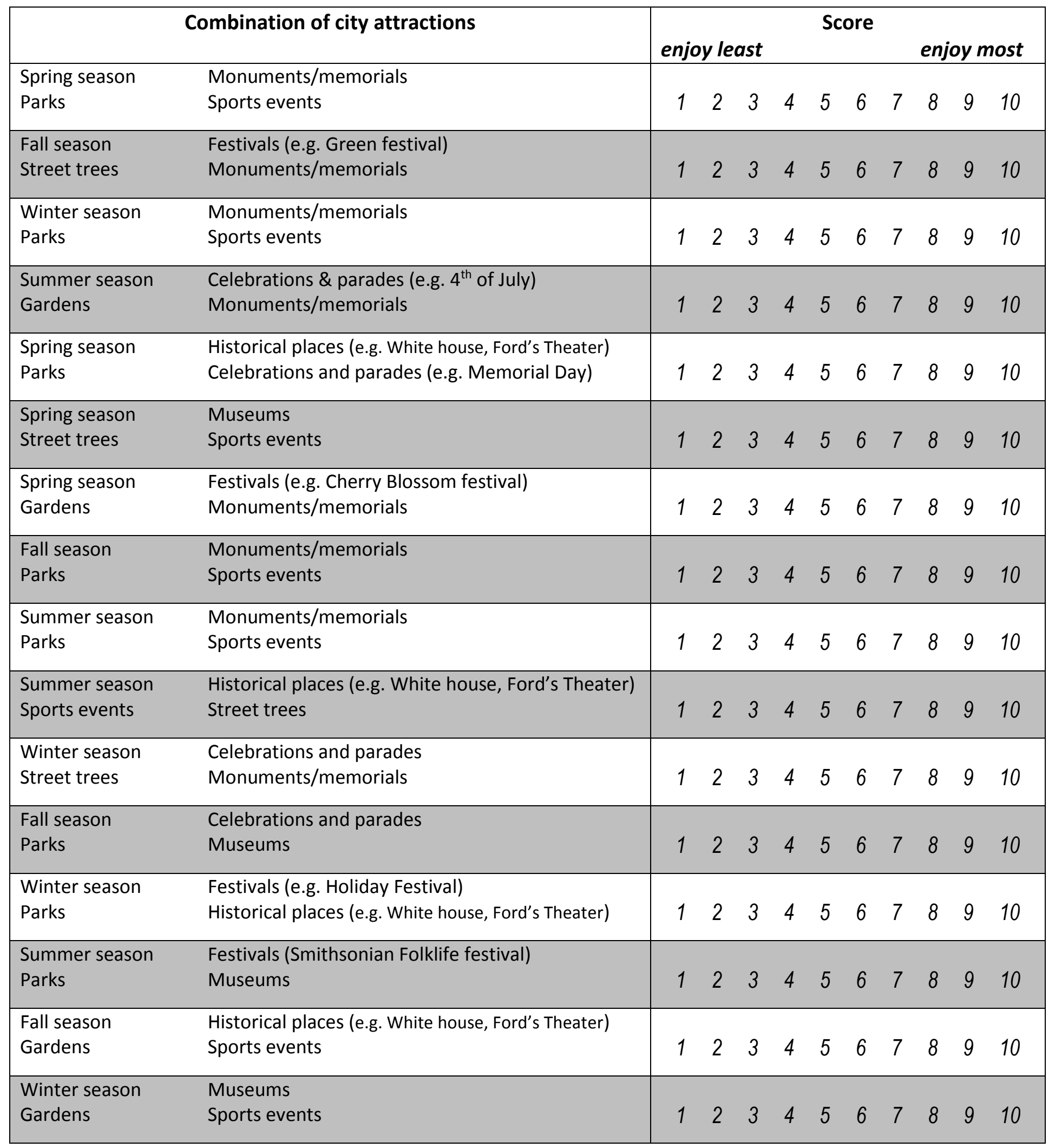




\section{Part III. Attitude towards Urban Forests}

For the purpose of this study, an URBAN FOREST is defined as:

The land in and around areas ranging from small communities to city centers, that is occupied or potentially occupied by trees, other plants and associated natural resources. These areas include public and private property, transportation and utility corridors.

Below are statements about urban forests in Washington D.C. and please indicate how much you agree or disagree with each statement by encircling the number.

\begin{tabular}{|c|c|}
\hline Statements & $\begin{array}{l}\text { Strongly } \\
\text { Disagree }\end{array}$ \\
\hline
\end{tabular}
1. I believe that urban forests are part of the appeal of
1
2
3
4
5

Washington D.C.

2. I believe that urban forests give Washington D.C. a

1

2

3

$4 \quad 5$

more natural appearance

3. Parks, gardens and street trees make going around

1

2

3

4

5

the city interesting

4. Urban forests give unique scents and colors

5. Parks and gardens attract birds and other animals

1

that interest people

1

2

3

3

4

5

6. Urban forests tell us of seasonal changes

1

7. Parks, gardens and street trees make the city more relaxing for people

\begin{tabular}{|c|c|c|c|c|c|}
\hline 8. I feel rejuvenated after visiting parks and gardens & 1 & 2 & 3 & 4 & 5 \\
\hline $\begin{array}{l}\text { 9. Street trees give a feeling of security because they } \\
\text { separate pedestrians from traffic }\end{array}$ & 1 & 2 & 3 & 4 & 5 \\
\hline $\begin{array}{l}\text { 10. Street trees and plants along sidewalks help in } \\
\text { pedestrian mobility }\end{array}$ & 1 & 2 & 3 & 4 & 5 \\
\hline $\begin{array}{l}\text { 11. Trees and plants at the National Mall make it look } \\
\text { natural }\end{array}$ & 1 & 2 & 3 & 4 & 5 \\
\hline $\begin{array}{l}\text { 12. Parks, gardens and street trees are good to look at } \\
\text { when they are well kept }\end{array}$ & 1 & 2 & 3 & 4 & 5 \\
\hline $\begin{array}{l}\text { 13. Parks and gardens are places in the city where I do } \\
\text { recreational activities }\end{array}$ & 1 & 2 & 3 & 4 & 5 \\
\hline $\begin{array}{l}\text { 14. Crowds in parks and gardens add to my enjoyment } \\
\text { of these areas }\end{array}$ & 1 & 2 & 3 & 4 & 5 \\
\hline $\begin{array}{l}\text { 15. Urban forests of Washington D.C. are among the } \\
\text { things that I enjoy visiting in the city }\end{array}$ & 1 & 2 & 3 & 4 & 5 \\
\hline $\begin{array}{l}\text { 16. Visiting parks and gardens increase my curiosity of } \\
\text { trees and other plants }\end{array}$ & 1 & 2 & 3 & 4 & 5 \\
\hline
\end{tabular}


17. I enjoy taking pictures of places inside parks and gardens
1
2

1

18. I am impressed by the greenery of Washington D.C.

19. My leisure/recreation experience is enhanced by the urban forests of the city

20. I am satisfied with the appearance of the urban forests in the city

21. I will tell my relatives and friends to visit Washington D.C.'s parks and gardens

1

2

1

1

2

2

3

4

5

3

$\begin{array}{ll}4 & 5 \\ 4 & 5\end{array}$

3

5

3

$4 \quad 5$
22.Urban forests make Washington D.C. a better place to visit

23. I am satisfied with my stay here

1

1

2

3

4

5

1

2

2

3

3

3

$4 \quad 5$

3

4

5

\section{Part IV. Preferences on the Appearance of Urban Forests}

Here, you will be given a short description of how urban forests may look like in an area. Score each according to its appeal to you. Scores can be identical if you like two or more sets equally. Please go through each set carefully before scoring.

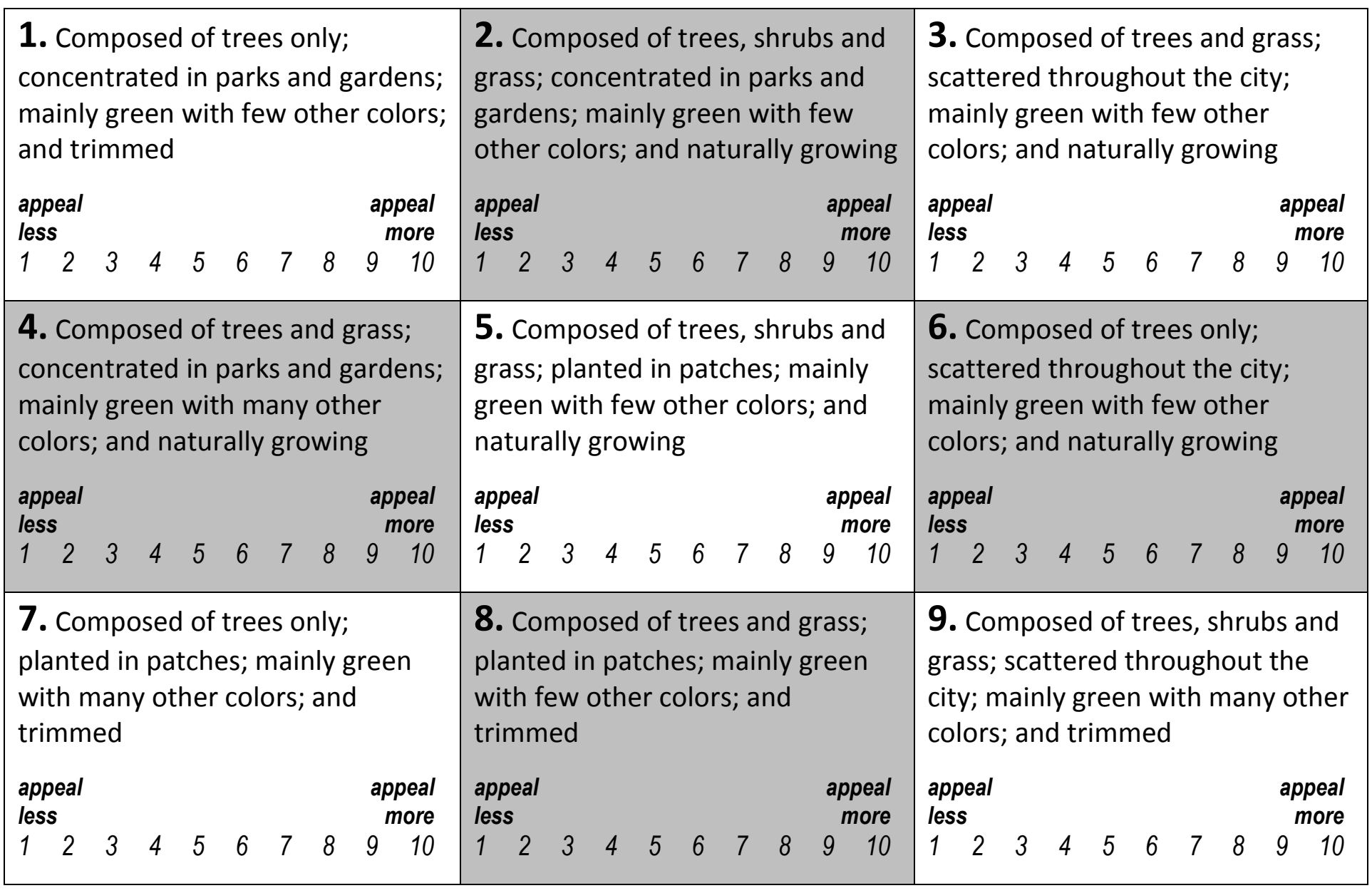




\section{Part V. Background Information}

11. Place of residence (US State or Country):

Zip Code

12. What is your primary reason for visiting Washington DC in this trip? Please check $(\checkmark)$ one.
$\square$ Business (meeting, conferences, etc)
$\square$ Vacation/Leisure/Recreation
$\square$ Educational (Field trip, study tour, etc)
$\square$ Visiting family, friends or relatives

$\square$ Other, please specify

13. Are you staying overnight? $\square$ Yes $\square$ No, If YES, how many days?

14. Including yourself, how many persons are with you in this trip?

15. How are they related to you? Please check $(\checkmark)$ one
$\square$ Spouse/ Partner
$\square$ Family
$\square$ Friends
$\square$ Family \& Friends
Colleague/Co-worker

口other, specify

16. Is Washington D.C. your only destination for this trip? $\square$ Yes $\quad \square$ No

17. How important is visiting Washington D.C. for you?

$\square$ Not important $\quad \square$ Somewhat important $\quad \square$ Important $\quad \square$ Very important $\quad \square$ Extremely important

18. Is this your first visit to Washington D.C.? $\square$ Yes $\square$ No

If NO, how many times have you visited Washington D.C. for the past 12 months?

19. Sex: $\square$ Male $\quad \square$ Female

20. Age: years

21. Education level attained. Please check only $(\checkmark)$ one
$\square$ High School
$\square$ Graduate
$\square$ College
DOthers, please specify

22. Estimated annual household income (in US\$). Please check only ( $\checkmark$ ) one
$\square$ less than $\$ 20,000$
$\square \$ 20,000$ to $\$ 39,999$
$\square \$ 40,000$ to $\$ 59,999$
$\square \$ 60,000$ to $\$ 79,999$
$\square \$ 80,000$ to $\$ 99,999$
$\square \$ 100,000$ and above

23. Line of work: (Occupation)

Please write any other comments you may have related to this study 